NASACONTRACTOR REPOR T

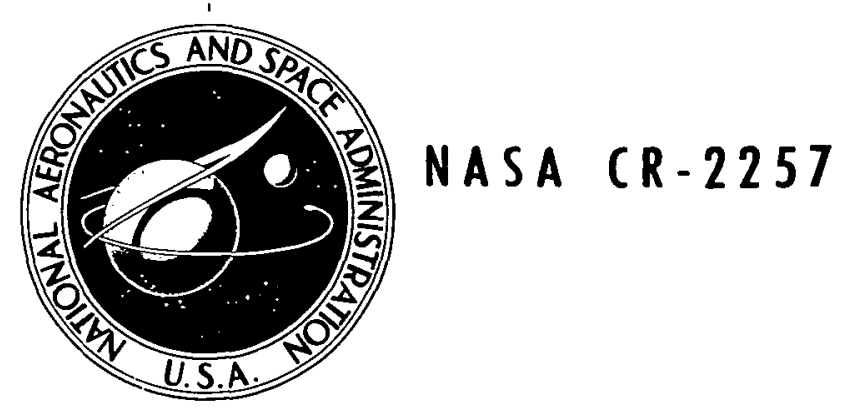

\title{
A FINITE DIFFERENCE METHOD FOR THE SOLUTION OF THE TRANSONIC FLOW AROUND HARMONICALLY OSCILLATING WINGS
}

by F. Edward Eblers

Prepared by

BOEING COMMERCIAL AIRPLANE COMPANY

Seattle, Wash. 98124

for Langley Research Center

NATIONAL AERONAUTICS AND SPACE ADMINISTRATION - WASHINGTON, D. C. • JULY 1974 


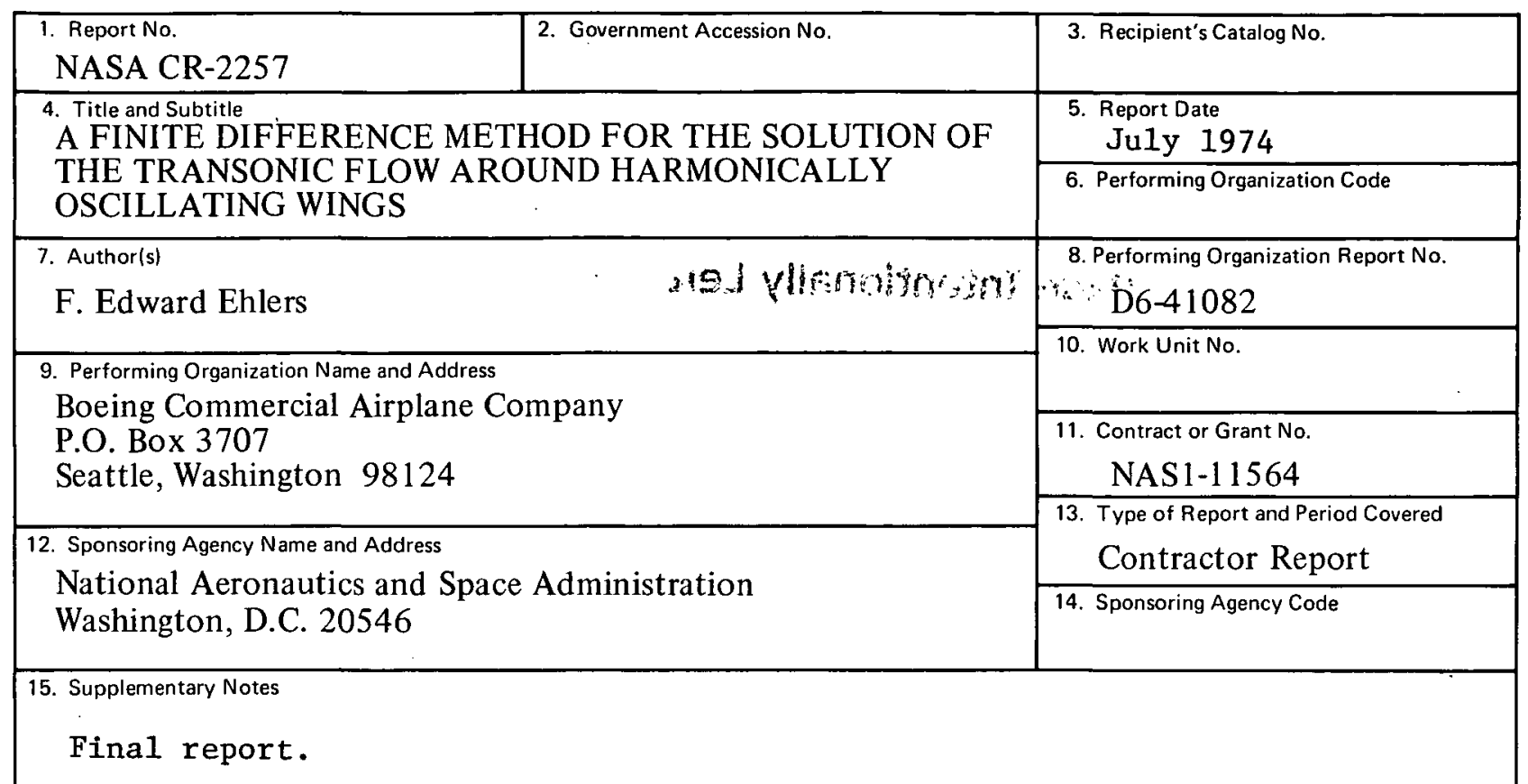

16. Abstract

A finite difference method for the solution of the transonic flow about a harmonically oscillating wing is presented. The partial differential equation for the unsteady transonic flow was linearized by dividing the flow into separate steady and unsteady perturbation velocity potentials and by assuming small amplitudes of harmonic oscillation. The resulting linear differential equation is of mixed type, being elliptic or hyperbolic where ever the steady flow equation is elliptic or hyperbolic. Central differences were used for all derivatives except at supersonic points where backward differencing was used for the streamwise direction.

Detailed formulae and procedures are described in sufficient detail for programming on high speed computers. To test the method, the problem of the oscillating flap on a NACA 64 A006 airfoil was programmed. The numerical procedure was found to be stable and convergent even in regions of local supersonic flow with shocks. Numerical results for the oscillating quarterchord flap predict the pressure patterns observed by Tijdeman and Schippers although some cases show a discrepancy in magnitude. Suggestions are given for improving speed and accuracy and for extending the method to thick, blunt airfoils and to planar wings.

\begin{tabular}{|l|l|l|l|}
\hline $\begin{array}{l}\text { 17. Key Words (Suggested by Author(s)) } \\
\begin{array}{l}\text { Unsteady flow, transonic flow, } \\
\text { oscillating wings, oscillating airfoils }\end{array}\end{array}$ & $\begin{array}{l}\text { 18. Distribution Statement } \\
\text { Unclassified--unlimited }\end{array}$ \\
& & \multicolumn{3}{|c|}{ STAR Category 01 } \\
\hline $\begin{array}{l}\text { 19. Security Classif. (of this report) } \\
\text { Unclassified }\end{array}$ & $\begin{array}{c}\text { 20. Security Classif. (of this page) } \\
\text { Unclassified }\end{array}$ & $\begin{array}{c}\text { 21. No. of Pages } \\
81\end{array}$ & $\begin{array}{c}\text { 22. Price* } \\
\$ 4.00\end{array}$ \\
\hline
\end{tabular}




\section{CONTENTS}

Page

SUMMARY

INTRODUCTION . . . . . . . . . . .

SYMBOLS AND ABBREVIATIONS . . . . . . . . . . . . . . . . . . . . . . . . 5

DESCRIPTION OF THE METHOD FOR COMPUTING UNSTEADY FLOW FOR

THE HARMONIC MOTION OF A WING . . . . . . . . . . . . . . . . . . . . . 8

DISCUSSION OF COMPUTED RESULTS FOR THE HARMONICALLY

OSCILLATING FLAP ON AN AIRFOIL . . . . . . . . . . . . . . . . . . . . 12

RECOMMENDATIONS FOR INCREASED ACCURACY AND

REDUCED COMPUTING TIME . . . . . . . . . . . . . . . . . . . . 30

EXTENSION OF THE WORK TO THREE-DIMENSIONAL WINGS . . . . . . . 31

EXTENSION OF THE WORK TO ELIMINATE THE SMALL

DISTURBANCE ASSUMPTION . . . . . . . . . . . . . . . . . . . . . 31

CONCLUSION . . . . . . . . . . . . . . . . . . . . . . . . . . . . . . 32

APPENDIX . . . . . . . . . . . . . . . . . . . . . . . . . . . . . 35 


\title{
A FINITE DIFFERENCE METHOD FOR THE SOLUTION OF THE TRANSONIC FLOW AROUND HARMONICALLY OSCILLATING WINGS
}

\author{
by F. Edward Ehlers \\ Boeing Commercial Airplane Company
}

\section{SUMMARY}

A finite difference method is presented for the solution of the unsteady pressure distribution on harmonically oscillating wings in transonic flow. The differential equation for the velocity potential of compressible flow was simplified first by the assumption of small perturbation from a nearly sonic parallel flow and then by representing the flow as a sum of two separate potentials for the steady and unsteady flow.

On the assumption that the amplitude of the unsteady oscillation is small, the unsteady transonic flow differential equation was linearized. The resulting differential equation contains coefficients which depend upon the mean steady flow and which must be computed beforehand from the solution of the nonlinear transonic small perturbation differential equation. When time is eliminated from the linear unsteady flow equation by the assumption of harmonic motion, then the resulting linear differential equation is of mixed type, being elliptic or hyperbolic in regions of the flow where the steady flow equation is elliptic or hyperbolic, respectively.

Because of the similarity of the unsteady linear differential equation to the steady nonlinear transonic small perturbation differential equation, a technique of column relaxation similar to that of Murman and Cole (ref. 2) and Krupp (refs. 3 and 4) was applied to find solutions to the differential equation expressed in difference form. For subsonic mesh points in the flow, central differences were employed for all derivatives; for supersonic points, backward (or upstream) differences were used for derivatives in the streamwise direction only. The boundary conditions for the wing were applied in the plane of the projection of the wing surface and incorporated in the difference equations for mesh points adjacent to the oscillating wing. On the plane vortex sheet downstream of the trailing edge, the condition of continuity of pressure and the Kutta condition on the trailing edge specify relations between the jump in potential along lines in the free-stream direction and the value of this jump just downstream of the trailing edge.

Integral relations based on the wing and wake boundary conditions were derived for the wing and the airfoil oscillating in harmonic motion in the manner of Klunker (ref. 8). These relations are 
used for the mesh far-field boundary conditions, which are updated during the computations. The use of far-field boundary conditions makes it possible to reduce the region of calculations, thereby saving computer time and storage.

Expanding the terms in the difference equation in Taylor series about the central point and retaining the lowest order terms in the mesh size lead to the original differential equation plus additional higher derivative terms which vanish as the mesh size goes to zero. For equally spaced points and subsonic flow, the resulting fourth-order differential operator is of second order in the mesh spacing and elliptic in form. Hence, there is no dependence upon the ratio of the mesh sizes for stability. For locally supersonic points, the additional truncation terms are of first order in the mesh spacing. This term is a third derivative in the free-stream direction and introduces a simulated viscosity proportional to the mesh size which was found to stabilize the calculations for shocks developing in the flow in solving for the steady flow equations by Murman and Cole (ref. 2) and Krupp (refs. 3 and 4). From this study, the differencing method would appear to be stable. Subsequent experience has shown this to be true for the oscillating airfoil.

The mathematical development of the method described in the foregoing for oscillating rectangular wings, swept wings, and airfoils is presented here in sufficient detail to be coded for actual numerical calculation. To test the feasibility of the method, the equations for the harmonically oscillating flap on a NACA 64A006 airfoil were coded for the CDC 6600. For the basic steady flow, the program (TEA-330) developed by Krupp in reference 4 for the transonic flow over a lifting airfoil was used.

Solutions were obtained for the unsteady flow over a flat plate with an oscillating flap of a quarter-chord length at a free-stream Mach number of 0.8 and reduced frequencies of $\omega=0.06$ and 0.1794 . These values correspond to frequencies of 30 and 90 cycles per second for the wind tunnel and model conditions in the experiments of Tijdeman and Schippers (ref. 9). The real part of the jump in pressure coefficient from the difference method agrees very closely with solutions from a subsonic kernel function method which solves the same differential equation. The imaginary part of the pressure coefficient has somewhat smaller negative values near the leading edge for $\omega=0.06$, although the pattern is essentially the same as the results from the kernel function method. For $\omega=0.1794$, the imaginary parts from the two methods agree more closely than for $\omega=0.06$. The convergence was slow and required about 3000 iterations to converge to a maximum difference between iterations of $2 \times 10^{-5}$ starting from a value of zero for the perturbation potential at all mesh points. See note added in proof on page 34.

The flat plate solution for a reduced frequency of 0.06 and Mach number of 0.8 was used as a starting solution for the unsteady flow around a NACA 64A006 airfoil with a quarter-chord oscillating flap at Mach 0.794 and reduced frequency $\omega=0.064$. Similar convergence of $2 \times 10^{-5}$ 
was attained in 1200 iterations. The pattern of the pressure jump across the airfoil agrees with the experiments of Tijdeman and Schippers (ref. 9), although the amplitude is considerably higher. The solution for $\mathrm{M}=0.804$ and $\omega=0.253$ (corresponding to a frequency of $120 \mathrm{cps}$ ) about the NACA 64A006 airfoil was obtained from the solution for $\mathrm{M}=0.794$ and $\boldsymbol{\omega}=0.064$ as starting values. Solutions were also found for $M=0.858$ and $\omega=0.179$ and for $M=0.853$ and $\omega=0.060$. The patterns for the jump in pressure coefficient from the calculations were similar to the experimental results of Tijdeman and Schippers in reference 9 but the amplitudes were generally higher.

Although only a few computed results were obtained, the feasibility of this approach for finding the unsteady pressure distributions around an oscillating wing in the transonic range is demonstrated. This methoci predicts the observed pressure patterns, while linearized subsonic theory does not. The numerical procedure for the unsteady flow is stable and convergent even when the steady flow contains local supersonic regions.

All the calculations were made with a fine fixed grid. Garabedian and Korn (ref. 1) found that first obtaining a solution of the exact steady flow potential with a coarse grid and then refining the grid for greater accuracy significantly reduced the number of iterations required for convergence of the final solution. A similar procedure should reduce the number of iterations for the unsteady solution as well.

The complete matrix for the coefficients of the unknown values of the unsteady perturbation potential at the points of the mesh contains only five or six nonzero diagonals. The time required for solution also may be reduced by using a special method for solving linear equations with sparse matrices to solve the complete set of difference equations rather than using column relaxation. This may be especially useful for the coarse grid solution.

The basic technique followed here of representing the flow as consisting of separate steady and unsteady flow potentials and then linearizing the unsteady differential equation by assuming small amplitude of oscillation can be applied directly to the complete nonlinear differential equation for compressible flow as well as to the nonlinear transonic small perturbation equation. The problem is easier for the airfoil than for the three-dimensional wing since mapping techniques such as that of Garabedian and Korn in reference 1 may be used to represent the boundary in a way convenient for the mesh system. The same finite difference scheme could be used for the unsteady flow equation after it is expressed in the same independent variables. The elimination of the small perturbation restriction for the three-dimensional wing solution is considerably more difficult, since convenient body coordinates are possible only for restricted classes of configurations. A suitable variable grid around the actual wing boundaries must be devised with appropriately defined difference equations. 
Further computations should be made with the airfoil program in its present form. The sensitivity of the program to mesh size near singularities and to various ways of conducting the column relaxation should be studied. Further calculations are needed to gain experience in determining optimum values of overrelaxation for subsonic regions and underrelaxation for supersonic regions, and to find criteria for the degree of convergence required for a good solution. Some of the discrepancy between calculated and experimental results may be due to the influence of the boundary layer and/or separation effects over the aft portion of the airfoil. Unknown problems associated with the theory or with the experiment, such as wind tunnel wall interference, may also be the cause of this discrepancy.

\section{INTRODUCTION}

In recent years, significant advances have been made in the theoretical treatment of two-dimensional steady transonic flow by such workers as Garabedian and Korn (ref. 1), Murman and Cole (ref. 2), Krupp (refs. 3 and 4), and Steger and Lomax (ref. 5). More recently, some progress has been achieved by Newman and Klunker (ref. 6), and Ballhaus ánd Bailey (ref. 7) toward the development of a useful method for predicting steady transonic airloads on finite wings. There are, however, no satisfactory methods for predicting transonic loads on oscillating surfaces for use in flutter and gust analysis of aircraft. Any completely adequate analysis for the transonic region should include the effects of airfoil bluntness, thickness, camber, angle of attack, and wing-body interference. It should include the effects of mixed subsonic and supersonic flows containing embedded shocks and of the boundary layer with shock wave interaction.

A method for treatment of oscillating wings by finite difference methods is presented here. The assumption of small perturbations from a uniform stream near the speed of sound allows the reduction of the equations of motion to a simple, more tractable form and retains the necessary nonlinearity for describing flows with local supersonic regions. The introduction of the perturbation velocity potential restricts the solution to weak shocks which, for thin wings of reasonably good design, is not too limiting an assumption. When the flow is steady the resulting nonlinear differential equation reduces to the well-known transonic small perturbation differential equation recently studied by Murman and Cole (ref. 2) and Krupp (refs. 3 and 4). The unsteady flow differential equation is simplified by considering the flow as consisting of the sum of two separate potentials representing the steady and unsteady effects and by linearizing the differential equation for small amplitudes of harmonic oscillation. 


\section{SYMBOLS AND ABBREVIATIONS}
$a, b$
coefficients for $\mathrm{y}, \mathrm{z}$ or $\eta, \zeta$ differences corresponding to second derivatives, with appropriate subscripts (equation (23) in appendix)
$\mathrm{c}, \mathrm{d}$
coefficients for $\mathrm{x}$ or $\xi$ difference corresponding to second derivative (equation (19) in appendix)
$c_{1}, d_{1}, c_{2}$
c
$c_{3 i}$
$\mathrm{c}_{4 \mathrm{i}}, \mathrm{d}_{4 \mathrm{i}}$
$\mathrm{c}_{\mathrm{s} 1}, \mathrm{c}_{\mathrm{s} 2}, \mathrm{~d}_{\mathrm{s} 1}, \mathrm{~d}_{\mathrm{s} 2}$
$\mathrm{c}_{\mathrm{k} 1}, \mathrm{c}_{\mathrm{k} 2}, \mathrm{c}_{\mathrm{k} 3}, \mathrm{c}_{\mathrm{k} 4}$
$D_{n}=i \partial / \partial x_{n}$
coefficients for second-order accurate difference corresponding to first derivative (equations (20) and (26) in appendix)
velocity of sound in units of $u_{0}$
equation (92) in appendix
equation (94) in appendix
equation (105) in appendix
equations (117) and (121) in appendix
$\left(\mathrm{x}_{1}, \mathrm{x}_{2}, \mathrm{x}_{3}\right)=(\xi, \eta, \zeta)$

E

$f(x, y, t)$

$f(x, t)$

$\mathrm{f}_{0}$

$\mathrm{f}_{1}$

$f_{i j}=f_{1 x}+i \quad f_{1}$

$\mathrm{h}$

$\mathrm{h}_{\mathrm{i}}$

$\mathrm{i}, \mathrm{j}, \mathrm{k}$

$\mathrm{i}_{\mathrm{a}}$

$\mathrm{i}_{\max } \mathrm{j}_{\max }, \mathrm{k}_{\max }$

$\mathrm{i}_{1}$

$\mathrm{j}_{\mathrm{m}}$ coefficients in difference equations, with appropriate subscripts

instantaneous wing shape defined by $z_{0}=\delta f(x, y, t)$

instantaneous airfoil shape defined by $\mathrm{y}_{0}=\delta \mathrm{f}(\mathrm{x}, \mathrm{t})$

undisturbed wing or airfoil shape

unsteady contribution to wing or airfoil shape

unsteady wing boundary conditions

$y_{j_{m}}+1-y_{j_{m}}$

$\mathrm{z}_{\mathrm{k}_{\mathrm{m}}+1}-\mathrm{z}_{\mathrm{k}_{\mathrm{m}}}$

$\mathrm{x}, \mathrm{y}, \mathrm{z}$ or $\xi, \eta, \zeta$ subscripts for points in the mesh

$\mathrm{x}$ index for first mesh point behind hinge

maximum number of $\mathrm{x}, \mathrm{y}, \mathrm{z}$ mesh planes, respectively

$\mathrm{x}$ index for trailing edge

y mesh line just below airfoil 


\begin{tabular}{|c|c|}
\hline K & $\left(1-M^{2} / M^{2} \epsilon\right.$ \\
\hline $\mathrm{k}_{\mathrm{m}}$ & $\mathrm{z}$ mesh plane below wing \\
\hline $\mathrm{L}, \mathrm{U}$ & superscripts denoting lower or upper boundary on $\mathrm{F}_{\mathrm{ij}}$ \\
\hline M & free-stream Mach number \\
\hline $\mathrm{P}(\mathrm{D})$ & polynomial operator, $\mathrm{D}=\left(\mathrm{D}_{1}, \mathrm{D}_{2}, \mathrm{D}_{3}\right)$ \\
\hline $\mathrm{P}(\mathrm{x}, \mathrm{y})$ & $\varphi_{1 \mathrm{x}}+\mathrm{i} \omega \varphi_{1}$ acceleration (or pressure) potential \\
\hline $\mathrm{q}$ & \lrcorner$^{2} / \epsilon-i \omega(\gamma-1) \varphi_{0 x x}$ \\
\hline $\mathrm{r}$ & $\sqrt{\mathrm{x}_{1}^{2}+\mathrm{y}_{1}^{2}+\mathrm{z}_{1}^{2}}$ \\
\hline $\mathrm{s}$ & semi-chord of wing \\
\hline $\mathrm{s}_{1}$ & $\left(\mathrm{y}_{\mathrm{m}}+2-\mathrm{y}_{\mathrm{j}}+1\right) / \mathrm{h}$ \\
\hline$s_{2}$ & $\left(\mathrm{y}_{\mathrm{j}_{\mathrm{m}}}-\mathrm{y}_{\mathrm{j}_{\mathrm{m}}-1}\right) / \mathrm{h}$ \\
\hline$t, t_{0}$ & time in units of $s / u_{0}$ \\
\hline $\mathrm{u}_{0}$ & free-stream velocity \\
\hline $\mathrm{u}, \mathrm{v}, \mathrm{w}$ & $\begin{array}{l}x, y, z \text { velocity components of flow at beginning of the derivation of the } \\
\text { equations }\end{array}$ \\
\hline $\mathrm{u}$ & $\mathrm{K}-(\gamma+1) \varphi_{0 \mathrm{x}}$ throughout remainder of text \\
\hline $\mathbf{v}$ & $\mathrm{K}-(\gamma+1) \varphi_{0 \mathrm{x}}+\lambda^{2}$ throughout remainder of text \\
\hline $\mathrm{x}, \mathrm{y}, \mathrm{z}$ & $\left(\mathrm{x}_{0}, \mu \mathrm{y}_{0}, \nu \mathrm{z}_{0}\right)$ scaled coordinates \\
\hline $\mathrm{x}_{0}, \mathrm{y}_{0}, \mathrm{z}_{0}$ & dimensionless coordinates in units of $s$ \\
\hline $\mathrm{x}_{1}, \mathrm{y}_{1}, \mathrm{z}_{1}$ & $(\mathrm{x}, \mathrm{y} \sqrt{ } \mathrm{K}, \mathrm{z} \sqrt{ } \mathrm{K})$ \\
\hline$\alpha$ & sweep angle of leading edge \\
\hline$\beta$ & $\sqrt{1-M^{2}}$ \\
\hline$\beta_{1}$ & $\mathrm{D}_{1} / \mathrm{D}_{2}$ \\
\hline$\gamma$ & ratio of specific heats for air \\
\hline
\end{tabular}




\section{$\Delta \varphi$} $\delta$

$\delta_{1}$

$\delta_{2}$

$\epsilon$

$\xi, \eta, \xi$

$\lambda$

$\lambda_{1}$

$\mu, \nu$

$\rho$

$\tau$

$\phi$

$$
\varphi
$$

$x$

$\psi_{0}$

$\psi$

$\omega$
Jump in $\varphi_{1}$ at plane of wing or vortex wake

thickness ratio or measure of camber and angle of attack

$x_{2}-x_{1}$

$\mathrm{x}_{\mathrm{i}_{\max }}-\mathrm{x}_{\mathrm{i}_{\text {max }}}-1$

$(\delta \mathrm{M})^{2 / 3}$

swept wing scaled coordinates $(\xi=\mathrm{x}-\mathrm{y} \sin \alpha)$

$\sin \alpha$

$\omega \mathrm{M} /\left(1-\mathrm{M}^{2}\right)$

scale factors on $\mathrm{y}_{0}$ and $\mathrm{z}_{0}$, respectively $\left(\mu=\nu=\delta^{1 / 3} \mathrm{M}^{2 / 3}\right)$

density made dimensionless to free-stream value

parameter in analysis of differential operator

dimensionless perturbation velocity potential

scaled perturbation velocity potential, $\phi=\epsilon \varphi$

$\psi_{\mathrm{X}}+\mathrm{i} \omega \psi$ acceleration or pressure potential

$\mathrm{e}^{\mathrm{\iota} \omega \mathrm{r}} / \mathrm{r}$ for planar wing, $\mathrm{H}_{0}{ }^{(2)}(\lambda \mathrm{r})$ for airfoil

$e^{i M \lambda_{1} x} \psi_{0}$ fundamental source solution for integral equation

angular reduced frequency ( $\mathrm{x}$ frequency $/ \mathrm{u}_{0}$ ) 


\section{DESCRIPTION OF THE METHOD FOR COMPUTING UNSTEADY FLOW FOR THE HARMONIC MOTION OF A WING.}

A detailed mathematical derivation of the method of finite differences applied to the solution of the unsteady velocity potential for the flow about a harmonically oscillating wing is presented in the appendix. Formulas are derived for the rectangular wing, for the swept wing, and for two-dimensional airfoils. Boundary conditions on the wing, on the trailing vortex sheet, and on the outer boundaries of the mesh are treated in sufficient detail to be coded for implementation on an electronic digital computer. A brief discussion will be presented here and will be limited to the oscillating airfoil, since only the two-dimensional problem was programmed to test the method.

The complete nonlinear differential equation was simplified by assuming the flow to be a small perturbation from a uniform stream near the speed of sound. The resulting equation for steady flow is (see appendix, equation 12)

$$
\left[\mathrm{K}-(\gamma-1) \varphi_{\mathrm{t}}-(\gamma+1) \varphi_{\mathrm{X}}\right] \varphi_{\mathrm{XX}}+\varphi_{\mathrm{yy}}-\left(2 \varphi_{\mathrm{Xt}}+\varphi_{\mathrm{tt}}\right) / \epsilon=0
$$

where $\mathrm{K}=\left(1-\mathrm{M}^{2}\right) / \mathrm{M}^{2} \epsilon, \mathrm{M}$ is the free-stream Mach number of velocity $\mathrm{U}_{0}$ in the $\mathrm{x}$-direction, $\mathrm{x}$ and $y$ are made dimensionless to the semichord $s$ of the airfoil, and the time $t$ to the ratio $s / U_{0}$. With the airfoil shape as a function of time defined by the relation

$$
\mathrm{y}_{0}=\delta \mathrm{f}(\mathrm{x}, \mathrm{t})
$$

the linearized boundary condition becomes

$$
\varphi_{\mathrm{y}}=\mathrm{f}_{\mathrm{x}}(\mathrm{x}, \mathrm{t})+\mathrm{f}_{\mathrm{t}}(\mathrm{x}, \mathrm{t})
$$

The quantity $\delta$ is associated with properties of the airfoil such as maximum thickness ratio, camber, or maximum angle of attack and is assumed small. The coordinate $y$ is scaled to the physical coordinate $\mathrm{y}_{0}$ by the factor

$$
\mathrm{y}=\delta^{1 / 3} \mathrm{M}^{2 / 3} \mathrm{y}_{0}
$$

and $\epsilon$ is given in terms of $\delta$ by

$$
\epsilon=\sim(\delta / \mathrm{M})^{2 / 3}
$$


The pressure coefficient is found from the relation

$$
C_{p}=-2 \epsilon\left(\varphi_{x}+\varphi_{t}\right)
$$

The preceding differential equation is simplified by assuming harmonic motion and by assuming the velocity potential to be separable into a steady-state potential and a potential representing the unsteady effects. We write for a perturbation velocity potential

$$
\varphi=\varphi_{0}(x, y)+\varphi_{1}(x, y) e^{i \omega t}
$$

and for the body shape

$$
f(x, t)=f_{0}(x)+f_{1}(x) e^{i \omega t}
$$

Since the steady-state terms must satisfy the boundary conditions and the differential equation in the absence of oscillations, we obtain

$$
\left[\mathrm{K}-(\gamma+1) \varphi_{0 \mathrm{x}}\right] \varphi_{0 \mathrm{xx}}+\varphi_{0 \mathrm{yy}}=0
$$

with

$$
\varphi_{0 \mathrm{y}}=\mathrm{f}_{0}^{\prime}(\mathrm{x}), \quad \mathrm{y}=0,-1 \leqslant \mathrm{x} \leqslant 1
$$

On the assumption that the oscillations are small and products of $\varphi_{1}$ may be neglected, equations (1) and (2) with the aid of equations (3) and (4) yield

$$
\left\{\left[\mathrm{K}-(\gamma+1) \varphi_{0 \mathrm{x}}\right] \varphi_{1 \mathrm{x}}\right\}_{\mathrm{x}}+\varphi_{1 \mathrm{yy}}-(2 \mathrm{i} \omega / \epsilon) \varphi_{1 \mathrm{x}}+\mathrm{q} \varphi_{1}=0
$$

where

$$
\mathrm{q}=\omega^{2} / \epsilon-\mathrm{i} \omega(\gamma-1) \varphi_{0 x x}
$$

subject to the wing boundary conditions

$$
\varphi_{1 y}=f_{1}^{\prime}(x)+i \omega f_{1}(x)=F(x), \quad y=0,-1 \leqslant x \leqslant 1
$$

A computer program for solving the steady-state transonic flow about lifting airfoils based on equations (4) and (5) was developed by J. A. Krupp (ref. 4) and is designated as program TEA-330 by The Boeing Company. The output of this program was used in computing the coefficients for 
the differential equation of the unsteady potential. The similarity of the unsteady differential equation with the steady-state equation suggests that the method of column relaxation used by Krupp (ref. 4) for the nonlinear steady-state problem should be an effective way to solve equation (6) for the unsteady potential $\varphi_{1}$. Note that equation (6) is of mixed type, being elliptic or hyperbolic whenever equation (4) is elliptic or hyperbolic. Central differencing was used at all points for the $\mathrm{y}$ derivative and at all subsonic or elliptic points for the $\mathrm{x}$ derivatives. Backward (or upstream) differences were used for the $\mathrm{x}$ derivatives at all hyperbolic points.

The boundary condition that the pressure be continuous across the wake from the trailing edge was found in terms of the jump in potential $\Delta \varphi_{1}$ to be

$$
\Delta \varphi_{1}=\Delta \varphi_{\mathrm{t}} \mathrm{e}^{-\mathrm{i} \omega(\mathrm{x}-\mathrm{xt})}
$$

where $\Delta \varphi_{\mathrm{t}}$ is the jump in the potential at $\mathrm{x}=\mathrm{x}_{\mathrm{t}}$ just downstream of the trailing edge and is determined to satisfy the Kutta condition that the jump in pressure vanish at the trailing edge. The quantity $\Delta \varphi_{1}$ is also used in the difference formulation for the derivative $\varphi_{1 \text { yy }}$ to satisfy continuity of normal flow across the trailing edge wake.

For the set of difference equations to be determinate, the value of $\varphi_{1}$ or its derivative must be prescribed on the mesh boundary. Following Klunker (ref. 8), we found an asymptotic integral representation for the far-field $\varphi_{1}$ potential and for the related pressure potential $\varphi_{1 \mathrm{x}}+\mathrm{i} \omega \varphi_{1}$. Because of the difficulty with convergence of the integral over the wake for the integral equation of the velocity potential, upstream and downstream boundary conditions for the mesh were given in terms of the pressure potential $\varphi_{1 \mathrm{x}}+\mathrm{i} \omega \varphi_{1}$ for which the wake integral can be integrated in closed form. The value of $\varphi_{1}$ was computed at one point on the upper boundary and one point on the lower boundary which were conveniently chosen to facilitate rapid convergence of the wake integral. The values of $\varphi_{1}$ at other points on the upper and lower boundaries were found by integrating numerically with respect to $x$ the quantity $\varphi_{1 \mathrm{x}}+\mathrm{i} \omega \varphi_{1}$.

The complete boundary value problem for the oscillating airfoil is illustrated in figure 1 . The notation used in the computer program is also shown. Finer mesh in the $y$ direction was used in the vicinity of the wing plane. Finer grid in the $x$ direction was used to obtain greater accuracy near leading and trailing edges where velocity gradients are higher. 


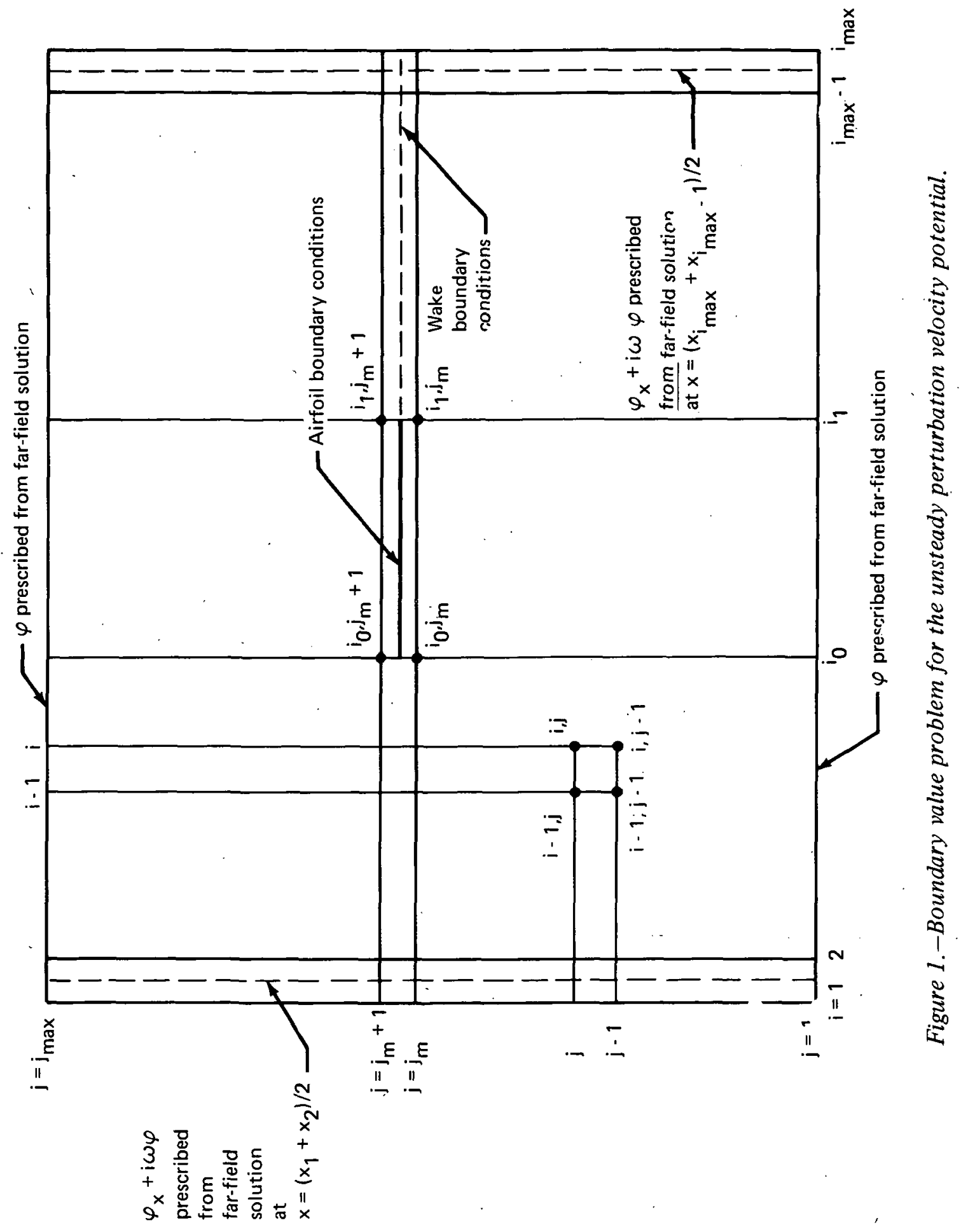




\section{DISCUSSION OF COMPUTED RESULTS FOR THE HARMONICALLY OSCILLATING FLAP ON AN AIRFOIL}

The numerical procedure for computing the transonic unsteady flow described in the foregoing section was applied to the airfoil with the harmonically oscillating flap. For the basic steady transonic flow, we chose the flow about a NACA 64A006 airfoil at zero angle of attack for free-stream Mach numbers of $M=0.8$ and 0.85 . The steady flow potential $\varphi_{0}$ used in computing the coefficients for the unsteady method was computed by the program TEA-330 developed by J. A. Krupp (ref. 4). The distribution of pressure coefficients on the airfoil for the two Mach numbers is shown in figures 2 and 3. Mach numbers and the airfoil were chosen for the purpose of comparing computed results with the experimental measurements of Tijdeman and Schippers in reference 9 for an oscillating flap of quarter-chord length. We note that for $M=0.8$ the airfoil is subcritical, while for $\mathrm{M}=0.85$ it is supercritical over a small region. The reduced frequencies for the flap oscillating at 30 cycles per second in free-stream Mach numbers of $M=0.8$ and 0.85 for the wind tunnel speeds used by Tijdeman and Bergh in reference 9 are $\omega=0.060$ and 0.056 , respectively. The grid consisted of 75 points along $\mathrm{y}=$ constant lines and 58 points along $x=$ constant lines, yielding a total of 4350 points in the mesh. The far-field boundaries are at $x=-2.62$ and 2.75 and $y= \pm 6$. This same grid was used for both the steady and unsteady calculations.

The unsteady contribution to the location of the airfoil surface for the harmonically oscillating flap as a function of chord position is given bý

$$
\begin{aligned}
& \mathrm{f}_{1}(\mathrm{x})=0, \quad-1 \leqslant \mathrm{x} \leqslant 1-\mathrm{L}_{\mathrm{f}} \\
& \mathrm{f}_{1}(\mathrm{x})=\mathrm{a}\left(\mathrm{x}-1+\mathrm{L}_{\mathrm{f}}\right), \quad 1-\mathrm{L}_{\mathrm{f}} \leqslant \mathrm{x} \leqslant 1
\end{aligned}
$$

where the airfoil is defined by $-1 \leq \mathrm{x} \leq 1$ and $\mathrm{L}_{\mathrm{f}}$ is the length of the flap in units of semichord. For the experiments of Tijdeman and Schippers (ref. 9), $\mathrm{L}_{\mathrm{f}}=1 / 2$, and the amplitude was $1.5^{\circ}$. The boundary conditions in equation (82) of the appendix become

$$
\begin{aligned}
& \varphi_{1 y}=0, \quad-1 \leqslant x \leqslant 1-L_{f}, \quad y=0 \\
& \varphi_{1 y}=(a / \delta)\left[1+i \omega\left(x-1+L_{f}\right)\right], 1-L_{f} \leqslant x \leqslant 1
\end{aligned}
$$




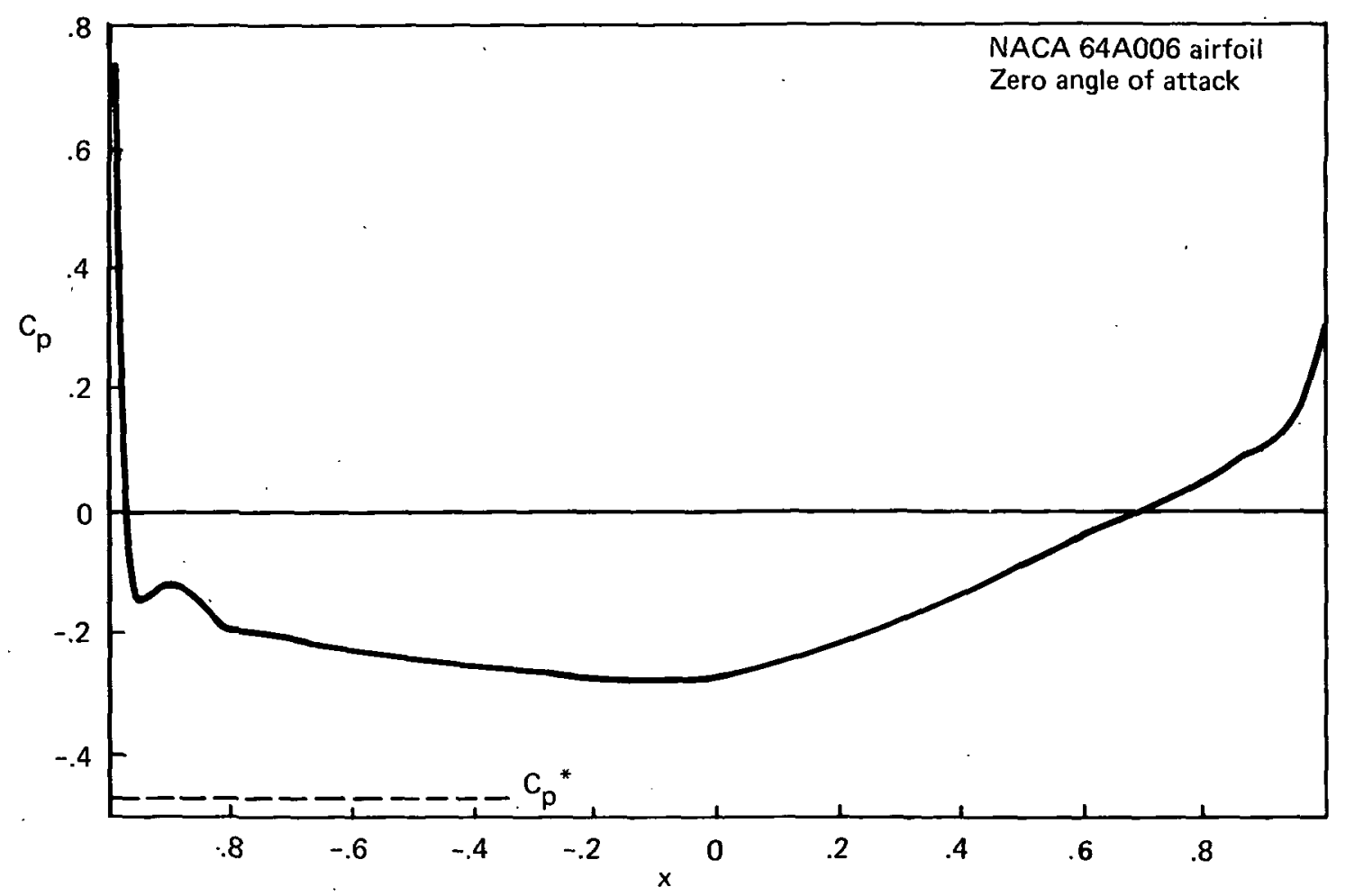

Figure 2.-Distribution of coefficient of pressure, $C_{p}$, at Mach 0.794.

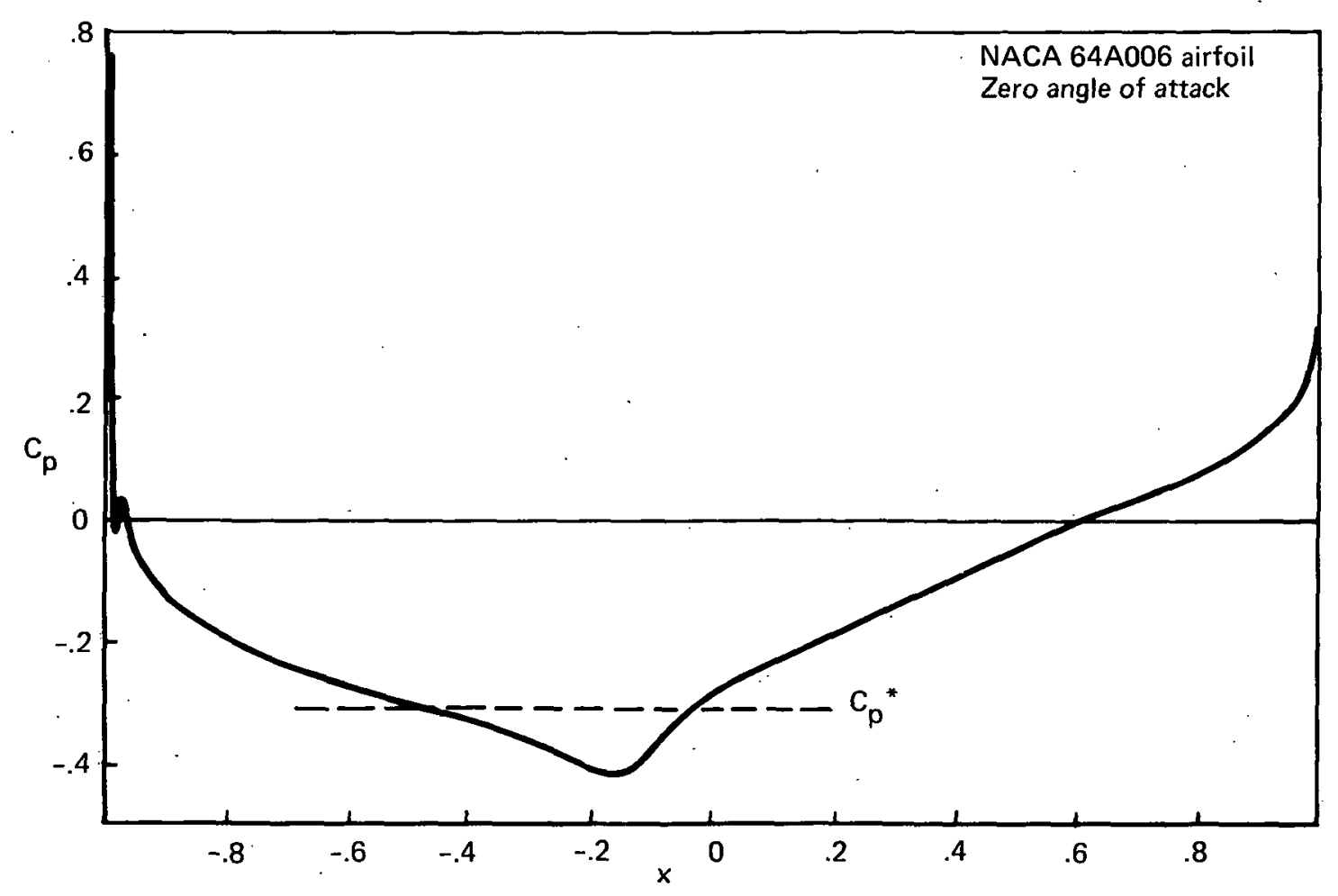

Figure 3.-Distribution of coefficient of pressure, $C_{p}$, at Mach 0.853 
Thus, the quantities $F_{i}(U)$ and $F_{i}(L)$, defined at the mesh points $x_{i}$ and used in the difference equations near the boundary, become

$$
\begin{aligned}
& F_{i}^{(U)}=F_{i}^{(L)}=(a / \delta)\left[1+i \omega\left(x_{i}-1+L_{f}\right)\right], i>i_{a}, \\
& F_{i}(U)=F_{i}(L)=0, \quad i<i_{a},
\end{aligned}
$$

where $i_{a}$ is the $x$-index in the mesh satisfying the relation

$$
\mathrm{x}_{\mathrm{i}_{\mathrm{a}}}<1-\mathrm{L}_{\mathrm{f}}<\dot{\mathrm{x}}_{\mathrm{i}_{\mathrm{a}+1}}
$$

' To check out the program, the flow at Mach number $M=0.8$ over a flat plate was computed for the oscillating boundary conditions of equation (7) and for $\omega=0.06$. For this case $\varphi_{0 \mathrm{x}}=\varphi_{0 \mathrm{xx}} \equiv 0$. The resulting differential equation is equivalent to the classical linearized unsteady subsonic differential flow equation for harmonic motion; namely,

$$
\left(1-\mathrm{M}^{2}\right) \varphi_{\mathrm{Xx}}+\varphi_{\mathrm{yy}}-2 \mathrm{i} \mathrm{M}^{2} \omega \varphi_{\mathrm{X}}+\mathrm{M}^{2} \omega^{2} \varphi=0
$$

This equation has been studied extensively and several kernel function integral equation methods have been developed to solve for the related acceleration or pressure potential, $\varphi_{1 \mathrm{x}}+\mathrm{i} \omega \varphi_{1}$.

The jump in pressure coefficient computed by the present method for the flat plate at $M=0.8$ and $\omega=0.06$ is given in figures 4 and 5 for the real and imaginary parts, respectively. The convergence of the solution was very slow. Overrelaxation with a parameter of 1.3 in the manner of Murman and Cole (ref. 2) and Krupp (refs. 3 and 4) was used in the iteration process, and the relaxation calculations were made by sweeping alternately downstream and upstream for many of the iterations. No definite advantage in alternate direction sweeping of the field as compared with the customary mode of sweeping downstream followed in references 2 through 4 was proven, although Newman and Klunker (ref. 6) found that symmetry of nonlifting solutions for steady subsonic flow was preserved. For the far-field boundary conditions, the value of the unsteady potential $\varphi_{1}$ was computed for upper and lower mesh boundaries, and $\varphi_{1 \mathrm{x}}+\mathrm{i} \omega \varphi_{1}$ boundary conditions were prescribed following the discussion in the section on far-field boundary conditions. The far-field boundary data were updated every 100 iterations near the beginning of the calculations and every 20 iterations for the later calculations. The more frequent updating seems to be more efficient in obtaining the final result. With all values of $\varphi_{1}$ in the mesh starting with zero, the complete calculations shown in figures 4 and 5 were accomplished in about 3000 iterations to a convergence of $2 \times 10^{-5}$ for the magnitude of the maximum difference between iterations. In spite 

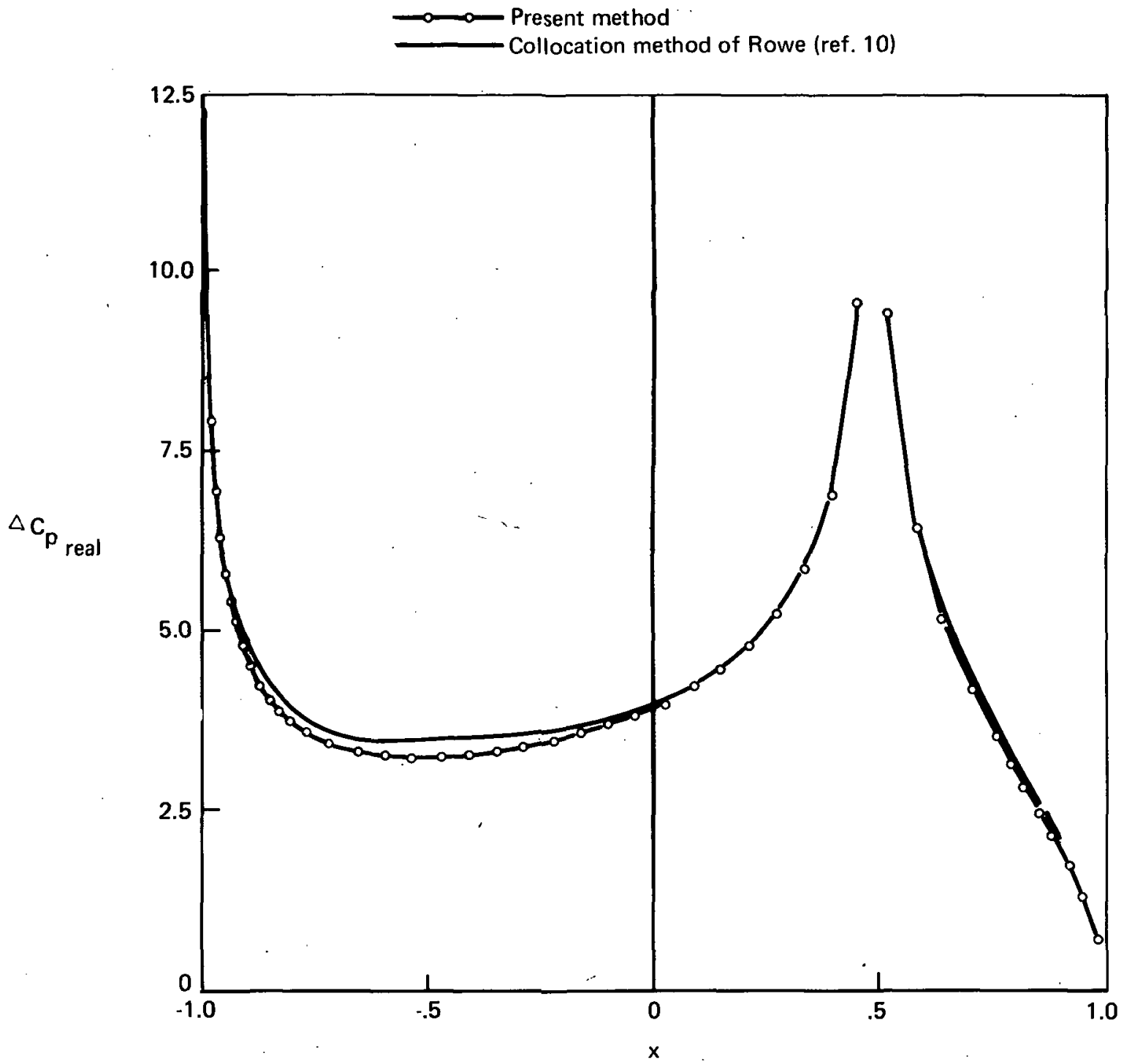

Figure 4.-Real component of the jump in unsteady pressure coefficient across a flat plate with a harmonically oscillating quarter-chord flap. Free-stream Mach number $M=0.8$ and reduced frequency $\omega=0.06$. 


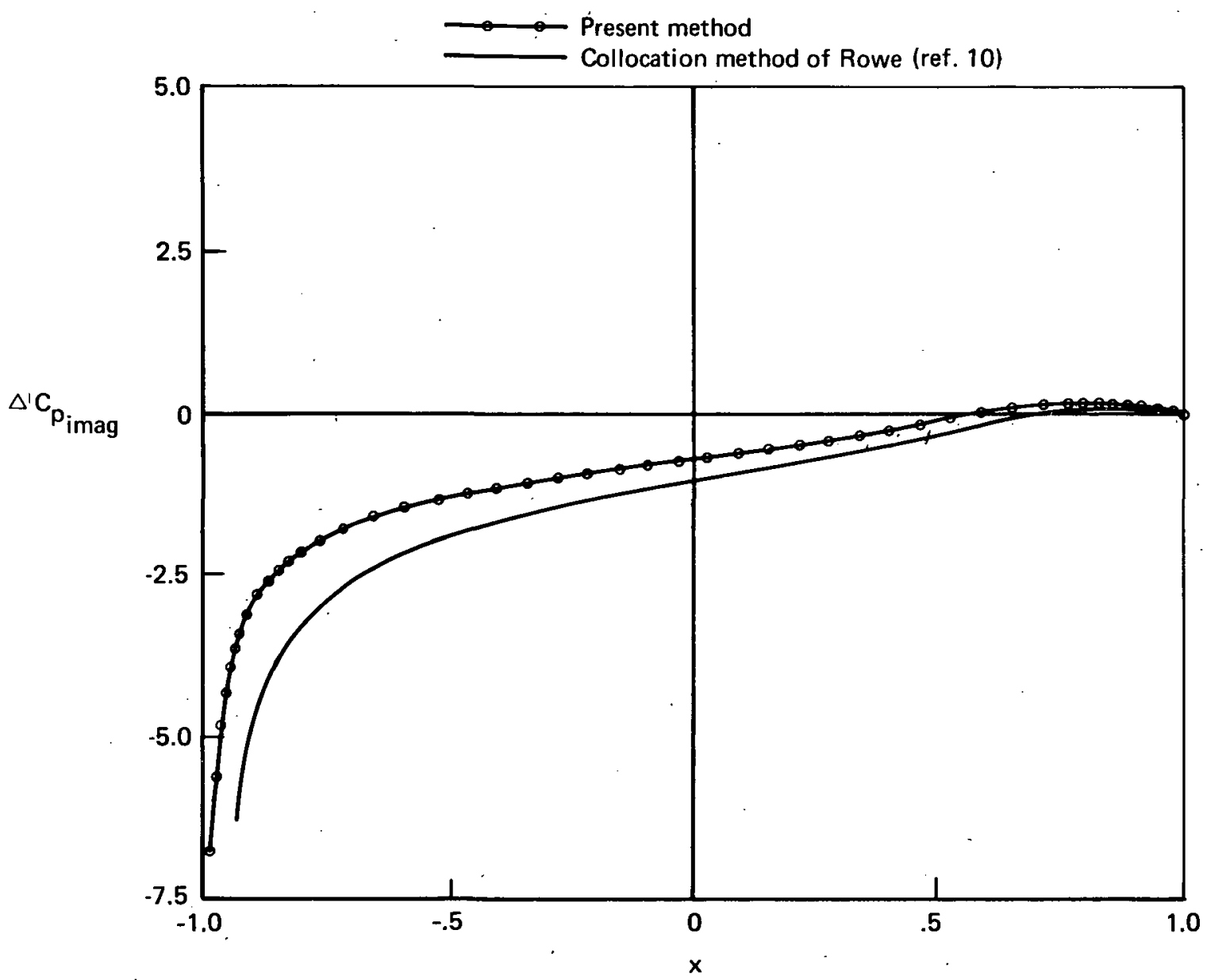

Figure 5.-Imaginary component of the jump in unsteady pressure coefficient across a flat plate with a harmonically oscillating quarter-chord flap. Free-stream Mach number $M=0.8$ and reduced frequency $\omega=0.06$.

of the complex arithmetic and the more complicated equations, the computing time for each iteration is about 1 second on the CDC 6600 compared with the steady flow program which requires about $2 / 3$ second per iteration for the 58 by 75 grid.

The results are compared in figures 4 and 5 with calculations by the kernel function of reference 10 for three-dimensional flow at the center of a rectangular wing of aspect ratio 20 . The real parts of the jump in pressure coefficient by the two methods agree quite well, but the imaginary part from the present method gives amplitudes with less negative value near the leading edge and larger positive value on the flap. The $\mathrm{x}, \mathrm{y}$ mesh points were those used to compute the steady-state potential using TEA-330 and contain a finer spacing near the leading and trailing edges. The grid points used in the calculations are indicateu by circles on graphs of computed results. It 
has been shown in reference 11 that there is a logarithmic singularity at the hinge point and an. infinite square root singularity at the leading edge. Because of these singularities, no mesh points for the unsteady flow should lie on the lines $x=-1$ and 0.5 . Increasing the fineness of the $x$-grid in the vicinity of $x=0.5$ had no noticeable effect on the solution for the flat plate, however. The results also appear to be insensitive to the far-field boundary conditions. Setting $\varphi_{1 \mathrm{x}}+\mathrm{i} \omega \varphi_{1}=0$ on all four far mesh boundaries located at $y= \pm 6.5$ and $x= \pm 3.5$ yielded differences scarcely observable in figures 4 and 5 .

The solution for the flat plate with a free-stream Mach number $M=0.8$ and reduced frequency $\omega=0.06$ was used as a starting solution for $\omega=0.1794$, corresponding to a frequency of 90 cycles per second. The singularity at the leading edges for $\omega=0.1794$ has the opposite sign from that at $\omega=0.06$. After 2800 iterations the solution converged to $10^{-5}$, and the real part along with the equivalent solution from the collocation method of Rowe is shown in figure 6 . The agreement is quite good. Similarly, the comparison of the finite difference solution for the imaginary part of the pressure jump with the corresponding solution by the collocation method is shown in figure 7 . The agreement is better than that for $\omega=0.06$ (fig. 5). The rate of convergence is illustrated in figures 8 and 9 . The cause of the large number of iterations required for convergence is apparently the change in sign of the leading edge singularity for $\omega$ changing from 0.06 to 0.1794 .

With the calculations of the flat plate solution for $\mathrm{M}=0.8$ and $\omega=0.06$ as starting values for $\varphi_{1}$, the solution of the complete linear differential equations for Mach 0.794 and $\omega=0.064$ with

$$
\mathrm{u}=\mathrm{K}-(\gamma+1) \varphi_{0 \mathrm{x}}
$$

provided by the solution from TEA-330 was obtained in about 1200 iterations. Agreement with the experimental results of Tijdeman and Schippers (ref. 9) is not as good as the agreement between the classical linear solution and the present method for flat plate flow. The pattern of the present method agrees with that obtained by Tijdeman and Schippers (ref. 9), as shown in figures 10 and 11. The computed values of real $\Delta C_{p}$ are considerably larger than the experimental measurements. The discrepancy between experiment and theory is not understood. There are a number of possibilities: boundary layer or separation effects, or both, near the aft portion of the airfoil, or unknown problems associated with the theory or with the pressure measurements. However, the validity of the calibration of the pressure tube system used by NLR is confirmed by Destuynder and Tijdeman in reference 12, and should provide reasonable experimental results.

Starting with the $M=0.8$ and $\omega=0.06$ mesh values of $\varphi_{1}$ and with $\varphi_{0}$ from TEA-330, we computed the solution for $\mathrm{M}=0.853$ and $\omega=0.060$ with another 1200 iterations to a maximum error between iterations of about $3.5 \times 10^{-5}$. The results for the jump in pressure coefficient on the 


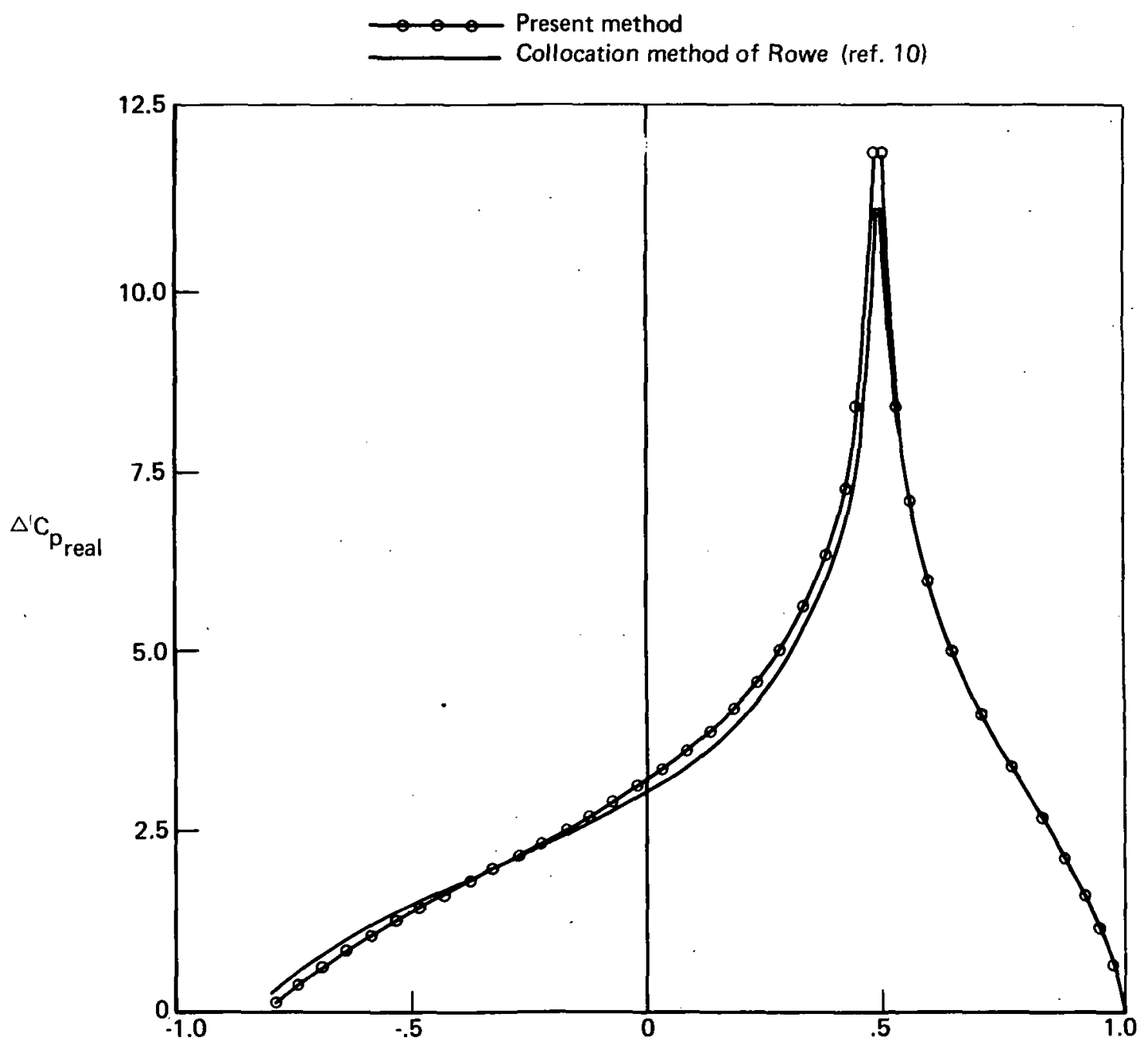

Figure 6.-Real component of the jump in unsteady pressure coefficient across a flat plate with a harmonically oscillating quarter-chord flap. 'Free-stream! Mach number $M=0.8$ and reduced frequency $\omega=0.1794$. 


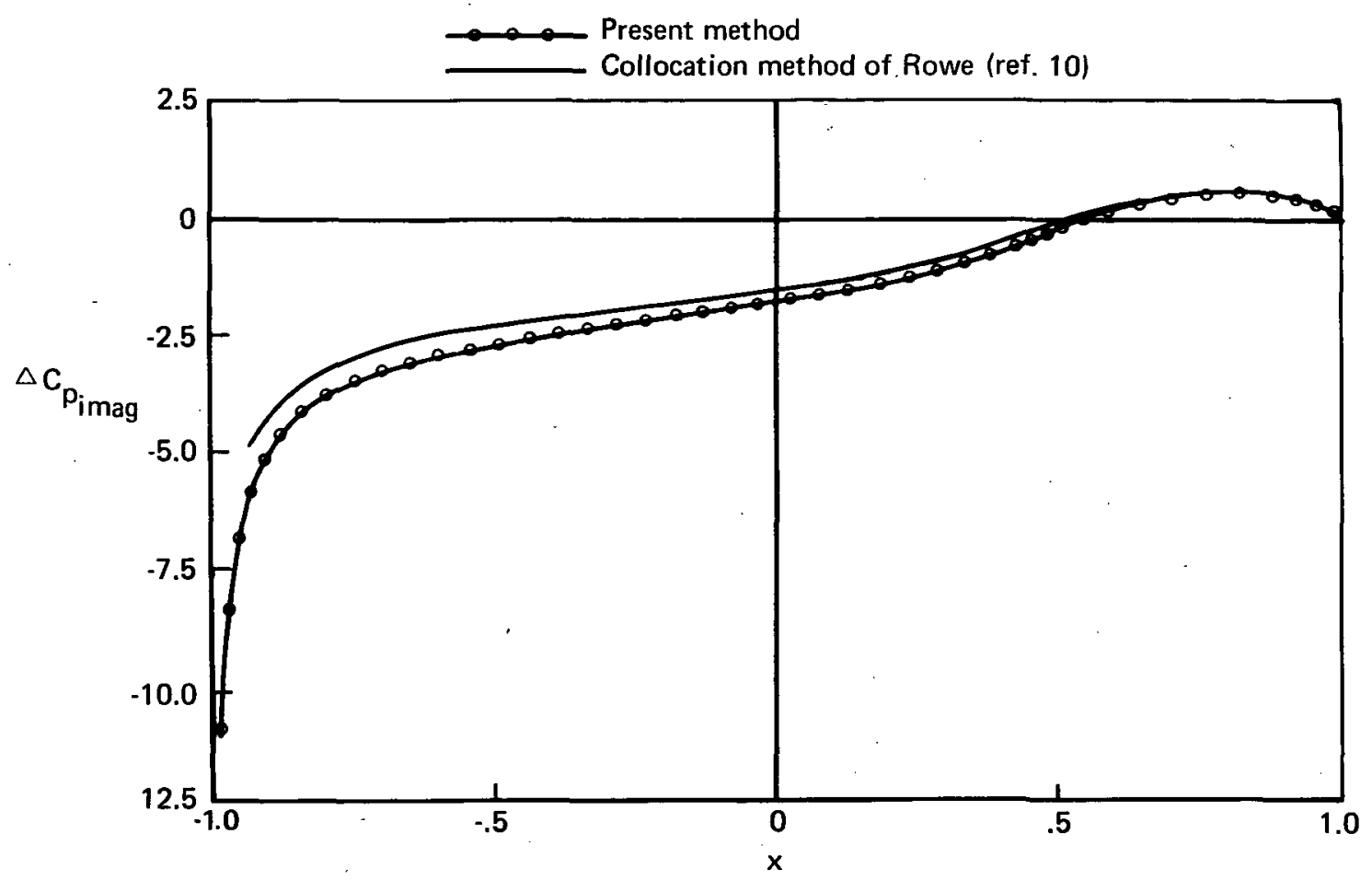

Figure 7.-Imaginary component of the jump in unsteady pressure coefficient across a flat plate with a harmonically oscillating quarter-chord flap.

Free-stream Mach number $M=0.8$ and reduced frequency $\omega=0.1794$.

airfoil are shown in figures 12 and 13 for the real and imaginary parts, respectively. The pressure peak for both the real and imaginary parts close to the midchord as observed by Tijdeman and Schippers (ref. 9) is also predicted by the present method. Although magnitudes are somewhat higher, the pattern of the theoretical imaginary part from the present method agrees with the experiments.

By comparing the two solutions in figures 10 through 13, one can see the influence of increasing Mach number on the propagation of disturbance from the oscillating flap. Note that the real component of the pressure amplitude decreases with Mach number near the leading edge. A peak builds up at the semichord point due to the local supersonic region, which becomes subsonic just downstream of the midchord. These observed properties are common to both the theoretical and experimental results.

The solution for $\omega=0.06$ and $\mathrm{M}=0.794$ was used as the starting solution for $\omega=0.253$ and $\mathrm{M}=0.804$, corresponding to a frequency of 120 cycles per second. After 4000 iterations the solution was converged to $4 \times 10^{-5}$ for the maximum difference between iterations. The column relaxation was swept alternately upstream and downstream and an overrelaxation parameter of 1.4 was used. This flow is completely subsonic. The pattern of the real part of the jump in pressure coefficient from the finite difference method in figure 14 matches the experimental data as in the 


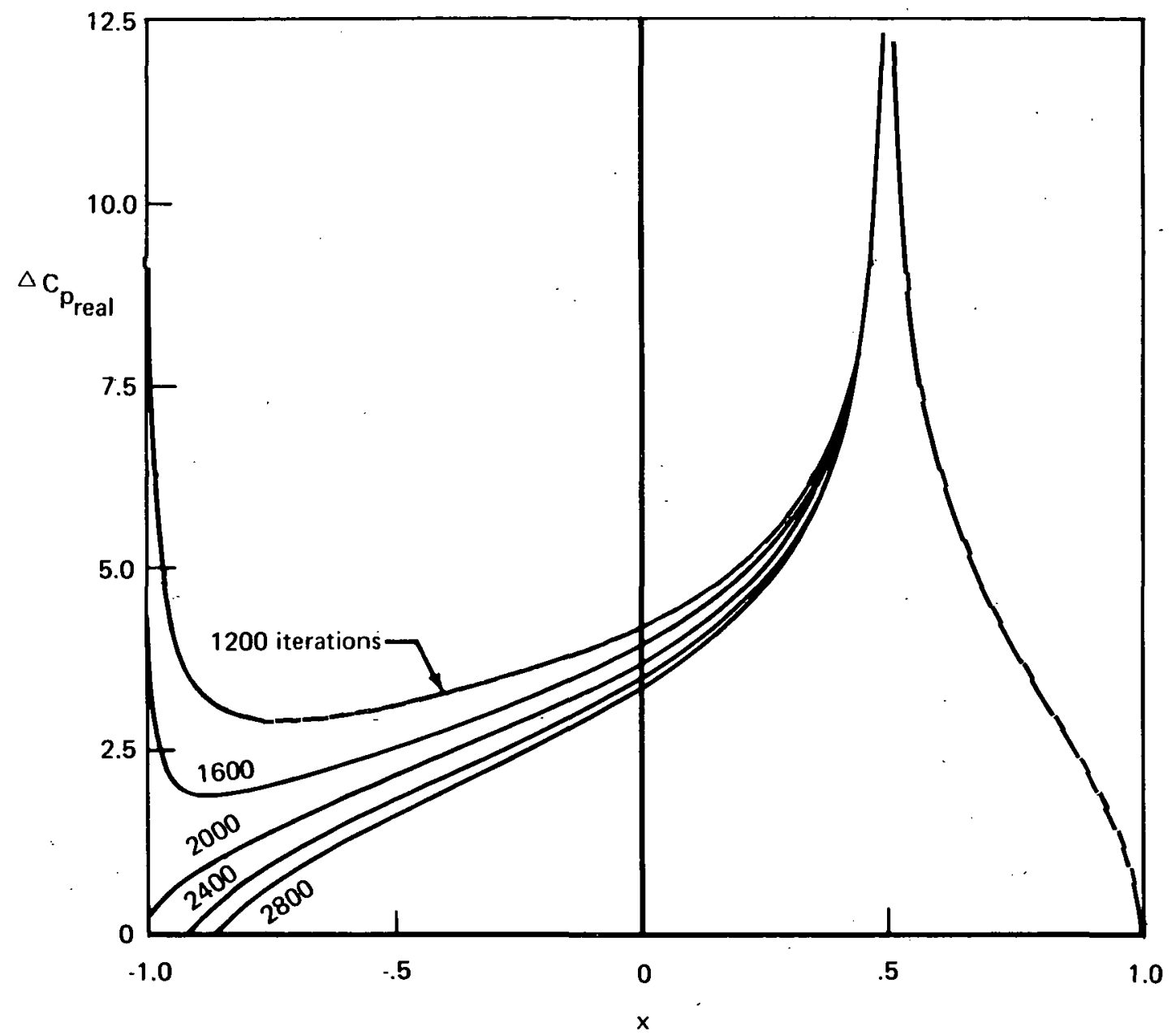

Figure 8.-Rate of convergence of the real part of the jump in pressure coefficient on a flat plate with oscillating quarter-chord flap for a change in reduced frequency from $\omega=0.06$ to $\omega=0.1794$ and free-stream Mach number $M=0.08$.

other cases, but here the magnitude is in somewhat better agreement. The imaginary part shown in figure 15, however, has much higher negative values near the leading edge than the experimental data, but the match is better aft of the hinge line.

The solution for $\omega=0.056$ and $\mathrm{M}=0.85$ was also extended to $\omega=0.179$. This solution was run 3600 iterations and the convergence is $1.93 \times 10^{-5}$ maximum difference between iterations. From figure 16 just downstream of midchord, a peak in the real part of the jump in pressure coefficient has developed and increased to 12 , while the imaginary part in figure 17 shows a peak of -20 just upstream of midchord. The experimental measurements also show these peaks, but on a much smaller scale. The amplitude buildup occurs near the sonic line in the decelerating region of the flow for both values of reduced frequency (see figs. 12 and 13). From the experience in 


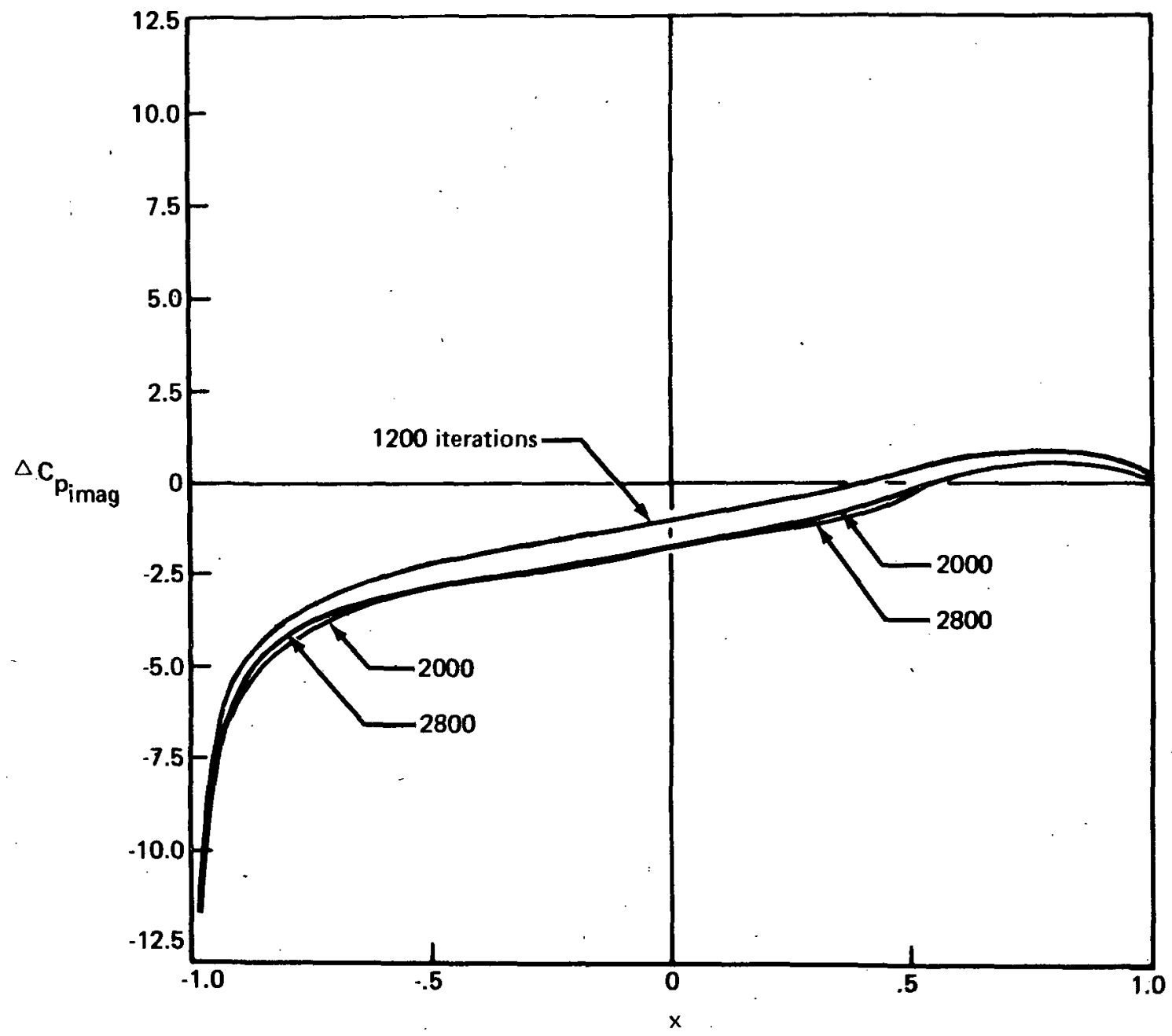

Figure 9.-Rate of convergence of the imaginary part of the jump in pressure coefficient on a flat plate with oscillating quarter-chord flap for a change in reduced frequency frum $\omega=0.06$ to $\omega=0.1794$ and free-stream Mach number $M=0.08$. 


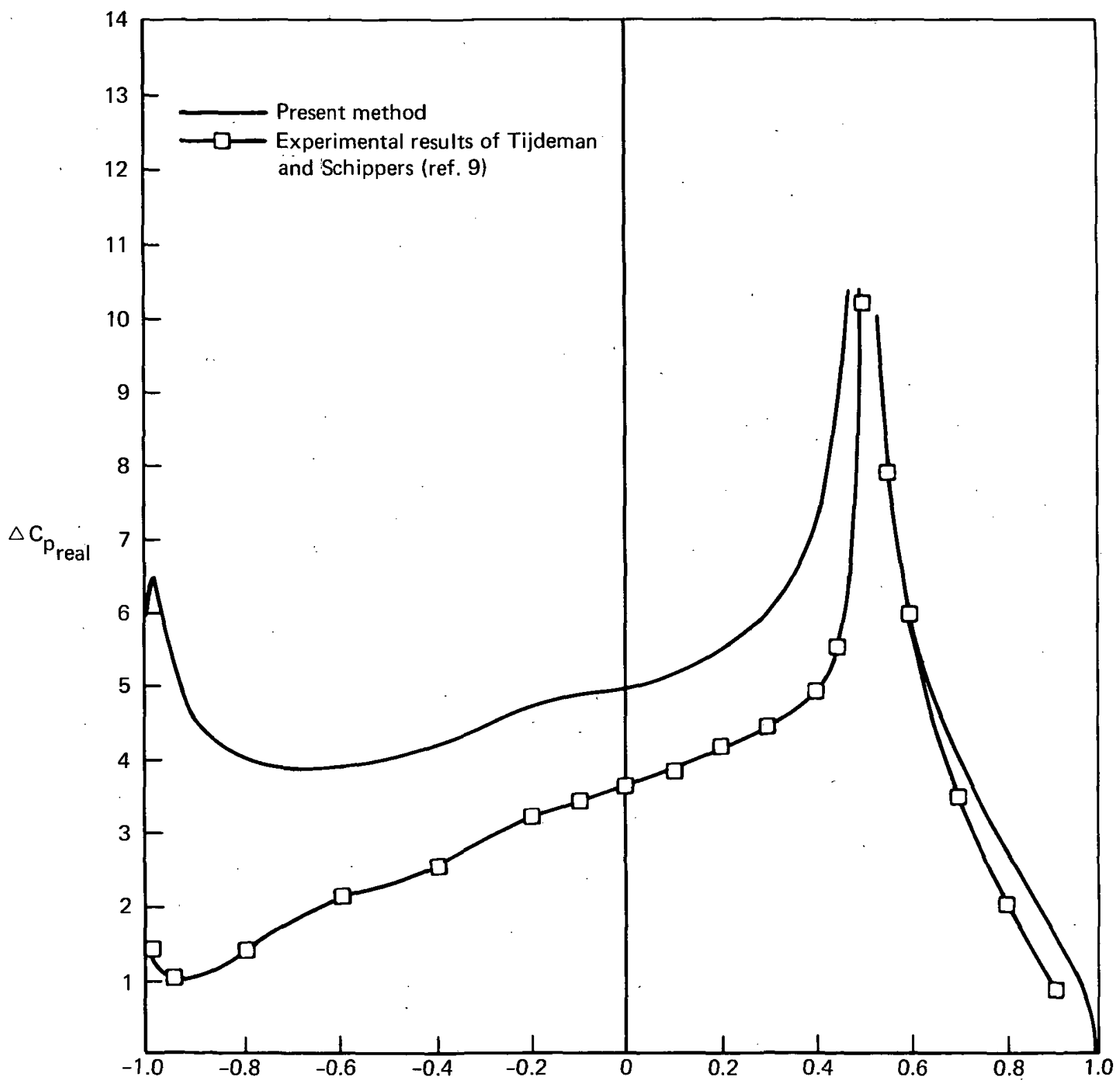

Figure 10.-Real component of the jump in unsteady pressure coefficient across NACA $64 A 006$ airfoil with a harmonically oscillating quarter-chord flap. Free-stream Mach number $M=0.794$ and reduced frequency $\omega=0.064$. 


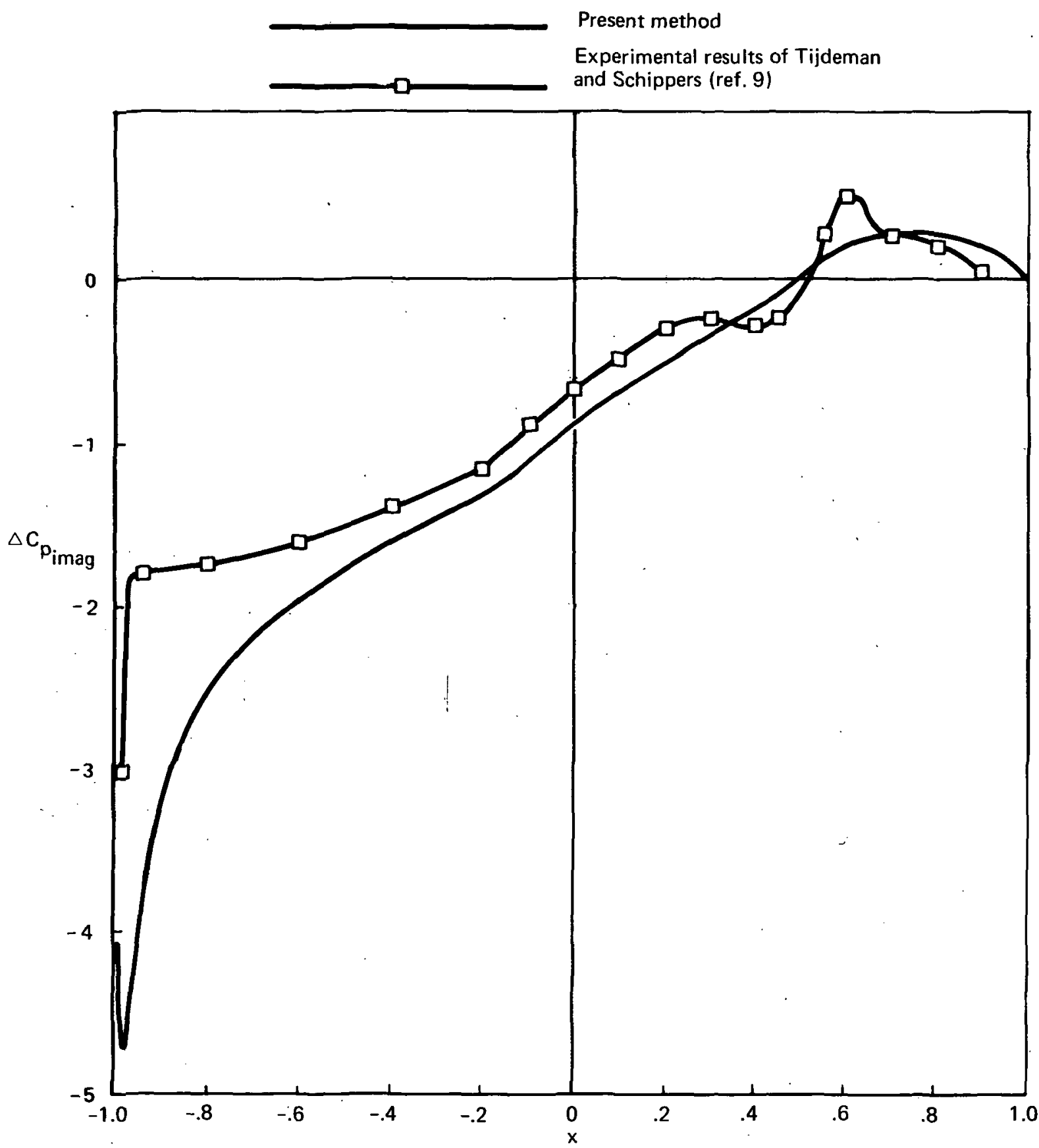

Figure 11.-Imaginary component of the jump in unsteady pressure coefficient across NACA $64 A 006$ airfoil with a harmonically oscillating quarter-chord flap. Free-stream Mach number $M=0.794$ and reduced frequency $\omega=0.064$. 


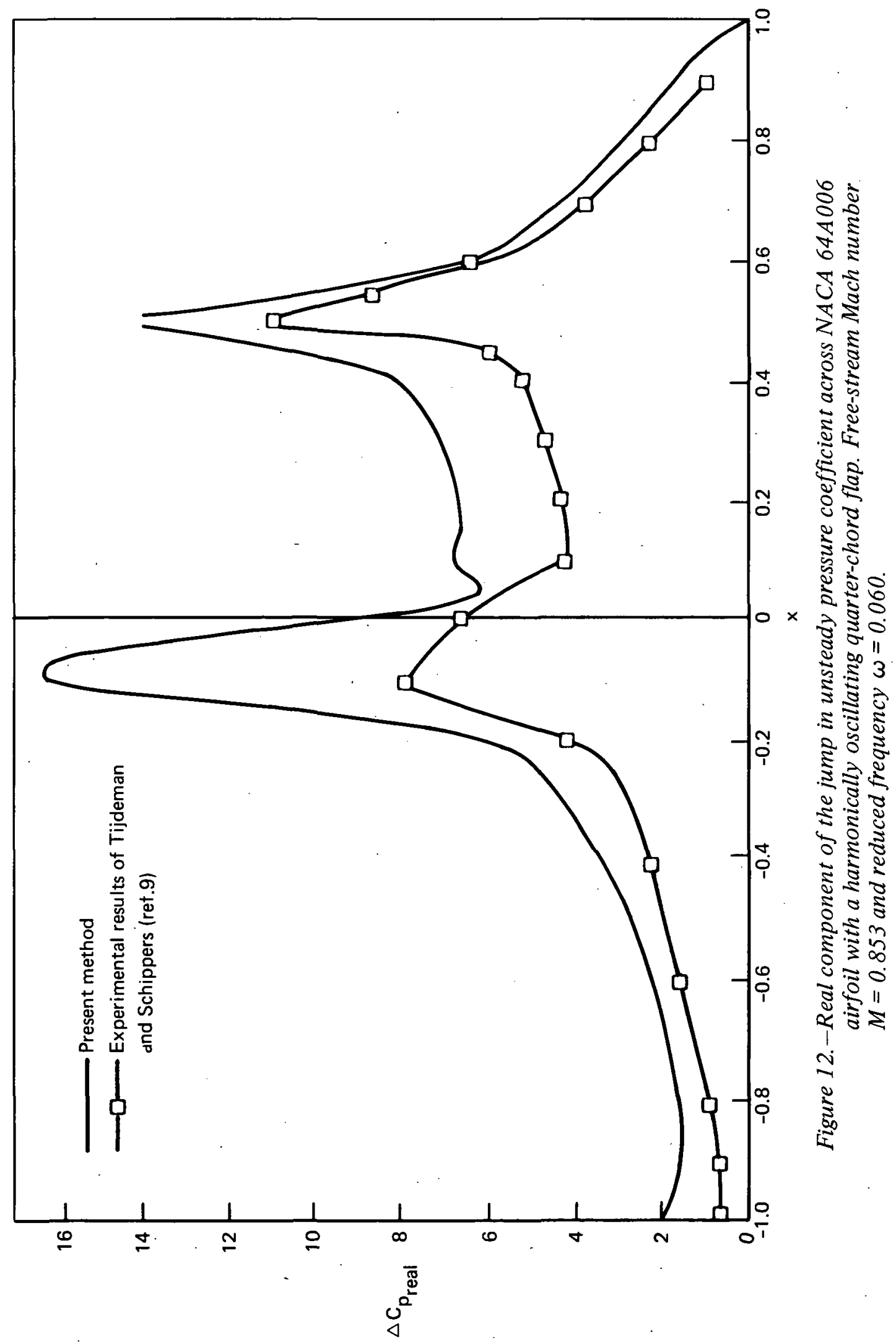




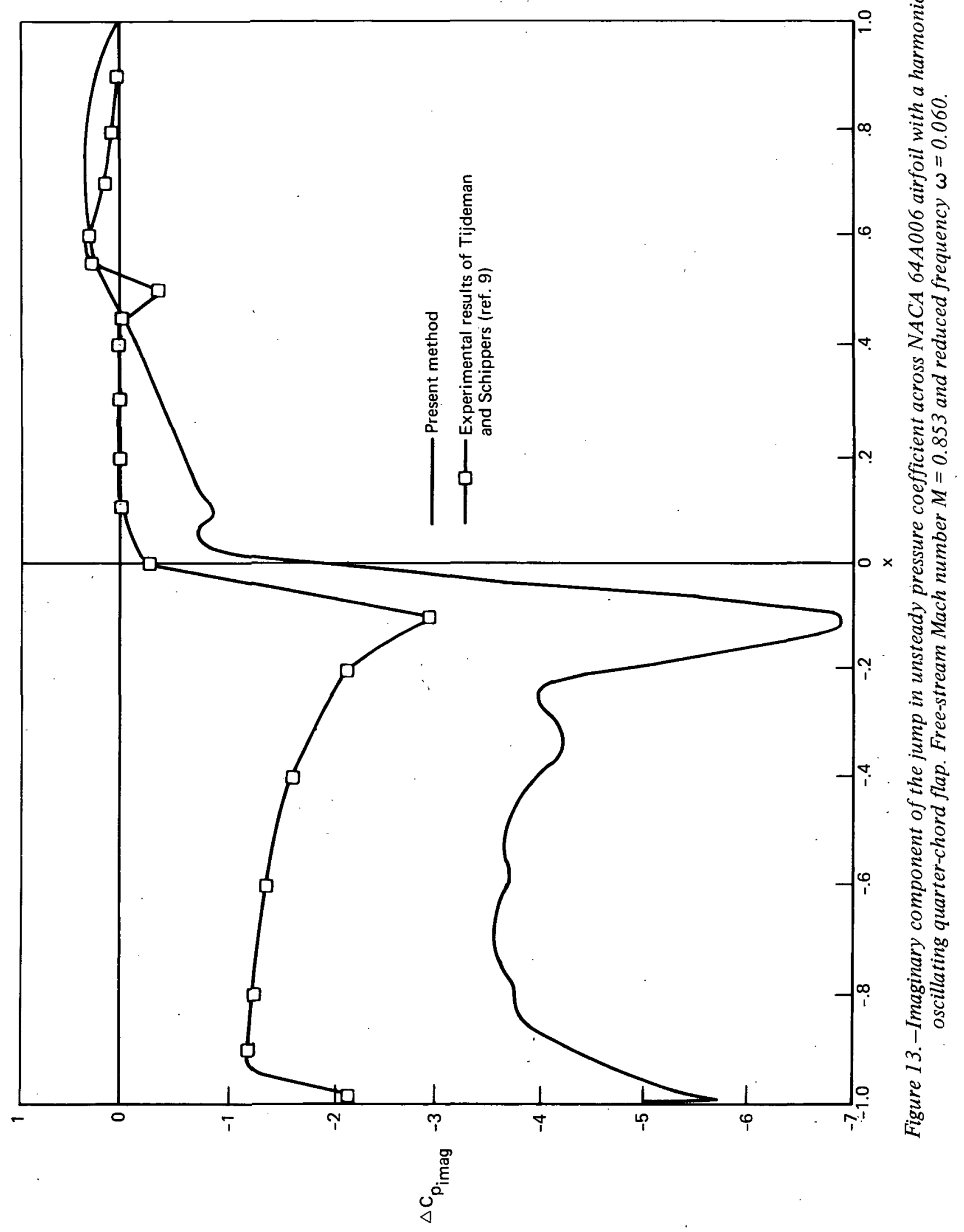


Present method

Experimental results of Tijdeman

and Schippers (ref. 9)

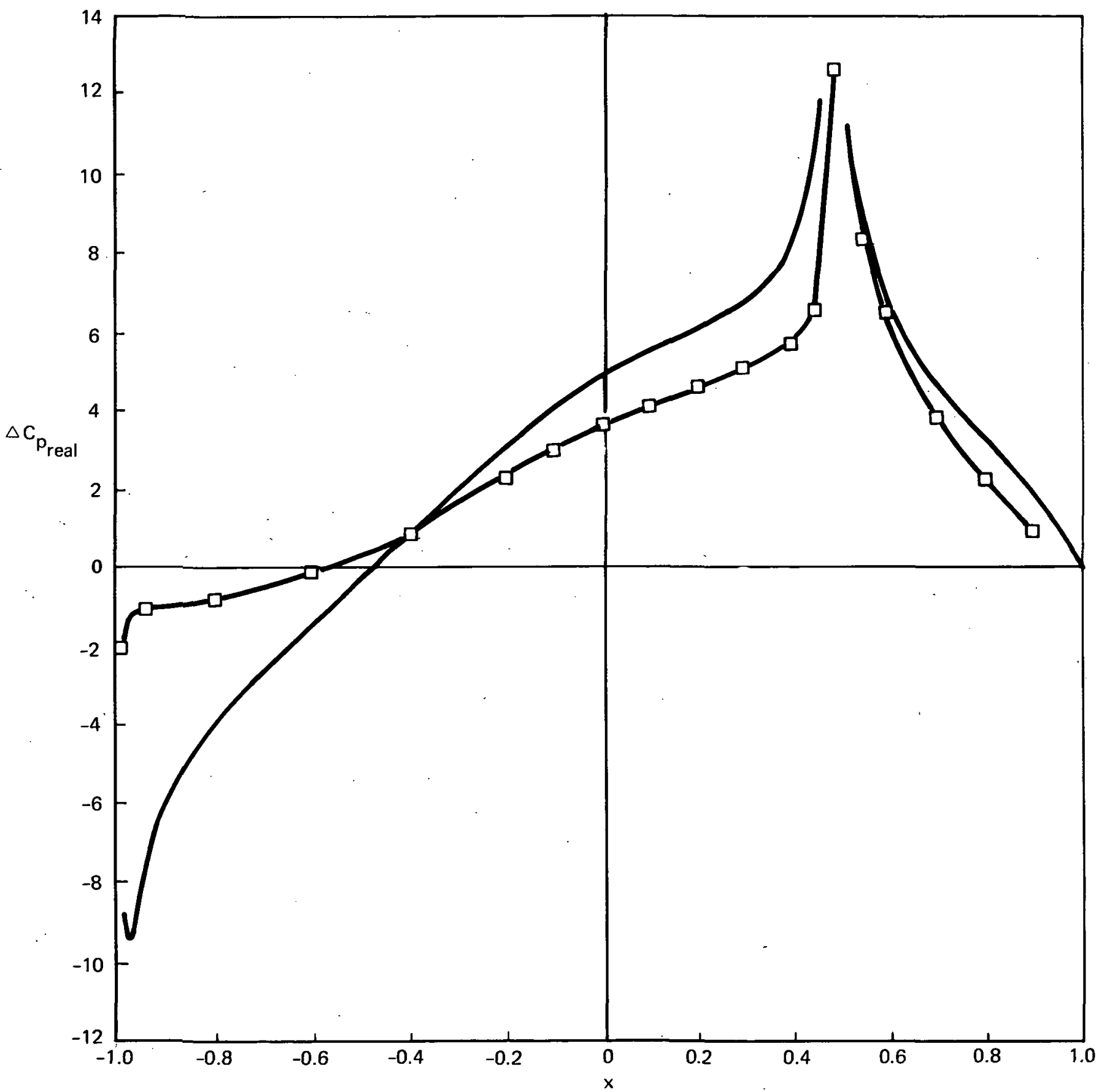

Figure 14.-Real component of the jump in unsteady pressure coefficient across NACA $64 A 006$ airfoil with a harmonically oscillating quarter-chord flap. Free-stream Mach number $M=0.804$ and reduced frequency $\omega=0.253$. 


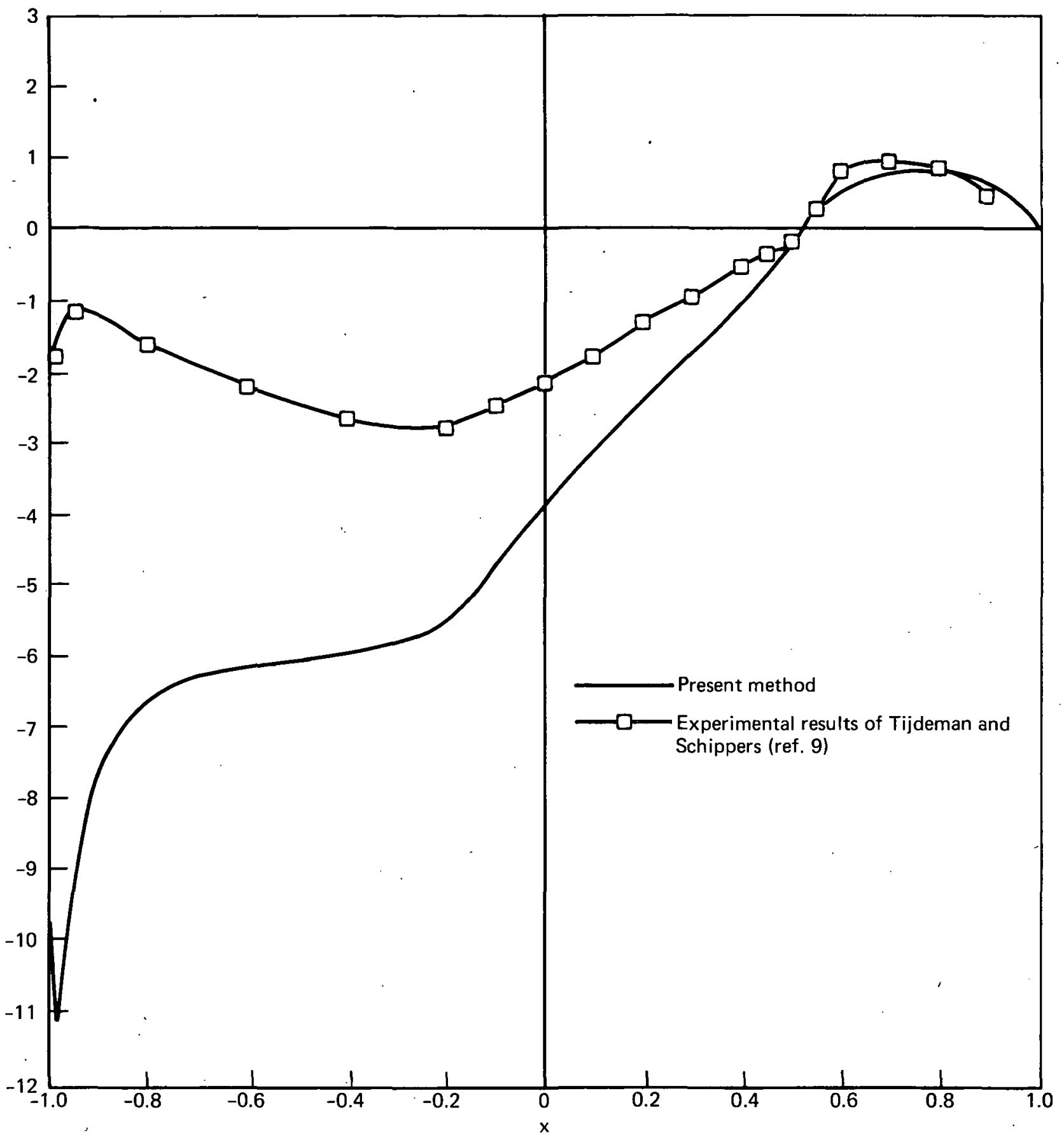

Figure 15. -Imaginary component of the jump in unsteady pressure coefficient across NACA $64 A 006$ airfoil with a harmonically oscillating quarter-chord flap. Free-stream Mach number $M=0.804$ and reduced frequency $\omega=0.253$. 


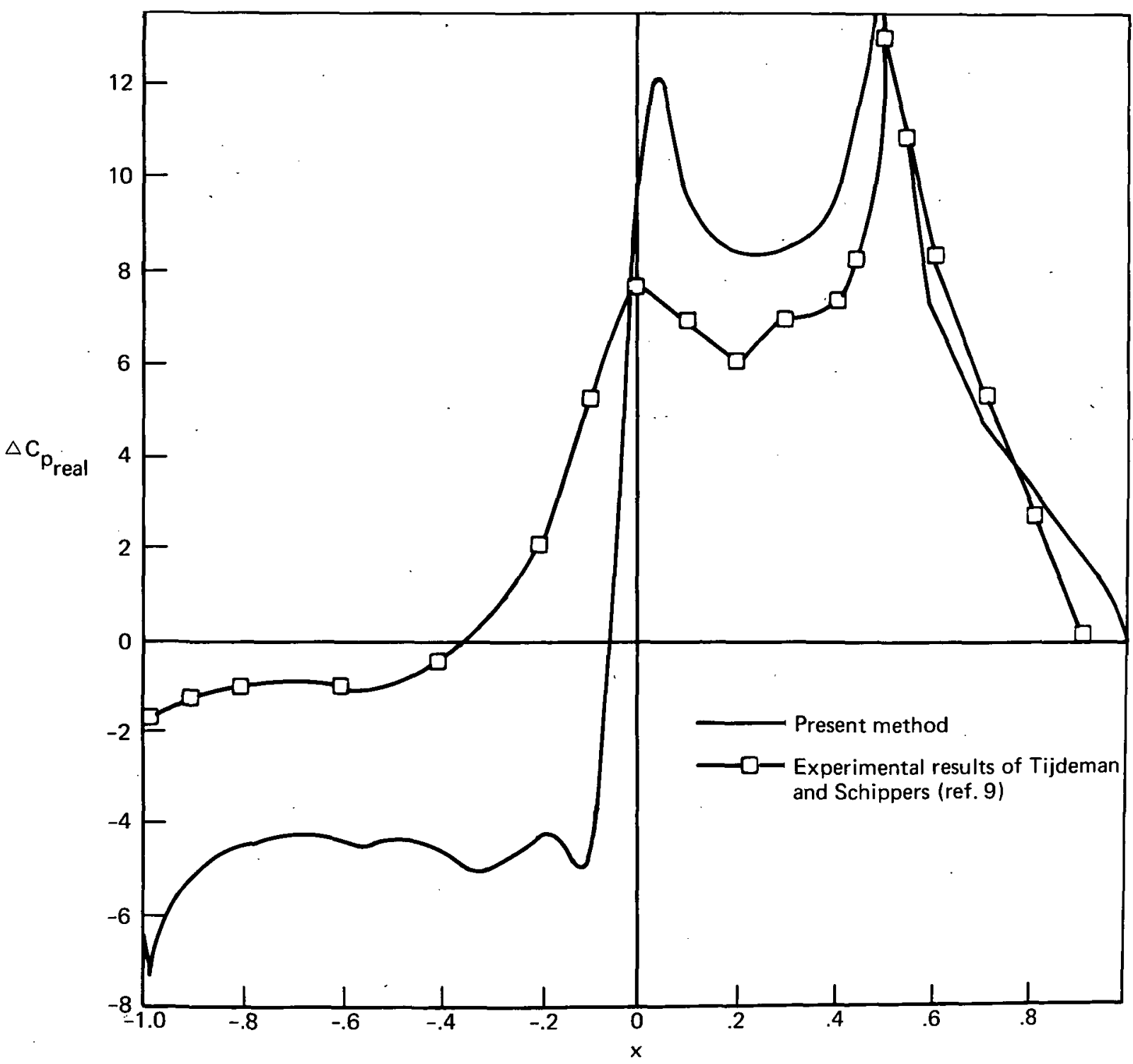

Figure 16.-Real component of the jump in unsteady pressure coefficient across NACA $64 A 006$ with a harmonically oscillating quarter-chord flap. Free-stream Mach number $M=0.858$ and reduced frequency $\omega=0.179$. 


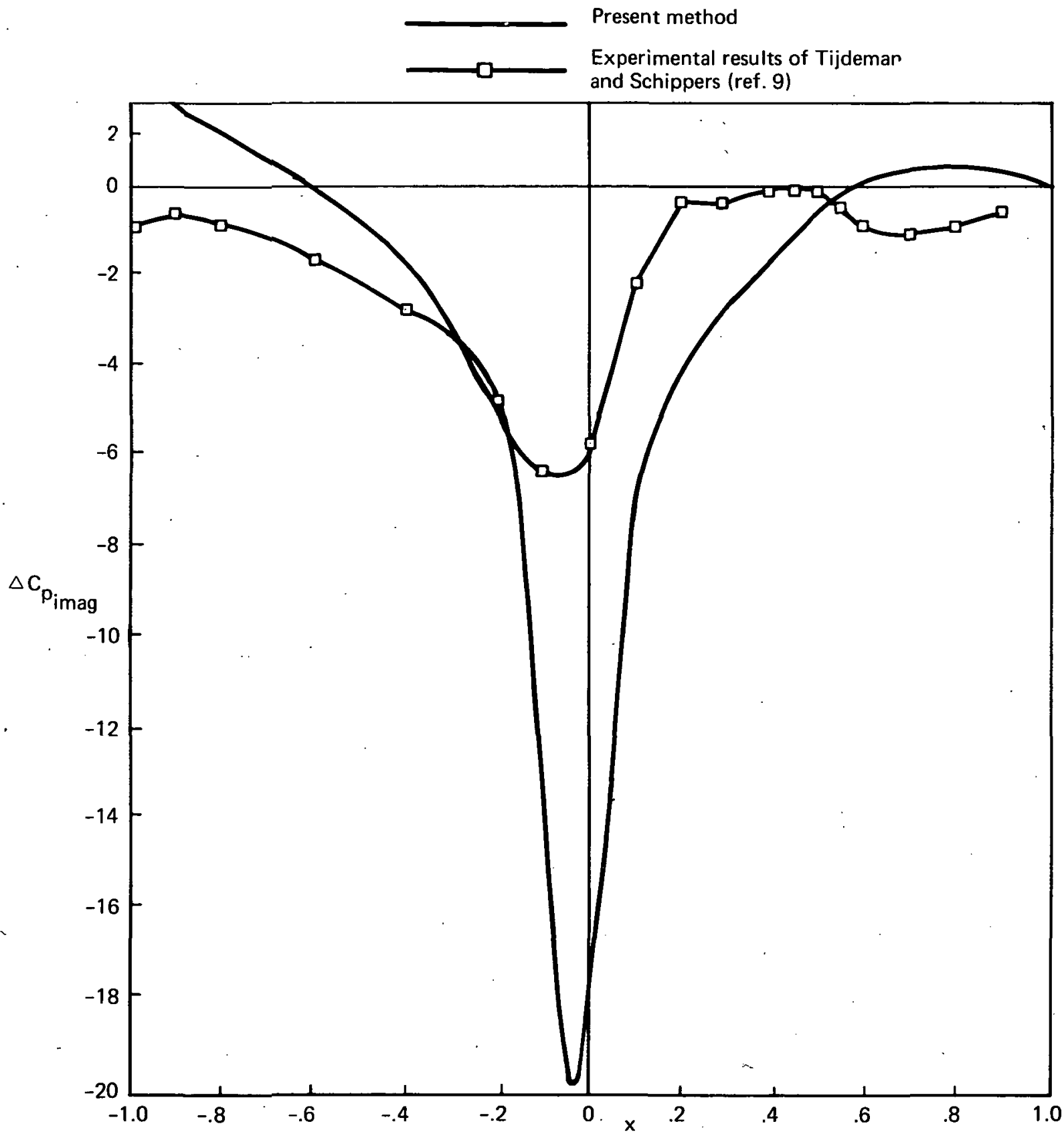

Figure 17.-Imaginary component of the jump in unsteady pressure coefficient across NACA $64 A 006$ airfoil with a harmonically oscillating quarter-chord flap. Free-stream Mach number $M=0.858$ and reduced frequency $\omega=0.179$. 
calculation with the amplitude of oscillation of $1-1 / 2^{\circ}$, it appears that calculations must be continued until the maximum magnitude of the difference between iterations is about $10^{-5}$.

From a study of figures 10 through 17 , we see that solutions from the finite difference method predict the essential features of the pressure distributions found by experiment, whereas the linearized subsonic kernel function method does not. The larger amplitudes may be due to inaccuracies in the method of measurement, to boundary layer and separation effects on the aft portion of the airfoil, or to wind tunnel wall influence.

\section{RECOMMENDATIONS FOR INCREASED ACCURACY AND REDUCED COMPUTING TIME}

It is pointed out in the appendix that the difference equations for the flow field result in a large set of linear equations for the values of the unsteady velocity potential at the mesh points. Column relaxation methods were found to require a large number of iterations to obtain the solution. Since the matrix of the equations contains only five or six nonzero diagonals for two-dimensional flow (and only seven or eight for planar wings), the matrix is very sparse, containing mostly zeros.

Special methods which take advantage of this property should be applied to solving this set of equations. One possible technique is the Gram-Schmidt orthogonalization method of references 13 and 14 , which construct a solution from a set of vectors orthogonal to the set of vectors spanned by the coefficients and right-hand side terms of equations (127) and (128). Scalar products used in constructing these orthogonal vectors will contain only six or seven products at most. The actual number of operations should be considerably less than the 1200 to 3000 iterations of the column relaxation required for the convergence by the column relaxation method. As formulated in this manner, the complete calculations will have to be carried out several times to match far-field boundary conditions and to satisfy the Kutta condition. Each updating of the far-field boundary conditions and the Kutta conditions from the last solution requires only a modification of the right-hand side terms in preparation for the next solution. Satisfying the Kutta condition could be incorporated into the solution of the linear equations, but this would involve additional nonzero elements in the matrix for those points adjacent to the plane of the wake. Many terms in the matrix are duplicated, and taking advantage of this feature can reduce some of the computation. A study of the various special methods available for solving large orders of linear equations should be made to determine which method is best suited to this particular problem. 
It is also possible to improve the efficiency and accuracy of the column relaxation procedure. This may take the form of finding optimum values of the overrelaxation parameter at subsonic points and of underrelaxation at supersonic points, or possibly changing the mesh size near the leading edge and near the hinge line.

In calculating the exact potential steady transonic flow over the blunt airfoil, Garabedian and Korn in reference 1 found that obtaining first a solution with a coarse grid and then refining the grid to obtain greater accuracy reduced significantly the number of iterations required for satisfactory accuracy in the final solution. This procedure should improve both efficiency and accuracy of the unsteady finite difference solution as well.

Experience in computing additional unsteady flows, such as harmonic pitching of the airfoil and comparison with careful measurements on an oscillating airfoil, is needed to clarify the validity of the method.

\section{EXTENSION OF THE WORK TO THREE-DIMENSIONAL WINGS}

In the appendix, a complete analysis based on transonic small perturbation theory is given for applying the method of finite differences to the solution of unsteady flow about finite wings of both rectangular and swept planforms. All formulas required for programming the method are presented. Much of the computer logic in the airfoil program could be directly employed in the program for finite wings. The basic approach would be essentially unchanged, but with the additional dimension adding more complication and a greater number of points. The program either of Newman and Klunker (ref. 6) or Ballhaus and Bailey (ref. 7) would be required to provide the values of the steady perturbation potential at the grid points for the coefficients of the unsteady flow difference equations.

\section{EXTENSION OF THE WORK TO ELIMINATE THE SMALL DISTURBANCE ASSUMPTION}

The general procedure followed here for setting up the linear equation for the unsteady velocity potential could be applied to the more complete potential equation. Garabedian and Korn (ref. 1) transformed the independent variables of the differential equation by a conformal mapping of the physical plane to map the flow field about a blunt airfoil into the interior of a unit circle. 
The transformed differential equation is expressed in difference form in the new variables and solved numerically by relaxation in the manner of Murman and Cole (ref. 2) and Krupp (refs. 3 and 4). In this way the airfoil boundary conditions are satisfied exactly and far-field boundary conditions are easily prescribed.

This same transformation of the independent variable could be similarly applied to the differential equation for the velocity potential of unsteady two-dimensional flow. By representing the complete flow as the sum of a steady-state potential and an unsteady potential, the transformed differential equation for the unsteady flow could be linearized in the same fashion by using the condition that the steady-state potential satisfies the nonlinear equation and by neglecting all terms containing products of the unsteady potential and its derivatives. The unsteady boundary conditions could be linearized by satisfying them on the boundaries of the stationary airfoil and steady wake. The techniques for solution would differ more in the increase of actual computation required for the coefficients than in the actual number of difference equations to be solved.

The Boeing Company has developed a similar method for solving the complete nonlinear differential equation for the steady transonic flow potential about a blunt airfoil by using as independent variables the velocity potential and stream function from the incompressible solution. With the differential equation for steady flow expressed in these variables, the boundary conditions on the airfoil are satisfied exactly. The same procedure could also be applied to this formulation. There appears to be no basic reason why the numerical procedure used for the differential equation' based on the assumption of small perturbations near sonic velocity could not be carried over to the blunt airfoil solutions.

Since no mapping technique exists for simplifying the application of the boundary conditions on three-dimensional wings, the problem of eliminating the restriction to small perturbations for transonic flow is considerably more difficult. A fairly elaborate mesh system must be constructed near the wing surface, and a method of satisfying the boundary conditions must be devised.

\section{CONCLUSION}

A method for applying the finite difference technique to the solution of the unsteady transonic small perturbation differential equation has been developed analytically with sufficient detail in this document that it can be programmed for computation on a high-speed digital computer. Coefficients of the differential equation contain the nonlinear steady flow solution about the wing and must be computed and supplied to the unsteady flow program at the outset of 
computations of the unsteady flow. To test the method, the technique for the oscillating airfoil was programmed and computations were made for the oscillating flap of quarter-chord length on a NACA 64A006 airfoil.

Analysis of the truncation terms of the difference equation indicates that the stability of the difference formulation for subsonic points is not dependent upon the relative grid sizes in the three directions. For supersonic points, a viscous-like term was found in the truncation terms which is similar to that found by Murman and Cole (ref. 2) to yield stable and smooth calculations near shock waves. Calculations using the method indicate that the procedure is indeed stable and convergent.

Five cases were computed involving two free-stream Mach numbers and two frequencies. The numerical method was found to be stable for flows with local supersonic regions as well as strictly subcritical flows. The pattern of the distribution of pressure coefficient on the airfoil in all cases follows closely the distributions observed by Tijdeman and Schippers (ref. 9); however, the pressure levels in the calculated cases are generally, higher than those found by Tijdeman and Schippers (ref. 9). The discrepancy between theory and experiment may be due to boundary layer and separation effects near the aft portion of the airfoil, possible wind tunnel wall interference, or to unknown problems associated either with the theory or with the pressure measurements. The validity of the calibrations used by Tijdeman and Schippers (ref. 9) is confirmed by Destuynder and Tijdeman in reference 12.

For 75 grid points in the $\mathrm{x}$ or stream direction and 56 in the $\mathrm{y}$ direction, the number of iterations for convergence to a maximum difference between iterations of $2 \times 10^{-5}$ varied from 1200 to 3000 depending upon the starting solution. Each iteration takes about 1 second on the CDC 6600 as compared to $2 / 3$ second for the steady-state program TEA-330 developed.by Krupp (ref. 4). More computations are needed to improve the rate of convergence by finding optimum values of the overrelaxation parameter for subsonic points and of the underrelaxation parameter for supersonic points, and to establish suitable criteria for acceptable convergence of the solution. Since Garabedian and Korn (ref. 1) found that first obtaining a solution with a coarse grid and refining the grid to carry on the calculations reduced significantly the number of iterations required for solution of the steady-state equation, a similar procedure should also reduce computing time for the unsteady problem. See note added in proof on page 34 .

Efficiency also may be improved by solving the complete set of equations instead of the column relaxation used in the study. Because the set of difference equations is linear in the unsteady potential and because the matrix of coefficients contains only a few nonzero diagonals, a special procedure for solving the complete set of equations at once seems feasible and should be a subject of future study. 
The present method was formulated on the assumption of small perturbations near the speed of sound, but the method could be extended without too much difficulty to the flow around a blunt airfoil for which the steady flow boundary conditions are not linearized but are satisfied exactly. The two-dimensional problem is made easy by the possibility of using body coordinates to simplify the application of boundary conditions in the finite difference method. Since no simple body coordinate system can be formulated for the three-dimensional wing, a more elaborate mesh system would be required in the neighborhood of the wing surface, making it more difficult to eliminate the restriction of small perturbations. The unsteady boundary conditions presumably would be linearized and applied at the steady-state wing position.

The results of the present study indicate the feasibility of the proposed method of finite differences for finding the unsteady transonic flow about harmonically oscillating wings.

Boeing Commercial Airplane Company

P.O. Box 3707

Seattle, Washington 98104, February 25, 1974

Note added in proof:

Recent studies have shown that, by the use of larger values of the overrelaxation parameters such as 1.8 to 1.9 , the number of iterations to obtain a converged solution was reduced by an order of magnitude when applied to a recomputation of one of the flat plate examples. 


\section{APPENDIX}

\section{Derivation of the Differential Equation and Boundary \\ Conditions for Harmonic Motion of the Thin Wing in Transonic Flow}

Let

$$
\mathrm{u}=\mathrm{u}_{0}\left(1+\phi_{\mathrm{x}_{0}}\right), \quad \mathrm{v}=\mathrm{u}_{0} \phi_{\mathrm{y}_{0}}, \quad \mathrm{w}=\mathrm{u}_{0} \phi_{\mathrm{z}_{0}}
$$

be the velocity components of the flow, where $\phi$ is the perturbation velocity potential, $\mathrm{x}_{0}, \mathrm{y}_{0}, \mathrm{z}_{0}$ Cartesian coordinates, $\mathrm{t}_{0}$ the time, and $\mathrm{u}_{0}$ the undisturbed flow velocity. As given in Landahl (ref. 15), the equations of motion are

$$
\begin{gathered}
\rho_{\mathrm{t}_{0}}+\left[\rho\left(1+\phi_{\mathrm{x}_{0}}\right)\right]_{\mathrm{x}_{0}}+\left(\rho \phi_{\mathrm{y}_{0}}\right)_{\mathrm{y}_{0}}+\left(\rho \phi_{\mathrm{z}_{0}}\right)_{\mathrm{z}_{0}}=0 \\
\mathrm{c}^{2}=1 / \mathrm{M}^{2}-(\gamma-1)\left[\phi_{\mathrm{t}}+\phi_{\mathrm{x}_{0}}+\left(\phi_{\mathrm{x}_{0}}{ }^{2}+\phi_{\mathrm{y}_{0}}{ }^{2}+\phi_{\mathrm{z}_{0}}{ }^{2}\right) / 2\right]
\end{gathered}
$$

where $\rho$ is the density, $c$ the velocity of sound, $\gamma$ the ratio of specific heats, and $\mathrm{M}$ the freestrea $\mathrm{m}$ Mach number. The coordinates $\left(\mathrm{x}_{0}, \mathrm{y}_{0}, \mathrm{z}_{0}\right)$ are made dimensionless to the wing semichord and the time $t_{0}$ to the ratio of the semichord to the velocity $u_{0}$. Since

$$
\mathrm{dc}^{2} /(\gamma-1)=\mathrm{c}^{2} \mathrm{~d} \rho / \rho
$$

we have from equation (3),

$$
\mathrm{c}^{2} \rho_{\mathrm{t}_{0}} / \rho=-\left[\phi_{\mathrm{t}_{0} \mathrm{t}_{0}}+\phi_{\mathrm{x}_{0} \mathrm{t}_{0}}+\phi_{\mathrm{x}_{0}} \phi_{\mathrm{x}_{0} \mathrm{t}_{0}}+\phi_{\mathrm{y}_{0}} \phi_{\mathrm{y}_{0} \mathrm{t}_{0}}+\phi_{\mathrm{z}_{0}} \phi_{\mathrm{z}_{0} \mathrm{t}_{0}}\right]
$$

Similar relations for $\mathrm{c}^{2} \rho_{\mathrm{x}_{0}} / \rho, \mathrm{c}^{2} \rho_{\mathrm{y}_{0}} / \rho$, and $\mathrm{c}^{2} \rho_{\mathrm{z}_{0}} / \rho$ may be written down by replacing the last subscripted variable $\mathrm{t}_{0}$ with $\mathrm{x}_{0}, \mathrm{y}_{0}$, and $\mathrm{z}_{0}$, respectively. By expanding the derivatives in equation (2), eliminating $\mathrm{c}^{2} \rho_{\mathrm{t}_{0}} / \rho$ by equation (5), and eliminating $\mathrm{c}^{2} \rho_{\mathrm{x}_{0}} / \rho, \mathrm{c}^{2} \rho_{\mathrm{y}_{0}} / \rho$, and $\mathrm{c}^{2} \rho_{\mathrm{z}_{0}} / \rho$ by equations similar to equation (5), the following differential equation for $\phi$ results 


$$
\begin{aligned}
& \phi_{\mathrm{t}_{0} \mathrm{t}_{0}}+\phi_{\mathrm{x}_{0} \mathrm{t}_{0}}+\phi_{\mathrm{x}_{0}} \phi_{\mathrm{x}_{0} \mathrm{t}_{0}}+\phi_{\mathrm{y}_{0}} \phi_{\mathrm{y}_{0} \mathrm{t}_{0}}+\phi_{\mathrm{z}_{0}} \phi_{\mathrm{z}_{0} \mathrm{t}_{0}} \\
& +\left[\phi_{\mathrm{t}_{0} \mathrm{x}_{0}}+\phi_{\mathrm{x}_{0} \mathrm{x}_{0}}+\phi_{\mathrm{x}_{0}} \phi_{\mathrm{x}_{0} \mathrm{x}_{0}}+\phi_{\mathrm{y}_{0}} \phi_{\mathrm{y}_{0} \mathrm{x}_{0}}+\phi_{\mathrm{z}_{0}} \phi_{\mathrm{z}_{0} \mathrm{x}_{0}}\right]\left(1+\phi_{\mathrm{x}_{0}}\right) \\
& +\left[\phi_{\mathrm{t}_{0} \mathrm{y}_{0}}+\phi_{\mathrm{x}_{0} \mathrm{y}_{0}}+\phi_{\mathrm{x}_{0}} \phi_{\mathrm{x}_{0} \mathrm{y}_{0}}+\phi_{\mathrm{y}_{0}} \phi_{\mathrm{y}_{0} \mathrm{y}_{0}}+\phi_{\mathrm{z}_{0}} \phi_{\mathrm{z}_{0} \mathrm{y}_{0}}\right] \phi_{\mathrm{y}_{0}} \\
& +\left[\phi_{\mathrm{t}_{0} \mathrm{z}_{0}}+\phi_{\mathrm{x}_{0} \mathrm{z}_{0}}+\phi_{\mathrm{x}_{0}} \phi_{\mathrm{x}_{0} \mathrm{z}_{0}}+\phi_{\mathrm{y}_{0}} \phi_{\mathrm{y}_{0} \mathrm{z}_{0}}+\phi_{\mathrm{z}_{0}} \phi_{\mathrm{z}_{0} \mathrm{z}_{0}}\right] \phi_{\mathrm{z}_{0}} \\
& -\left[1 / \mathrm{M}^{2}-(\gamma-1)\left(\phi_{\mathrm{t}_{0}}+\phi_{\mathrm{x}_{0}}+\phi_{\mathrm{x}_{0}}{ }^{2 / 2}+\phi_{\mathrm{y}_{0}}{ }^{2 / 2}+\phi_{\mathrm{z}_{0}}{ }^{2 / 2}\right)\right]\left(\phi_{\mathrm{x}_{0} \mathrm{x}_{0}}+\phi_{\mathrm{y}_{0} \mathrm{y}_{0}}+\phi_{\mathrm{z}_{0} \mathrm{z}_{0}}\right)=0
\end{aligned}
$$

Since we shall consider small perturbations from a parallel flow, it is convenient at this stage to discard third-order terms in equation (6). Combining terms and simplifying yields

$$
\begin{aligned}
& {\left[1-\mathrm{M}^{2}-(\gamma \cdot 1) \mathrm{M}^{2} \phi_{\mathrm{t}_{0}}-(\gamma+1) \mathrm{M}^{2} \phi_{\mathrm{x}_{0}}\right] \phi_{\mathrm{x}_{0} \mathrm{x}_{0}}+\phi_{\mathrm{y}_{0} \mathrm{y}_{0}}+\phi_{\mathrm{z}_{0} \mathrm{z}_{0}}} \\
& \quad-2 \mathrm{M}^{2} \phi_{\mathrm{x}_{0} \mathrm{t}_{0}}-\mathrm{M}^{2} \phi_{\mathrm{t}_{0} \mathrm{t}_{0}}-\mathrm{M}^{2}\left[2 \phi_{\mathrm{x}_{0}} \phi_{\mathrm{x}_{0} \mathrm{t}_{0}}+2 \phi_{\mathrm{y}_{0}} \phi_{\mathrm{y}_{0} \mathrm{t}_{0}}\right. \\
& +2 \phi_{\mathrm{z}_{0}} \phi_{\mathrm{z}_{0} \mathrm{t}_{0}}+{ }^{2} \psi_{\mathrm{y}_{0}} \phi_{\mathrm{y}_{0} \mathrm{x}_{0}}+2 \phi_{\mathrm{z}_{0}} \phi_{\mathrm{z}_{0} \mathrm{x}_{0}} \\
& \left.\quad-(\gamma-1)\left(\phi_{\mathrm{t}_{0}}+\phi_{\mathrm{x}_{0}}\right)\left(\phi_{\mathrm{y}_{0} \mathrm{y}_{0}}+\phi_{\mathrm{z}_{0} \mathrm{z}_{0}}\right)\right]=0
\end{aligned}
$$

We now introduce a small parameter $\epsilon$ and scale factors $\mu$ and $\nu$ on $\mathrm{y}_{0}, \mathrm{z}_{0}$ and, by an order of magnitude comparison of terms of equation (7), we determine which second-order terms in equation (7) are to be retained for free-stream Mach numbers near 1 . Let $\phi=\epsilon \varphi, x_{0}=x_{0}, t=t_{0}$, $\dot{\mathrm{y}}=\mu \mathrm{y}_{0}$, and $\mathrm{z}=\nu \mathrm{z}_{0}$. The quantity $\epsilon$ is a small quantity whose magnitude in terms of the thickness ratio is to be determined later in the development. The quantities $\mu$ and $\nu$ are scale factors for setting the orders of magnitude of the principal linear terms. With these substitutions the differential equation becomes

$$
\begin{aligned}
& \epsilon\left[\left(1-\mathrm{M}^{2}\right)-(\gamma-1) \mathrm{M}^{2} \epsilon \varphi_{\mathrm{t}}-(\gamma+1) \mathrm{M}^{2} \epsilon \varphi_{\mathrm{X}}\right] \varphi_{\mathrm{XX}}+\mu^{2} \epsilon \phi_{\mathrm{yy}} \\
& +\nu^{2} \epsilon \varphi_{\mathrm{zz}}-2 \mathrm{M}^{2} \epsilon \varphi_{\mathrm{Xt}}-\mathrm{M}^{2} \epsilon \varphi_{\mathrm{tt}}-\mathrm{M}^{2} \epsilon^{2}\left[2 \varphi_{\mathrm{X}} \varphi_{\mathrm{Xt}}\right. \\
& +2 \mu^{2} \varphi_{\mathrm{y}} \varphi_{\mathrm{yt}}+2 \nu^{2} \varphi_{\mathrm{zz}} \varphi_{\mathrm{zt}}+2 \mu^{2} \varphi_{\mathrm{y}} \varphi_{\mathrm{yx}}+2 \nu^{2} \varphi_{\mathrm{z}} \varphi_{\mathrm{zX}} \\
& \left.+(\gamma-1)\left(\varphi_{\mathrm{t}}+\varphi_{\mathrm{X}}\right)\left(\varphi_{\mathrm{yy}} \mu^{2}+\varphi_{\mathrm{zz}} \nu^{2}\right)\right]=0 .
\end{aligned}
$$


Since our primary interest is in transonic flow, we assume that the small quantity $\epsilon$ is of the same order as $1-M^{2}$. Dividing the equation by $M^{2} \epsilon^{2}$ and setting $\left(1-M^{2}\right) / M^{2} \epsilon=K$ leads to

$$
\begin{aligned}
& {\left[\mathrm{K}-(\gamma-1) \varphi_{\mathrm{t}}-(\gamma+1) \varphi_{\mathrm{X}}\right] \varphi_{\mathrm{XX}}+\left(\mu^{2} / \mathrm{M}^{2} \epsilon\right) \varphi_{\mathrm{yy}}+\left(\nu^{2} / \mathrm{M}^{2} \epsilon\right) \varphi_{\mathrm{zz}}} \\
& -\left(2 \varphi_{\mathrm{Xt}}+\varphi_{\mathrm{tt}}\right) / \epsilon-\left[2 \varphi_{\mathrm{X}} \varphi_{\mathrm{Xt}}+2 \mu^{2} \varphi_{\mathrm{y}} \varphi_{\mathrm{yt}}+2 \nu^{2} \varphi_{\mathrm{z}} \varphi_{\mathrm{zt}}\right. \\
& \left.+2 \mu^{2} \varphi_{\mathrm{y}} \varphi_{\mathrm{yX}}+2 \nu^{2} \varphi_{\mathrm{z}} \varphi_{\mathrm{zX}}+(\gamma-1)\left(\varphi_{\mathrm{X}}+\varphi_{\mathrm{t}}\right)\left(\mu^{2} \varphi_{\mathrm{yy}}+\nu^{2} \varphi_{\mathrm{zz}}\right)\right]=0 .
\end{aligned}
$$

It is convenient to set $\nu^{2} / \mathrm{M}^{2} \epsilon=1$ and $\mu^{2} / \mathrm{M}^{2} \epsilon=1$, thereby making $\varphi_{\mathrm{yy}}$ and $\varphi_{\mathrm{zz}}$ terms of the same order as the $\varphi_{\mathrm{XX}}$ term. Equation (8) then becomes

$$
\begin{aligned}
& {\left[\mathrm{K}-(\gamma-1) \varphi_{\mathrm{t}}-(\gamma+1) \varphi_{\mathrm{X}}\right] \varphi_{\mathrm{xx}}+\varphi_{\mathrm{yy}}+\varphi_{\mathrm{zz}}} \\
& -\left(2 \dot{\varphi}_{\mathrm{Xt}}+\varphi_{\mathrm{tt}}\right) / \epsilon-\left\{2 \varphi_{\mathrm{x}} \varphi_{\mathrm{xt}}+2 \mu^{2}\left[\varphi_{\mathrm{y}} \varphi_{\mathrm{yt}}+\varphi_{\mathrm{z}} \varphi_{\mathrm{zt}}\right.\right. \\
& \left.\left.+\varphi_{\mathrm{y}} \varphi_{\mathrm{yt}}+\varphi_{\mathrm{z}} \varphi_{\mathrm{zX}}+(\gamma-1)\left(\varphi_{\mathrm{t}}+\varphi_{\mathrm{X}}\right)\left(\varphi_{\mathrm{yy}}+\varphi_{\mathrm{zz}}\right) / 2\right]\right\}=0 .
\end{aligned}
$$

To determine $\mu$ in terms of the thickness ratio $\delta$ we consider the boundary conditions on the wing; we let

$$
\mathrm{F}\left(\mathrm{x}_{0}, \mathrm{y}_{0}, \mathrm{t}_{0}\right)=\mathrm{z}_{0}-\delta \mathrm{f}\left(\mathrm{x}_{0}, \mathrm{y}_{0}, \mathrm{t}_{0}\right)=0
$$

describe the wing surface at each time $\mathrm{t}_{0}$. Then the boundary conditions that the flow be tangential to the wing surface become

$$
\mathrm{DF} / \mathrm{Dt}=0
$$

or

$$
-\delta \mathrm{f}_{\mathrm{x}_{0}}\left(1+\phi_{\mathrm{x}_{0}}\right)-\delta \mathrm{f}_{\mathrm{y}_{0}} \phi_{\mathrm{y}_{0}}+\phi_{\mathrm{z}_{0}}-\delta \mathrm{f}_{\mathrm{t}_{0}}=0
$$

In scaled coordinates with $\phi=\epsilon \varphi$, we have

$$
\varphi_{\mathrm{z}}-(\delta / \epsilon \mu)\left(\mathrm{f}_{\mathrm{x}}+\mathrm{f}_{\mathrm{t}}\right)-(\delta / \mu) \mathrm{f}_{\mathrm{x}} \varphi_{\mathrm{x}}-(\delta \mu) \mathrm{f}_{\mathrm{y}} \varphi_{\mathrm{y}}=0
$$


Letting $\delta / \epsilon \mu=1$ makes all the linear terms have the same order of magnitude. Then the boundary conditions beçome

$$
\varphi_{\mathrm{Z}}-\mathrm{f}_{\mathrm{X}}-\mathrm{f}_{\mathrm{t}}-\epsilon \varphi_{\mathrm{X}} \mathrm{f}_{\mathrm{X}}-\epsilon \mu^{2} \mathrm{f}_{\mathrm{y}} \varphi_{\mathrm{y}}=0
$$

Since $\mu=\delta / \epsilon$ and $\mu^{2} / \mathrm{M}^{2} \epsilon=1$, we can solve for $\mu$ and $\epsilon$ in terms of $\delta$. Thus

$$
\epsilon=(\delta / M)^{2 / 3}
$$

and

$$
\mu=\nu=\delta^{1 / 3} \mathrm{M}^{2 / 3}=\mathrm{M \epsilon}^{1 / 2}
$$

Upon neglecting terms of the order of $\epsilon$ in equation (9), we finally obtain the differential equation

$$
\begin{aligned}
& {\left[\mathrm{K}-(\gamma-1) \varphi_{\mathrm{t}}-(\gamma+1) \varphi_{\mathrm{X}}\right] \varphi_{\mathrm{XX}}+\varphi_{\mathrm{yy}}+\varphi_{\mathrm{zZ}}} \\
& -2 \varphi_{\mathrm{X}} \varphi_{\mathrm{Xt}}-\left(2 \varphi_{\mathrm{Xt}}+\varphi_{\mathrm{tt}}\right) / \epsilon=0
\end{aligned}
$$

The boundary condition from equation (11)

$$
\varphi_{\mathrm{z}}=\mathrm{f}_{\mathrm{x}}+\mathrm{f}_{\mathrm{t}}
$$

is to be satisfied on the wing, represented by its projection on the $z_{0}=0$ plane.

For convenience, we separate the perturbation potential $\varphi$ into a steady flow $\varphi_{0}$ and an unsteady flow $\varphi_{1}$. Thus, we let

$$
\varphi=\varphi_{0}(\mathrm{x}, \mathrm{y}, \mathrm{z})+\varphi_{1}(\mathrm{x}, \mathrm{y}, \mathrm{z}, \mathrm{t})
$$

The steady flow term $\varphi_{0}$ must satisfy equation (12) independently. Thus, we obtain

$$
\left[\mathrm{K}-(\gamma+1) \varphi_{0 \mathrm{x}}\right] \varphi_{0 \mathrm{xx}}+\varphi_{0 \mathrm{yy}}+\varphi_{0 \mathrm{zz}}=0
$$

This is the well-known transonic small perturbation equation for steady flow studied recently by Murman and Cole, Krupp, Newman and Klunker, and Ballhaus and Bailey (see refs. 2 through 7). It is nonlinear and of mixed type. When $\varphi_{0 \mathrm{x}}<\mathrm{K} /(\gamma+1)$, the equation is elliptic; and when $\varphi_{0 \mathrm{x}}>\mathrm{K} /(\gamma+1)$, it is hyperbolic. The quantity $\mathrm{K} /(\gamma+1)$ is seen to be the sonic velocity for the flow represented by the solution of equation (14). 
Substituting equation (13) into (12), making use of equation (14), and neglecting product terms in $\varphi_{1}$ yields the following linear differential equation for the unsteady perturbation potential:

$$
\begin{aligned}
& {\left[\mathrm{K}-(\gamma+1) \varphi_{0 \mathrm{x}}\right] \varphi_{1 \mathrm{xx}}-\left[(\gamma-1) \varphi_{1 \mathrm{t}}+(\gamma+1) \varphi_{1 \mathrm{x}}\right] \varphi_{0 \mathrm{xx}}} \\
& +\varphi_{1 \mathrm{yy}}+\varphi_{1 \mathrm{zz}}-\left(2 \varphi_{1 \mathrm{xt}}+\varphi_{1 \mathrm{tt}}\right) / \epsilon=0 .
\end{aligned}
$$

Here we have also neglected the coefficient $\varphi_{0 \mathrm{x}}$ of the $\varphi_{1 \mathrm{xt}}$ term as negligible compared to $1 / \epsilon$.

We shall assume harmonic motion for the wing; then with

$$
\varphi_{1}=\varphi_{1}(x, y, z) e^{i \omega t}
$$

equation (15) becomes

$$
\left\{\left[\mathrm{K}-(\gamma+1) \varphi_{0 \mathrm{x}}\right] \varphi_{1 \mathrm{x}}\right\} \mathrm{x}+\varphi_{1 \mathrm{yy}}+\varphi_{1 \mathrm{zz}}-(2 \mathrm{i} \omega / \epsilon) \varphi_{1 \mathrm{x}}+\left[\omega^{2} / \epsilon-(\gamma-1) \mathrm{i} \omega \varphi_{0 \mathrm{zz}}\right] \varphi_{1}=0
$$

This may be written as

$$
\left[\mathrm{u} \varphi_{1 \mathrm{x}}-(2 \mathrm{i} \omega / \epsilon) \varphi_{1}\right]_{\mathrm{x}}+\varphi_{1 \mathrm{yy}}+\varphi_{1 \mathrm{zz}}+\mathrm{q} \varphi_{1}=0
$$

where $\mathrm{u}=\mathrm{K}-(\gamma-1) \varphi_{0 \mathrm{x}}$ and $\mathrm{q}=\omega^{2} / \epsilon-i \omega(\gamma-1) \varphi_{0 \mathrm{xx}}$. Equation (17) is linear and like equation (14) is of mixed type, being elliptic or hyperbolic whenever the solution of equation (14) is elliptic or hyperbolic.

\section{Formulation of the Difference Equations for Numerical Solution of Unsteady Flow From Harmonic Motion of a Thin Wing}

Since $\varphi_{0}$ is a numerical solution of equation (14) whose values are known only at discrete points of a mesh, equation (17) is also to be solved numerically. For this purpose equation (17) is expressed in difference form. For subsonic flow points, we use central differences for derivatives in the $\mathrm{x}, \mathrm{y}, \mathrm{z}$ directions. For hyperbolic or supersonic points we use backward (or upstream differences) in $\mathrm{x}$ but retain central differences in the $\mathrm{y}$ and $\mathrm{z}$ directions. This is the practice followed by Murman and Cole (ref. 2), Krupp (refs. 3 and 4), Steger and Lomax (ref. 5), and Newman and Klunker (ref. 6), since only upstream data can influence a hyperbolic point in regions of local supersonic flow. Thus, for subsonic flow at the point $x_{i}, y_{j}, z_{k}$, we have

$$
\left(\mathrm{u} \varphi_{1 \mathrm{x}}\right)_{\mathrm{x}}=\left\{\mathrm{u}_{\mathrm{i}+1 / 2 . \mathrm{jk}}\left(\varphi_{\mathrm{i}+1 \mathrm{jk}}-\varphi_{\mathrm{ijk}}\right) /\left(\mathrm{x}_{\mathrm{i}+1}-\mathrm{x}_{\mathrm{i}}\right)-\mathrm{u}_{\mathrm{i}-1 / 2 \mathrm{jk}}\left(\varphi_{\mathrm{ijk}}-\varphi_{\mathrm{i}-1 \mathrm{jk}}\right) /\left(\mathrm{x}_{\mathrm{i}}-\mathrm{x}_{\mathrm{i}-1}\right)\right\}\left[2 /\left(\mathrm{x}_{\mathrm{i}+1}-\mathrm{x}_{\mathrm{i}-1}\right)\right]
$$


where

$$
\begin{aligned}
& \mathrm{u}_{\mathrm{i}+1 / 2 \mathrm{jk}}=\mathrm{K}-(\gamma+1)\left(\varphi_{0 \mathrm{i}+1 \mathrm{jk}}-\varphi_{0 \mathrm{ijk}}\right) /\left(\mathrm{x}_{\mathrm{i}+1}-\mathrm{x}_{\mathrm{i}}\right) \\
& \mathrm{u}_{\mathrm{i}-1 / 2 \mathrm{jk}}=\mathrm{K}-(\gamma+1)\left(\varphi_{0 \mathrm{ijk}}-\varphi_{0 \mathrm{i}-1 \mathrm{jk}}\right) /\left(\mathrm{x}_{\mathrm{i}}-\mathrm{x}_{\mathrm{i}-1}\right)
\end{aligned}
$$

and $i \pm 1 / 2$ denotes the value of the quantity at

$$
x=\left(x_{i}+x_{i \pm 1}\right) / 2
$$

the $\mathrm{x}$ midpoint of the mesh.

The $\mathrm{x}$ derivative may be written more simply as

$$
\begin{aligned}
\left(u \varphi_{1 \mathrm{x}}\right)_{\mathrm{x}}= & 2 \mathrm{c}_{\mathrm{i}} \mathrm{u}_{\mathrm{i}+1 / 2 \mathrm{jk}}\left(\varphi_{\mathrm{i}+1 \mathrm{jk}}-\varphi_{\mathrm{ijk}}\right) \\
& -2 \mathrm{~d}_{\mathrm{i}} \mathrm{u}_{\mathrm{i}-1 / 2 \mathrm{j} \mathrm{k}}\left(\varphi_{\mathrm{ijk}}-\varphi_{\mathrm{i}-1 \mathrm{jk}}\right)
\end{aligned}
$$

where

$$
\begin{aligned}
& c_{i}=1 /\left(x_{i+1}-x_{i-1}\right)\left(x_{i+1}-x_{i}\right) \\
& d_{i}=1 /\left(x_{i+1}-x_{i-1}\right)\left(x_{i}-x_{i-1}\right)
\end{aligned}
$$

For the first derivative, we use a second-order difference equation. Writing

$$
\varphi_{1 \mathrm{x}}=\mathrm{c}_{1 \mathrm{i}}\left(\varphi_{\mathrm{i}+1 \mathrm{jk}}-\varphi_{\mathrm{ijk}}\right)+\mathrm{d}_{1 \mathrm{i}}\left(\varphi_{\mathrm{ijk}}-\varphi_{\mathrm{i}-1 \mathrm{jk}}\right)
$$

and expanding the terms about the point $i, j, k$, we find the values of $c_{1 i}$ and $d_{1 i}$ by setting the coefficient of $\varphi_{1 \mathrm{x}}$ equal to 1 and of $\varphi_{1 \mathrm{xx}}$ equal to zero on the right-hand side of equation (20). This leads to

$$
\begin{aligned}
& c_{1 i}=\left(x_{i}-x_{i-1}\right) c_{i} \\
& d_{1 i}=\left(x_{i+1}-x_{i}\right) d_{i}
\end{aligned}
$$


With these definitions, the complete $\mathrm{x}$ derivative term becomes

$$
\begin{aligned}
{\left[\mathrm{u} \varphi_{1 \mathrm{x}}-(2 \mathrm{i} \omega / \epsilon) \varphi_{1}\right]_{\mathrm{x}}=} & -2\left[\mathrm{c}_{\mathrm{i}} \mathrm{u}_{\mathrm{i}+1 / 2 \mathrm{jk}}+\mathrm{d}_{\mathrm{i}} \mathrm{u}_{\mathrm{i}-1 / 2 \mathrm{jk}}\right. \\
& \left.+\mathrm{i}(\omega / \epsilon)\left(\mathrm{d}_{1 \mathrm{i}}-\mathrm{c}_{1 \mathrm{i}}\right)\right] \varphi_{\mathrm{ijk}} \\
& +2\left[\mathrm{c}_{\mathrm{i}} \mathrm{u}_{\mathrm{i}+1 / 2 \mathrm{jk}}-\mathrm{i} \omega \mathrm{c}_{1 \mathrm{i}} / \epsilon\right] \varphi_{\mathrm{i}+1 \mathrm{jk}} \\
& +2\left[\mathrm{~d}_{\mathrm{i}} \mathrm{u}_{\mathrm{i}+1 / 2 \mathrm{jk}}+\mathrm{i} \omega \mathrm{d}_{1 \mathrm{i}} / \epsilon\right] \varphi_{\mathrm{i}-1 \mathrm{jk}}
\end{aligned}
$$

Similarly, we write for the central differences of $\varphi_{1 \mathrm{yy}}$ and $\varphi_{1 \mathrm{zz}}$ terms

$$
\varphi_{1 y y}=\frac{2}{y_{j+1}-y_{j-1}}\left[\frac{\varphi_{i j+1 k}-\varphi_{i j k}}{y_{j+1}-y_{j}}-\frac{\varphi_{i j k}-\varphi_{i j-1 k}}{y_{j}-y_{j-1}}\right]
$$

or

$$
\begin{aligned}
& \varphi_{1 \mathrm{yy}}=2 \mathrm{a}_{\mathrm{yj}} \varphi_{\mathrm{ij}-1 \mathrm{k}}-2\left(\mathrm{a}_{\mathrm{yj}}+\mathrm{b}_{\mathrm{yj}}\right) \varphi_{\mathrm{ijk}}+2 \mathrm{~b}_{\mathrm{yj}} \varphi_{\mathrm{ij}+1 \mathrm{k}} \\
& \varphi_{1 \mathrm{zz}}=2 \mathrm{a}_{\mathrm{zk}} \varphi_{\mathrm{ijk}-1}-2\left(\mathrm{a}_{\mathrm{zk}}+\mathrm{b}_{\mathrm{zk}}\right) \varphi_{\mathrm{ijk}}+2 \mathrm{~b}_{\mathrm{zk}} \varphi_{\mathrm{ijk}}+1
\end{aligned}
$$

where

$$
\begin{aligned}
& a_{y j}=1 /\left(y_{j+1}-y_{j-1}\right)\left(y_{j}-y_{j-1}\right) \\
& b_{y j}=1 /\left(y_{j+1}-y_{j-1}\right)\left(y_{j+1}-y_{j}\right) .
\end{aligned}
$$

The formulas for $\mathrm{a}_{\mathrm{zk}}$ and $\mathrm{b}_{\mathrm{zk}}$ are similar to equation (23) with $\mathrm{z}$ and $\mathrm{k}$ replacing $\mathrm{y}$ and $\mathrm{j}$, respectively. Substituting equations (20), (21), and (22) into the differential equation for $\varphi_{1}$ yields

$$
\begin{aligned}
& -2\left(E_{1}+E_{2}\right) \varphi_{i j k}+2 E_{1} \varphi_{i+1 j k}+2 E_{2} \varphi_{i-1 j k}+q_{i j k} \varphi_{i j k} \\
& +2 a_{y j} \varphi_{i j-1 k}-2\left(a_{y j}+b_{y j}\right) \varphi_{i j k}+2 b_{y j} \varphi_{i j+1 k} \\
& +2 a_{z k} \varphi_{i j k-1}-2\left(a_{z k}+b_{z k}\right) \varphi_{i j k}+2 b_{z k} \varphi_{i j k+1}=0,
\end{aligned}
$$

where

$$
E_{1}=c_{i} u_{i+1 / 2 j k}-i \omega c_{1 i} / \epsilon, \quad E_{2}=d_{i} u_{i+1 / 2 j k}+i \omega d_{1 i} / \epsilon
$$


In solving the equations, we relax a column at a time. At each planar point $x_{i}, y_{i}$, we solve for $\varphi_{\mathrm{ijk}}, \mathrm{k}=2$ to $\mathrm{k}_{\max }-1$. Therefore, we place all other terms on the right-hand side and obtain for the elliptic point form of the difference equation:

$$
\begin{aligned}
& a_{z k} \varphi_{i j k-1}-\left(a_{y j}+b_{y j}+a_{z k}+b_{z k}+E_{1}+E_{2}-q_{i j k} / 2\right) \varphi_{i j k} \\
& +b_{z k} \varphi_{i j k+1}=-E_{1} \varphi_{i+1 j k}-E_{2} \varphi_{i-1 j k}-a_{y j} \varphi_{i j-1 k}-b_{y j} \varphi_{i j+1 k}
\end{aligned}
$$

For fixed $\mathrm{i}, \mathrm{j}$, and for $\mathrm{k}$ ranging from 2 to $\mathrm{k}_{\max }-1$, this is a set of $\mathrm{k}_{\max }-2$ equations to be solved for an equal number of $\varphi_{\mathrm{ijk}}$ provided that $\varphi_{\mathrm{ij} 1}$ and $\varphi_{\mathrm{ijk}} \mathrm{max}_{\text {max }}$ are prescribed by the far-field boundary conditions. This yields a system of equations with a tridiagonal matrix for the coefficients which is simple to solve.

When the point is hyperbolic, backwards differencing in $\mathrm{x}$ is used. This may be achieved by shifting all the $\mathrm{i}$ indices one less for the term $\left(\mathrm{u} \varphi_{1 \mathrm{x}}\right)_{\mathrm{x}}$. For $\varphi_{1 \mathrm{x}}$ we derive a three-point backwards difference formula which is second-order accurate in the mesh spacing. For the point $i, j, k$, we write

$$
\varphi_{1 \mathrm{x}}=\mathrm{c}_{2 \mathrm{i}}\left(\varphi_{\mathrm{ijk}}-\varphi_{\mathrm{i}-1 \mathrm{jk}}\right)+\mathrm{d}_{2 \mathrm{i}}\left(\varphi_{\mathrm{i}-1 \mathrm{jk}}-\varphi_{\mathrm{i}-2 \mathrm{jk}}\right)
$$

We then determine $\mathrm{c}_{2 \mathrm{i}}$ and $\mathrm{d}_{2 \mathrm{i}}$ so that, when $\varphi_{\mathrm{i}-1 \mathrm{jk}}$ and $\varphi_{\mathrm{i}+1 \mathrm{jk}}$ are expanded in a Taylor's series in $\mathrm{x}$ about $\varphi_{\mathrm{ijk}}$, the coefficient of $\varphi_{1 \mathrm{x}}$ on the right-hand side equals unity and the coefficient of $\varphi_{1 \mathrm{xx}}$ vanishes. This leads to

$$
\begin{aligned}
& c_{2 i}=1 /\left(x_{i}-x_{i-1}\right)+1 /\left(x_{i}-x_{i-2}\right) \\
& d_{2 i}=-d_{1 i-1} .
\end{aligned}
$$

The $\mathrm{x}$ derivative terms for hyperbolic points then take the form

$$
\begin{aligned}
{\left[\mathrm{u} \varphi_{1 \mathrm{x}}-(2 \mathrm{i} \omega / \epsilon) \varphi_{1}\right]_{\mathrm{X}}=} & 2 \mathrm{c}_{\mathrm{i}-1} \mathrm{u}_{\mathrm{i}-1 / 2 \mathrm{jk}}\left(\varphi_{\mathrm{ijk}}-\varphi_{\mathrm{i}-1 \mathrm{jk}}\right) \\
& -2 \mathrm{~d}_{\mathrm{i}-1} \mathrm{u}_{\mathrm{i}-3 / 2 \mathrm{jk}}\left(\varphi_{\mathrm{i}-1 \mathrm{jk}}-\varphi_{\mathrm{i}-2 \mathrm{jk}}\right) \\
& -(2 \mathrm{i} \omega / \epsilon)\left[\mathrm{c}_{2 \mathrm{i}}\left(\varphi_{\mathrm{ijk}}-\varphi_{\mathrm{i}-1 \mathrm{jk}}\right)-\mathrm{d}_{1 \mathrm{i}-1}\left(\varphi_{\mathrm{i}-1 \mathrm{jk}}-\varphi_{\mathrm{i}-2 \mathrm{jk}}\right)\right]
\end{aligned}
$$


The complete difference equation equivalent to equation (17) in tridiagonal form for hyperbolic points becomes

$$
\begin{aligned}
& a_{z k} \varphi_{i j k-1}-\left(a_{y j}+b_{y j}+a_{z k}+b_{z k}-E_{3}+q_{i j k} / 2\right) \varphi_{i j k}+b_{z k+1} \varphi_{i j k+1} \\
& =\left(E_{3}+E_{4}\right) \varphi_{i-1 j k}-E_{4} \varphi_{i-2 j k} / j k \\
& -a_{y j} \varphi_{i j-1 k}-b_{y j} \varphi_{i j}+1 k
\end{aligned}
$$

where

$$
\begin{aligned}
& E_{3}=c_{i-1} u_{i-1 / 2 j k}-i \omega c_{2 i} / \epsilon \\
& E_{4}=d_{i-1} u_{i-3 / 2 j k}-i \omega d_{1 i-1} / \epsilon
\end{aligned}
$$

Equations (24) and (27) are the difference equations for interior points in the flow field. Since boundary conditions on the wing and on the vortex sheet are expressed in terms of the derivative of $\varphi_{1}$ with respect to $\mathrm{z}$, it is convenient to locate the linearized boundary of the wing and wake on the plane between $\mathrm{k}=\mathrm{k}_{\mathrm{m}}$ and $\mathrm{k}=\mathrm{k}_{\mathrm{m}}+1$. For these values of $\mathrm{k}$, equations (24) and (27) must be modified to incorporate these boundary conditions, and the appropriate relations are developed in subsequent sections.

\section{Boundary Conditions on the Wing}

For harmonic motion, the linearized boundary condition following equation (12) becomes

$$
\varphi_{1 z}=f_{1 x}(x, y)+i \omega f_{1}(x, y)
$$

where we have substituted

$$
\mathrm{z}_{0} / \delta=\mathrm{f}(\mathrm{x}, \mathrm{y}, \mathrm{t})=\mathrm{f}_{0}(\mathrm{x}, \mathrm{y})+\mathrm{f}_{1}(\mathrm{x}, \mathrm{y}) \mathrm{e}^{\mathrm{i} \omega \mathrm{t}}
$$

for the shape of the wing surface with harmonic oscillations. The steady flow perturbation potential satisfies the boundary condition $\varphi_{0 \mathrm{z}}=\mathrm{f}_{0 \mathrm{x}}$ where $\mathrm{z}_{0}=\delta \mathrm{f}_{0}(\mathrm{x}, \mathrm{y})$ defines the undisturbed wing shape. The boundary conditions are satisfied on the plane between the $\mathrm{z}$ mesh positions $\mathrm{k}_{\mathrm{m}}$ and $\mathrm{k}_{\mathrm{m}}+1$ or $\mathrm{z}=\left(\mathrm{zk}_{\mathrm{m}}+\mathrm{z}_{\mathrm{m}}+1\right) / 2$. For convenience, we choose this plane as

$$
\mathrm{z}=\mathrm{z}_{\mathrm{m}+1 / 2}=0
$$


The boundary conditions in equation (28) modify the $\varphi_{1 z z}$ derivative in the difference equation. At the point $i, j, k_{m}$, we have

$$
\varphi_{1 \mathrm{zz}}=\frac{2}{\mathrm{z}_{\mathrm{k}_{\mathrm{m}}+1}-\mathrm{z}_{\mathrm{k}_{\mathrm{m}}-1}}\left[\varphi_{1 \mathrm{z}} \mid \underset{\substack{\mathrm{z}=\mathrm{z}_{\mathrm{k}_{\mathrm{m}}+1 / 2} \\-}}{-\frac{\varphi_{\mathrm{ijk}}-\varphi_{\mathrm{ijk}}-1}{\mathrm{z}_{\mathrm{k}_{\mathrm{m}}}-\mathrm{z}_{\mathrm{k}_{\mathrm{m}}}-1}}\right]
$$

Applying the boundary conditions, equation (28), leads to

$$
\varphi_{1 \mathrm{zz}}=2 \mathrm{~h}_{1} \mathrm{~b}_{\mathrm{zk}_{\mathrm{m}}} \mathrm{F}_{\mathrm{ij}}{ }^{(\mathrm{L})}-2 \mathrm{a}_{\mathrm{zk}} \mathrm{m}\left(\varphi_{\mathrm{ijk}}-\varphi_{\mathrm{ijk}} \mathrm{k}^{-1}\right)
$$

where

$$
F_{i j}(L)=F^{(L)}\left(x_{i}, y_{j}\right)=f_{1 x}^{(L)}\left(x_{i}, y_{j}\right)+i \omega f_{1}{ }^{(L)}\left(x_{i}, y_{j}\right)
$$

and

$$
\mathrm{h}_{1}=\mathrm{z}_{\mathrm{k}_{\mathrm{m}}+1}-\mathrm{z}_{\mathrm{m}}
$$

Similarly, for the value of $\varphi_{1 \mathrm{zz}}$ at $\mathrm{z}=\mathrm{z}_{\mathrm{k}_{\mathrm{m}}}+1$, we have

$$
\begin{gathered}
\varphi_{1 \mathrm{zz}}=\frac{2}{\left(\mathrm{z}_{\mathrm{m}}+2-\mathrm{z}_{\mathrm{m}}\right)}\left[\frac{\varphi_{\mathrm{ijk}}+2-\varphi_{\mathrm{ijk}}+1}{\mathrm{z}_{\mathrm{k}_{\mathrm{m}}}+2-\mathrm{z}_{\mathrm{m}}+1}-\varphi_{1 \mathrm{z}} \mid\right] \\
\mathrm{z}=\mathrm{z}_{\mathrm{k}_{\mathrm{m}}+1 / 2} \\
\varphi_{1 \mathrm{zz}}=2 \mathrm{~b}_{\mathrm{zk}}+1\left(\varphi_{\mathrm{iik}}+2-\varphi_{\mathrm{ijk}}+1\right)-2 \mathrm{~h}_{1} \mathrm{a}_{\mathrm{zk}}+1 \mathrm{~F}_{\mathrm{ij}}(\mathrm{U})
\end{gathered}
$$

The superscripts $\mathrm{L}$ and $\mathrm{U}$ denote upper and lower surface values, respectively.

For $\mathrm{k}=\mathrm{k}_{\mathrm{m}}$, the difference equation corresponding to equation (24) is

$$
\begin{aligned}
& a_{z k_{m}} \varphi_{i j k_{m}-1}-\left(a_{y j}+b_{y j}+a_{z k_{m}}+E_{1}+E_{2}-q_{i j k_{m}} / 2\right) \varphi_{i j k_{m}} \\
& =-E_{1} \varphi_{i+1 j k_{m}}-E_{2} \varphi_{i-1 j k_{m}}-a_{y j} \varphi_{i j-1 k_{m}}-b_{y j} \varphi_{i j+1 k_{m}}-h_{1} b_{z k_{m}} F_{i j}(L)
\end{aligned}
$$


where

$$
\begin{aligned}
& E_{1}=c_{i} u_{i+1 / 2 j k_{m}}-i \omega c_{1 i} / \epsilon \\
& E_{2}=d_{i} u_{i-1 / 2 j k_{m}}+i \omega d_{1 i} / \epsilon
\end{aligned}
$$

Similarly, for $\mathrm{k}=\mathrm{k}_{\mathrm{m}}+1$, we have

$$
\begin{gathered}
-\left(a_{y j}+b_{y j}+b_{z k_{m}+1}+E_{1}+E_{2}-q_{i j k_{m}+1} / 2\right) \varphi_{i j k_{m}+1}+b_{z k_{m}+1} \varphi_{i j k_{m}}+2 \\
=-E_{1} \varphi_{i+1 j k_{m}+1}-E_{2} \varphi_{i-1 j k_{m}+1}-a_{y j} \varphi_{i j-1 k_{m}+1}-b_{y j} \varphi_{i j+1 k_{m}}+1+h_{1} a_{z_{k}}+1 F_{i j}(U)
\end{gathered}
$$

where

$$
\begin{aligned}
& E_{1}=c_{i} u_{i+1 / 2 j k_{m}+1}-i \omega c_{1 i} / \epsilon \\
& E_{2}=d_{i} u_{i-1 / 2 j k_{m}}+1+i \omega d_{1 i} / \epsilon
\end{aligned}
$$

Analogous equations are easily written down for hyperbolic points by comparing equations (24) and (27) and revising (32) and (33) accordingly.

\section{Boundary Conditions on the Wake}

The pressure and normal velocity component must be continuous across the vortex sheet shed from the wing trailing edge. At $z=\left(\mathrm{z}_{\mathrm{m}}+\mathrm{z}_{\mathrm{m}}+1\right) / 2$, these conditions become

$$
\varphi_{1 \mathrm{x}}^{+}+\mathrm{i} \omega \varphi_{1}^{+}=\varphi_{1 \mathrm{x}}^{-}+\mathrm{i} \omega \varphi_{1}^{-}
$$

for pressure continuity, and

$$
\varphi_{1 \mathrm{z}}^{+}=\varphi_{1 \mathrm{z}}^{-}
$$


for normal flow continuity. The superscripts + and - designate limits as the sheet is approached from above and below, respectively. Equation (34) may be written

$$
(\mathrm{d} / \mathrm{dx})\left(\Delta \varphi_{1}\right)+i \omega \Delta \varphi_{1}=0
$$

where $\Delta \varphi_{1}=\varphi_{1}^{+}-\varphi_{1}^{-}$. Along each line $\mathrm{y}=$ constant representing the linearized streamline from the wing trailing edge, equation (35) may be integrated to give

$$
\Delta \varphi_{\mathrm{ij}}=\Delta \varphi_{\mathrm{i}_{1}}+1 \mathrm{j} \mathrm{e}^{-\mathrm{i} \omega\left(\mathrm{x}_{\mathrm{i}}-\mathrm{x}_{\mathrm{i}_{1}}+1\right)}
$$

where $\Delta \varphi_{\mathrm{i} 1}+1 \mathrm{j}$ is the jump in the potential at the station $\mathrm{y}_{\mathrm{j}}$ for the first mesh point $\mathrm{x}$ location beyond the trailing edge on the plane $z=0$. This value is determined to satisfy the Kutta condition, which requires that the pressure on both sides of the trailing edge be equal. Let $i_{1}$ be the index for the value of $x$ on the trailing edge. Then the condition that the pressure jump vanish at the trailing edge at the station $y_{j}$ becomes

$$
c_{1 i_{1}}\left(\Delta \varphi_{i_{1}+i j}-\Delta \varphi_{i_{1} j}\right)+d_{1 i_{1}}\left(\Delta \varphi_{i_{1} j}-\Delta \varphi_{i_{1}-1 j}\right)+i \omega \Delta \varphi_{i_{1} j}=0
$$

Solving for $\Delta \varphi_{\mathrm{i}_{1}}+1 \mathrm{j}$ yields

$$
\Delta \varphi_{\mathrm{i}_{1}+1 \mathrm{j}}=\Delta \varphi_{\mathrm{i}_{1} \mathrm{j}}\left[1-\left(\mathrm{d}_{1 \mathrm{i}_{1}}+\mathrm{i} \omega\right) / \mathrm{c}_{1 \mathrm{i}}\right]+\left(\mathrm{d}_{1 \mathrm{i}_{1}} / \mathrm{c}_{1 \mathrm{i}_{1}}\right) \Delta \varphi_{\mathrm{i}_{1}-1 \mathrm{j}}
$$

To satisfy continuity of $\dot{\varphi}_{1 \mathrm{z}}$ across the vortex sheet, although $\varphi_{1}$ may be discontinuous, we write for $\varphi_{1 \mathrm{z}}$ at $\mathrm{z}=\mathrm{z}_{\mathrm{m}}+1 / 2=0$,

$$
\varphi_{1 \mathrm{z}}=\left(\varphi_{\mathrm{ijk}}+1-\Delta \varphi_{\mathrm{ij}}-\varphi_{\mathrm{ijk}}\right) /\left(\mathrm{z}_{\mathrm{m}} \mathrm{k}_{\mathrm{m}}+1-\mathrm{z}_{\mathrm{k}_{\mathrm{m}}}\right)
$$

Hence, for $\mathrm{k}=\mathrm{k}_{\mathrm{m}}+1$, the derivative $\varphi_{1 \mathrm{zz}}$ becomes

$$
\begin{aligned}
\varphi_{1 \mathrm{zz}}= & 2 \mathrm{a}_{\mathrm{zk}_{\mathrm{m}}+1} \varphi_{\mathrm{ij} \mathrm{k}_{\mathrm{m}}}-2\left(\mathrm{a}_{\mathrm{zk}_{\mathrm{m}}+1}+\mathrm{b}_{\mathrm{zk}_{\mathrm{m}}+1}\right) \varphi_{\mathrm{ijk}}+1 \\
& +2 \mathrm{~b}_{\mathrm{zk}_{\mathrm{m}}+1} \varphi_{\mathrm{ijk}}+2+2 \mathrm{a}_{\mathrm{zk}}+1 \Delta \varphi_{\mathrm{ij}}
\end{aligned}
$$


Similarly, for $\mathrm{k}=\mathrm{k}_{\mathrm{m}}$, we have

$$
\varphi_{1 \mathrm{zz}}=2 \mathrm{a}_{\mathrm{zk}_{\mathrm{m}}} \varphi_{\mathrm{ijk}}-1-2\left(\mathrm{a}_{\mathrm{zk}}+\mathrm{b}_{\mathrm{zk}_{\mathrm{m}}}\right) \varphi_{\mathrm{ijk}}+2 \mathrm{~b}_{\mathrm{zk}_{\mathrm{m}}} \varphi_{\mathrm{ijk}}+1-2 \mathrm{~b}_{\mathrm{zk}} \Delta \varphi_{\mathrm{ij}}
$$

By comparing equations (39) and (40) with equation (22) we see that, in the difference equations (24) and (27) for $\mathrm{k}=\mathrm{k}_{\mathrm{m}}$, the right-hand side has the additional term

$$
\mathrm{b}_{\mathrm{zk}_{\mathrm{m}}} \Delta \varphi_{\mathrm{ij}}
$$

while in the difference equation for $\mathrm{k}=\mathrm{k}_{\mathrm{m}}+1$, the right-hand side has the additional term

$$
-\mathrm{a}_{\mathrm{zk}}+1 \Delta \varphi_{\mathrm{ij}}
$$

By employing this form of the difference equations, we implicitly apply the condition of continuity of $\varphi_{1 \mathrm{z}}$ at the plane $\mathrm{z}=0$.

\section{Trnasformation of the Differential Equation for Swept Wings}

Since a finer mesh is desirable in the vicinity of the leading edge, it is convenient to transform the coordinates so that the swept wing is rectangular with the leading edge as one of the coordinate axes. Let the leading edge be defined by $\mathrm{x}=\mathrm{y} \sin \alpha$ or $\mathrm{y}=\mathrm{x} / \sin \alpha$. Then we introduce coordinates

$$
\begin{aligned}
& \xi=x-y \sin \alpha \\
& \eta=y \\
& \xi=z
\end{aligned}
$$

The derivatives with respect to $\mathrm{x}$ and $\mathrm{y}$ in terms of the new variables then become

$$
\begin{aligned}
& \varphi_{1 \mathrm{x}}=\varphi_{1 \xi} \\
& \varphi_{1 \mathrm{y}}=\varphi_{1 \eta}-\sin \alpha \varphi_{1 \xi}=\varphi_{1 \eta}-\lambda \varphi_{1 \xi}
\end{aligned}
$$


and

$$
\begin{aligned}
& \varphi_{1 \mathrm{zz}}=\varphi_{1 \zeta \xi} \\
& \varphi_{1 \mathrm{yy}}=\varphi_{1 \eta \eta}-2 \lambda \varphi_{1 \xi \eta}+\lambda^{2} \varphi_{1 \xi \xi}
\end{aligned}
$$

where

$$
\lambda=\sin \alpha
$$

Substitution into equation (17) then yields

$$
\left[\mathrm{v} \varphi_{1 \xi}-2 \lambda \varphi_{1 \eta}-(2 \mathrm{i} \omega / \epsilon) \varphi_{1}\right]_{\xi}+\varphi_{1 \eta \eta}+\varphi_{1 \zeta \zeta}+\mathrm{q} \varphi_{1}=0
$$

where

$$
v=u+\sin ^{2} \alpha=u+\lambda^{2}
$$

We consider the second-order operator of equation (44) and apply Hormander's theory (ref. 16) to find under what conditions it is hyperbolic and to define the cone of influence of a point disturbance in $\xi, \eta, \xi$ space. The operator is

$$
P(D)=v_{1}^{2}-2 \lambda D_{1} D_{2}+D_{2}^{2}+D_{3}^{2}
$$

where $D_{n}=i \partial / \partial x_{n}$ with $x_{1}=\xi, x_{2}=\eta, x_{3}=\zeta$. According to Hormander's definition (ref. 16), the operator is hyperbolic in the $\xi$ direction if

$$
P(1,0,0)=v=u+\lambda^{2} \neq 0
$$

and if

$$
\mathrm{P}\left(\mathrm{D}+\tau \overline{\mathrm{e}}_{1}\right)
$$

has only negative roots for $D$ real. Here $e_{1}$ is a unit vector in the $\xi$ direction. The roots of $\mathrm{P}\left(\mathrm{D}+\tau \mathrm{e}_{1}\right)$ are found from

$$
\mathrm{v}\left(\mathrm{D}_{1}+\tau\right)^{2-}-2 \lambda_{1}\left(\mathrm{D}_{\cdot 1}+\tau\right) \mathrm{D}_{2}+\mathrm{D}_{2}^{2}+\mathrm{D}_{3}^{2}=0
$$


Solving for $\tau$ yields

$$
\tau=-\mathrm{D}_{1}+\left(\lambda \mathrm{D}_{2} \pm \sqrt{\left.-\mathrm{uD}_{2}^{2}-\mathrm{vD}_{3}^{2}\right) / \mathrm{v}}<0\right.
$$

Since $\tau$ must be real for $\mathrm{D}$ real we see that $\mathrm{u}$ and $\mathrm{v}$ must be negative or $\mathrm{u}<-\lambda^{2}$. The condition $\tau<0$ becomes

$$
\mathrm{D}_{1}^{2} \mathrm{v}-2 \lambda \mathrm{D}_{1} \mathrm{D}_{2}+\mathrm{D}_{2}^{2}+\mathrm{D}_{3}^{2} \geqslant 0
$$

The cone of support of the solution in physical space must also satisfy

$$
\xi \mathrm{D}_{1}+\eta \mathrm{D}_{2}+\xi \mathrm{D}_{3} \geqslant 0
$$

for $D_{1}, D_{2}$, and $D_{3}$ satisfying equation (45). Both regions are convex. The boundary of the region is defined by the equality of the preceding two equations. Eliminating $\mathrm{D}_{3}$ from equation (45) by means of the preceding equation yields

$$
F\left(\beta_{1}\right)=\beta_{1}^{2}\left(\xi^{2} v+\xi^{2}\right)-2 \beta_{1}\left(\lambda \xi^{2}-\eta \xi\right)+\left(\eta^{2}+\zeta^{2}\right)=0
$$

with $\beta_{1}=D_{1} / D_{2}$.

We now find the envelope in the physical space by finding the value of $\beta_{1}$ for which

$$
F\left(\beta_{1}\right)=F^{\prime}\left(\beta_{1}\right)=0
$$

The equation for the envelope is found to be

$$
\zeta^{2}\left[u\left(\zeta^{2}+\eta^{2}\right)+(\eta \lambda-\xi)^{2}\right]=0
$$

Let $\xi^{2}+\xi^{2}=\mathrm{r}^{2}$ and $\eta=\mathrm{r} \cos \theta$, then we have, after solving for $\mathrm{r}$,

$$
\mathrm{r} / \xi=(\lambda \cos \theta \pm \sqrt{-\mathrm{u}}) /\left(\mathrm{u}+\lambda^{2} \cos ^{2} \theta\right)
$$

or

$$
\mathrm{r} \sqrt{-\mathrm{u}} / \xi=\left(\nu_{1} \cos \theta \pm 1\right) /\left(\nu_{1}^{2} \cos ^{2} \theta-1\right)
$$

where

$$
v_{1}=\lambda / \sqrt{-\mathrm{u}}<1
$$


Taking the minus sign gives us

$$
\mathrm{r} \sqrt{-\mathrm{u}} / \xi=1 /\left(1-\nu_{1} \cos \theta\right)
$$

This describes the cone of influence of the point $0,0,0$ downstream of the point. Taking the plus sign yields

$$
\mathrm{r} \sqrt{-\mathrm{u}} / \xi=1 /\left(1+\nu_{1} \cos \theta\right)
$$

This equation represents the boundary of the upstream region of influence on the point $\zeta, \eta, \xi=0,0,0$.

For the rectangular wing, $\lambda$ (or $\nu_{1}$ ) goes to zero and the equations reduce to the usual circular Mach cones for the regions of influence. For $-u<\lambda$, the cone cross sections for $\zeta=$ constant are ellipses, while for the limiting case $\nu_{1}=1$, or $\lambda=-\mathrm{u}$, they are parabolas and, of course, are not closed. The cross sections in the $\eta=0$ and $\zeta=0$ planes are bounded by two intersecting straight lines.

Since for $u<-\lambda^{2}$ or $\varphi_{0 x} \geqslant\left(K+\sin ^{2} \alpha\right) /(\gamma+1)$, the transformed differential equation is hyperbolic, we employ backward differences in the $\xi$ variable. Central differences are used when

$$
\varphi_{0 \mathrm{x}} \leqslant\left(\mathrm{K}+\sin ^{2} \alpha\right) /(\gamma+1)
$$

\section{Difference Form of the Differential Equation for the Swept Wing}

We first establish a second-order difference for $\varphi_{1 \eta}$. By comparison with the second-order difference for $\varphi_{1 \mathrm{x}}$, we write

$$
\varphi_{1 \mathrm{n}}=\mathrm{c}_{1 \mathrm{j}}\left(\varphi_{\mathrm{ij}+1 \mathrm{k}}-\varphi_{\mathrm{ijk}}\right)+\mathrm{d}_{\mathrm{ij}}\left(\varphi_{\mathrm{ijk}}-\varphi_{\mathrm{ij}-1 \mathrm{k}}\right)
$$

where $c_{i j}$ and $d_{i j}$ are given by the equations following equation (19) with $\eta$ replacing $x$ and $j$ replacing $i$.

Applying a second-order central difference operator for $\xi$ to equation (47) yields

$$
\begin{aligned}
\varphi_{1 \xi \eta}= & c_{1 j}\left[c_{1 i}\left(\varphi_{i+1 j}+1 k-\varphi_{i j+1 k}\right)+d_{1 i}\left(\varphi_{i j}+1 k-\varphi_{i-1 j+1 k}\right)\right] \\
& +\left(d_{1 j}-c_{1 j}\right)\left[c_{1 i}\left(\varphi_{i+1 j k}-\varphi_{i j k}\right)+d_{1 i}\left(\varphi_{i j k}-\varphi_{i-1 j k}\right)\right] \\
& -d_{1 j}\left[c_{1 i}\left(\varphi_{i+1 j-1 k}-\varphi_{i j-1 k}\right)+d_{1 i}\left(\varphi_{i j-1 k}-\varphi_{i-1 j-1 k}\right)\right]
\end{aligned}
$$


Then

$$
\begin{aligned}
-2 \lambda \varphi_{1 \xi \eta}-2(i \omega / \epsilon) \varphi_{1 \xi}= & -2 \lambda c_{1 j}\left[c_{1 i}\left(\varphi_{i+1 j+1 k}-\varphi_{i j+1 k}\right)\right. \\
& \left.+d_{1 i}\left(\varphi_{i j+1 k}-\varphi_{i-1 j}+1 k\right)\right] \\
& -2\left[i \omega / \epsilon+\lambda\left(d_{1 j}-c_{1 j}\right)\right]\left[c_{1 i}\left(\varphi_{i+1 j k}-\varphi_{i j k}\right)+d_{1 i}\left(\varphi_{i j k}-\varphi_{i-1 j k}\right)\right] \\
& +2 \lambda d_{1 j}\left[c_{1 i}\left(\varphi_{i+1 j-1 k}-\varphi_{i j-1 k}\right)+d_{1 i}\left(\varphi_{i j-1 k}-\varphi_{i-1 j-1 k}\right)\right]
\end{aligned}
$$

For the other derivatives we have

$$
\begin{gathered}
{\left[\varphi_{1 \xi}\right]_{\xi}=2 \mathrm{c}_{\mathrm{i}} \mathrm{v}_{\mathrm{j}+\mathrm{y}_{2} \mathrm{jk}}\left(\varphi_{\mathrm{i}+1 \mathrm{jk}}-\varphi_{\mathrm{ijk}}\right)-2 \mathrm{~d}_{\mathrm{i}} \mathrm{v}_{\mathrm{i}-1 / 2} \mathrm{jk}\left(\varphi_{\mathrm{ijk}}-\varphi_{\mathrm{i}-1 \mathrm{jk}}\right)} \\
\varphi_{1 \eta \eta}=2 \mathrm{~b}_{\eta \mathrm{j}}\left(\varphi_{\mathrm{ij}+1 \mathrm{k}}-\varphi_{\mathrm{ijk}}\right)-2 \mathrm{a}_{\eta \mathrm{j}}\left(\varphi_{\mathrm{ijk}}-\varphi_{\mathrm{ij}-1 \mathrm{k}}\right) \\
\varphi_{1 \zeta \zeta}=2 \mathrm{~b}_{\zeta \mathrm{k}}\left(\varphi_{\mathrm{ijk}+1}-\varphi_{\mathrm{ijk}}\right)-2 \mathrm{a}_{\zeta \mathrm{k}}\left(\varphi_{\mathrm{ijk}}-\varphi_{\mathrm{ijk}-1}\right)
\end{gathered}
$$

where $\mathrm{a}_{\eta \mathrm{j}}, \mathrm{b}_{\eta \mathrm{j}}, \mathrm{a}_{\zeta \mathrm{k}}$, and $\mathrm{b}_{\zeta \mathrm{k}}$ are defined by equation (23) with appropriate variables and subscripts. Substituting equations (49) through (52) into differential equation (44) and collecting terms yields

$$
\begin{aligned}
& { }^{a} \zeta_{k} \varphi_{i j k-1}-\left(a_{\eta j}+b_{\eta j}+a_{\zeta k}+b_{\zeta k}+E_{2}+E_{3}-q_{i j k} / 2\right) \varphi_{i j k} \\
& +\mathrm{b}_{\zeta k} \varphi_{i j k+1}=-E_{4} \varphi_{i j+1 k}-E_{5} \varphi_{i j-1 k}-E_{2} \varphi_{i+1 j k} \\
& -E_{3} \varphi_{i-1 j k}+\lambda c_{1 j}\left[c_{1 i} \varphi_{i+1 j+1 k}-d_{1 i} \varphi_{i-1 j+1 k}\right] \\
& -\lambda d_{1 j}\left[c_{1 i} \varphi_{i+1 j-1 k}-d_{1 i} \varphi_{i-1 j-1 k}\right]
\end{aligned}
$$

where

$$
\begin{aligned}
& E_{1}=i \omega / \epsilon+\lambda\left(d_{1 j}-c_{1 j}\right) \\
& E_{2}=c_{i} v_{i+1 / 2 j k}-E_{1} c_{1 i} \\
& E_{3}=d_{i} v_{i-1 / 2 j k}+E_{1} d_{1 i} \\
& E_{4}=\lambda c_{1 j}\left(c_{1 i}-d_{1 j}\right)+b_{\eta j} \\
& E_{5}=-\lambda d_{1 j}\left(c_{1 i}-d_{11}\right)+a_{\eta j}
\end{aligned}
$$


Equation (53) is the difference equation in swept wing coordinates equivalent to equation (24) for elliptic points.

For hyperbolic points, we have $\mathrm{v}<0$ or $\mathrm{u}<-\lambda^{2}$. For the $\xi$ derivatives we use backward differencing. Thus

$$
\begin{aligned}
{ }^{\left[{ }^{v} \varphi_{1 \xi}\right]_{\xi}}= & 2 c_{i-1} v_{i-1 / 2 j k}\left(\varphi_{i j k}-\varphi_{i-1 j k}\right) \\
& -2 d_{i-1} v_{i-3 / 2 j k}\left(\varphi_{i-1 j k}-\varphi_{i-2 j k}\right)
\end{aligned}
$$

and

$$
\begin{aligned}
-2 \lambda \varphi_{1 \xi \eta}-2 i \omega \varphi_{1 \xi} / \epsilon= & -2 \lambda c_{j}\left[c_{2 i}\left(\varphi_{i j}+1 k-\varphi_{j-1 j+1 k}\right)-d_{1 i-1}\left(\varphi_{i-1 j+1 k}\right.\right. \\
& \left.\left.-\varphi_{i-2 j+1 k}\right)\right]-2 E_{1}\left[c_{2 i}\left(\varphi_{i j k}-\varphi_{i-1 j k}\right)-d_{1 i-1}\left(\varphi_{j-1 j k}-\varphi_{j-2 j k}\right)\right] \\
& +2 \lambda d_{j}\left[c_{2 i}\left(\varphi_{i j-1 k}-\varphi_{i-1 j-1 k}\right)-d_{1 i-1}\left(\varphi_{i-1 j-1 k}-\varphi_{i-2 j-1 k}\right)\right]
\end{aligned}
$$

where $c_{2}$ is defined by equation (26) with $\xi$ replacing $x$. Substituting equations $(51),(52),(55)$, and (56) into the differential equation (44) yields

$$
\begin{aligned}
{ }_{\zeta k} \varphi_{i j k-1}-\left(a_{\eta j}\right. & \left.+b_{\eta j}+a_{\zeta k}+b_{\zeta k}+E_{6}+q_{i j k} / 2\right) \varphi_{i j k} \\
+b_{\zeta k} \varphi_{i j k+1}= & E_{8} \varphi_{i j+1 k}-E_{9} \varphi_{i j-1 k}+\left(E_{7}-E_{6}\right) \varphi_{i-1 j k} \\
& -E_{10} \varphi_{i-1 j+1 k}+E_{11} \varphi_{i-1 j-1 k}+E_{7} \varphi_{i-2 j k} \\
& +\lambda c_{1 j} d_{1 i-1} \varphi_{i-2 j+1 k}-\lambda d_{1 j} d_{1 i-1} \varphi_{i-2 j-1 k}
\end{aligned}
$$

where

$$
\begin{aligned}
& E_{6}=c_{2 i} E_{1}-c_{i-1} v_{i-1 / 2 j k} \\
& E_{7}=d_{1 i-1} E_{1}-d_{i-1} v_{i-3 / 2 j k} \\
& E_{8}=\lambda c_{1 j} c_{2 i}-b_{\eta j} \\
& E_{9}=\lambda d_{1 j} c_{2 i}+a_{\eta j} \\
& E_{10}=\lambda c_{1 j}\left(c_{2 i}+d_{1 i-1}\right) \\
& E_{11}=\lambda d_{1 j}\left(c_{2 i}+d_{1 i-1}\right)
\end{aligned}
$$


and $E_{1}$ is defined in equation (54). This is the difference equation for hyperbolic points in swept wing coordinates equivalent to equation (27).

\section{Root Chord Boundary Conditions for the Swept Wing}

To limit the field to one-half the span for $\eta \geqslant 0$, we require the symmetry condition

$$
\varphi_{1 \mathrm{y}}=0 \quad \text { at } \quad \mathrm{y}=0
$$

or in swept wing coordinates

$$
\varphi_{1 \eta}+\lambda \varphi_{1 \xi}=0
$$

Since this is true along $\eta=0$ for all $\xi$, then we also have

$$
\varphi_{1 \eta \xi}+\lambda \varphi_{1 \xi \xi}=0
$$

This relation conveniently enables us to eliminate the cross-derivative term $\varphi_{1} \eta \xi$. Thus, on the line of symmetry, the terms in the differential equation (44) involving the $\xi$ derivatives becomes

$$
\left[\mathrm{v} \varphi_{1} \xi^{-2 \lambda \varphi_{1}}-(2 \mathrm{i} \omega / \epsilon) \varphi_{1}\right]_{\xi}=\left[\left(\mathrm{v}+2 \lambda^{2}\right) \varphi_{1} \xi^{\left.-(2 \mathrm{i} \omega / \epsilon) \varphi_{1}\right]_{\xi}}\right.
$$

Let $\eta=0$ lie on the $j=1$ horizontal mesh line. Then for points $j=0,1$, and 2 , the difference form of the boundary condition is

$$
\begin{aligned}
\varphi_{1 \eta}+\lambda \varphi_{1 \xi} & =\left(\varphi_{\mathrm{i} 2 \mathrm{k}}-\varphi_{\mathrm{i} 0 \mathrm{k}}\right) /\left(\eta_{2}-\eta_{0}\right)-\lambda\left[\mathrm{c}_{1 \mathrm{i}}\left(\varphi_{\mathrm{i}+11 \mathrm{k}}-\varphi_{\mathrm{i} 1 \mathrm{k}}\right)\right. \\
& \left.+\mathrm{d}_{1 \mathrm{i}}\left(\varphi_{\mathrm{i} 1 \mathrm{k}}-\varphi_{\mathrm{i}-11 \mathrm{k}}\right)\right]=0
\end{aligned}
$$

We choose for convenience $\eta_{0}=-\eta_{1}$. Then for elliptic points, we solve for $\varphi_{\mathrm{i} 0 \mathrm{k}}$ and obtain

$$
\varphi_{\mathrm{i} O \mathrm{k}}=\varphi_{\mathrm{i} 2 \mathrm{k}}-\lambda\left(\eta_{2}+\eta_{1}\right)\left[\mathrm{c}_{1 \mathrm{i}}\left(\varphi_{\mathrm{i}+11 \mathrm{k}}-\varphi_{\mathrm{i} 1 \mathrm{k}}\right)+\mathrm{d}_{1 \mathrm{i}}\left(\varphi_{\mathrm{ilk}}-\varphi_{\mathrm{j}-11 \mathrm{k}}\right)\right]
$$

Similarly, for hyperbolic points

$$
\varphi_{\mathrm{i} 0 \mathrm{k}}=\varphi_{\mathrm{i} 2 \mathrm{k}}-\lambda\left(\eta_{2}+\eta_{1}\right)\left[\mathrm{c}_{2 \mathrm{i}}\left(\varphi_{\mathrm{ilk}}-\varphi_{\mathrm{i}-11 \mathrm{k}}\right)-\mathrm{d}_{1 \mathrm{i}-1}\left(\varphi_{\mathrm{i}-11 \mathrm{k}}-\varphi_{\mathrm{i}-21 \mathrm{k}}\right)\right]
$$

Also for $\mathrm{j}=1$, we have

$$
\varphi_{1 \eta \eta}=2\left(\varphi_{\mathrm{i} 2 \mathrm{k}}-\varphi_{\mathrm{i} 1 \mathrm{k}}\right) /\left(\eta_{2}{ }^{2}-\eta_{1}^{2}\right)-\left(\varphi_{\mathrm{i} 1 \mathrm{k}}-\varphi_{\mathrm{i} 0 \mathrm{k}}\right) / \eta_{1}\left(\eta_{2}+\eta_{1}\right)
$$


Eliminating $\varphi_{\mathrm{i} 0 \mathrm{k}}$ for elliptic points yields

$$
\begin{aligned}
\varphi_{1 \eta \eta}= & \left(\varphi_{\mathrm{i} 2 \mathrm{k}}-\varphi_{\mathrm{i} 1 \mathrm{k}}\right) / \eta_{1}\left(\eta_{2}-\eta_{1}\right)-\left(\lambda / \eta_{1}\right)\left[\mathrm{c}_{1 \mathrm{i}}\left(\varphi_{\mathrm{i}+11 \mathrm{k}}-\varphi_{\mathrm{i} 1 \mathrm{k}}\right)\right. \\
& \left.+\mathrm{d}_{1 \mathrm{i}}\left(\varphi_{\mathrm{i} 1 \mathrm{k}}-\varphi_{\mathrm{i}-11 \mathrm{k}}\right)\right]
\end{aligned}
$$

Similarly, for hyperbolic points

$$
\begin{aligned}
\varphi_{1 \eta \eta}= & \left(\varphi_{\mathrm{i} 2 \mathrm{k}}-\varphi_{\mathrm{i} 1 \mathrm{k}}\right) / \eta_{1}\left(\eta_{2}-\eta_{1}\right)-\left(\lambda / \eta_{1}\right)\left[\mathrm{c}_{2 \mathrm{i}}\left(\varphi_{\mathrm{i} 1 \mathrm{k}}-\varphi_{\mathrm{i}-11 \mathrm{k}}\right)\right. \\
& \left.-\mathrm{d}_{1 \mathrm{i}-1}\left(\varphi_{\mathrm{i}-11 \mathrm{k}}-\varphi_{\mathrm{i}-21 \mathrm{k}}\right)\right]
\end{aligned}
$$

For $j=1$ the $\xi$ derivative for elliptic points is

$$
\begin{aligned}
{\left[\left(\mathrm{v}+2 \lambda^{2}\right) \varphi_{1 \xi}-(2 \mathrm{i} \omega / \epsilon) \varphi_{1}\right] \xi } & =2 \mathrm{E}_{12}\left(\varphi_{\mathrm{i}+11 \mathrm{k}}-\varphi_{\mathrm{i} 1 \mathrm{k}}\right) \\
& -2 \mathrm{E}_{13}\left(\varphi_{\mathrm{i} 1 \mathrm{k}}-\varphi_{\mathrm{i}-11 \mathrm{k}}\right)
\end{aligned}
$$

where

$$
\begin{aligned}
& E_{12}=c_{i}\left(v_{i+1 / 21 k}+2 \lambda^{2}\right)-i \omega c_{1 i} / \epsilon \\
& E_{13}=d_{i}\left(v_{i-1 / 21 k}+2 \lambda^{2}\right)+i \omega d_{1 i} / \epsilon
\end{aligned}
$$

and for hyperbolic points

$$
\begin{aligned}
{\left[\left(\mathrm{v}+2 \lambda^{2}\right) \varphi_{1 \xi^{-}}-(2 \mathrm{i} \omega / \epsilon) \varphi_{1}\right]_{\xi}=} & 2 \mathrm{E}_{14}\left(\varphi_{\mathrm{i} 1 \mathrm{k}}-\varphi_{\mathrm{i}-11 \mathrm{k}}\right) \\
& -2 \mathrm{E}_{15}\left(\varphi_{\mathrm{i}-11 \mathrm{k}}-\varphi_{\mathrm{i}-21 \mathrm{k}}\right)
\end{aligned}
$$

where

$$
\begin{aligned}
& E_{14}=c_{i-1}\left(v_{i-1 / 21 k}+2 \lambda^{2}\right)-i \omega c_{2 i} / \epsilon \\
& E_{15}=d_{i-1}\left(v_{i-3 / 21 k}+2 \lambda^{2}\right)-i \omega d_{1 i-1} / \epsilon
\end{aligned}
$$

Substituting equations (62), (60), and (52) into the differential equation yields the following difference equation for $\mathrm{j}=1$.

$$
\begin{aligned}
& { }_{\zeta k} \varphi_{i 1 k-1}-\left[b_{\eta 1}+a_{\zeta k}+b_{\zeta k}+E_{12}+E_{13}+\lambda\left(d_{1 i}-c_{1 i}\right) / 2 \eta_{1}\right. \\
& \left.-q_{i 1 k} / 2\right] \varphi_{i 1 k}+b_{\zeta k} \varphi_{i 1 k+1}=-b_{\eta 1} \varphi_{i 2 k} \\
& +\left(\lambda c_{1 i} / 2 \eta_{1}-E_{12}\right) \varphi_{i+11 k}-\left(\lambda d_{1 i} / 2 \eta_{1}+E_{13}\right) \varphi_{i-11 k}
\end{aligned}
$$


where

$$
\mathrm{b}_{\eta_{1}}=1 / 2 \eta_{1}\left(\eta_{2}-\eta_{1}\right)
$$

Similarly, for hyperbolic points, we have

$$
\begin{aligned}
& \mathrm{a}_{\zeta \mathrm{k}} \varphi_{\mathrm{ilk}-1}-\left(\mathrm{b}_{\eta_{1}}+\mathrm{a}_{\zeta \mathrm{k}}+\mathrm{b}_{\zeta \mathrm{k}}+\lambda \mathrm{c}_{2 \mathrm{i}} / 2 \eta_{1}-\mathrm{E}_{14}\right) \varphi_{\mathrm{i} 1 \mathrm{k}} \\
& +\mathrm{b}_{\zeta \mathrm{k}} \varphi_{\mathrm{i} 1 \mathrm{k}+1}=-\mathrm{b}_{\eta_{1}} \varphi_{\mathrm{i} 2 \mathrm{k}}+\left[\mathrm{E}_{14}+\mathrm{E}_{15}-\left(\lambda / 2 \eta_{1}\right)\left(\mathrm{c}_{2 \mathrm{i}}\right.\right. \\
& \left.\left.+\mathrm{d}_{1 \mathrm{i}-1}\right)\right] \varphi_{\mathrm{i}-11 \mathrm{k}}-\left(\mathrm{E}_{15}-\lambda \mathrm{d}_{1 \mathrm{i}-1} / 2 \eta_{1}\right) \varphi_{\mathrm{i}-21 \mathrm{k}} .
\end{aligned}
$$

These last two equations replace equations (53), (54), (57), and (58) for $\mathrm{j}=1$ points in the mesh, which are the points on the plane of symmetry for the flow.

\section{Wing and Wake Boundary Conditions for the Swept Wing}

The boundary conditions on the wing and on the wake involve only the $\varphi_{1 \zeta \zeta}$ term, which is unaffected by the coordinate transformation. The difference equations for $\mathrm{k}=\mathrm{k}_{\mathrm{m}}$ and $\mathrm{k}_{\mathrm{m}}+1$ are found by modifying some of the terms in equations (53) and (57). For $\mathrm{k}=\mathrm{k}_{\mathrm{m}}, \mathrm{b}_{\boldsymbol{\xi}} \mathrm{k}_{\mathrm{m}}$ is deleted from the coefficient of $\varphi_{\mathrm{ijk}}$, the $\varphi_{\mathrm{ijk}} \mathrm{m}^{+1}$ term is omitted, and

$$
-\mathrm{h}_{1} \mathrm{~b}_{\zeta \mathrm{k}_{\mathrm{m}}} \mathrm{F}_{\mathrm{ij}}(\mathrm{L})
$$

is added to the right-hand side. Similarly, for $\mathrm{k}=\mathrm{k}_{\mathrm{m}}+1$, the $\varphi_{\mathrm{ij}} \mathrm{k}_{\mathrm{m}}$ term is deleted along with a $\zeta \mathrm{k}_{\mathrm{m}}+1$ from the coefficient of $\varphi_{\mathrm{ijk}} \mathrm{m}^{+1}$ and

$$
\mathrm{h}_{1} \mathrm{a} \zeta \mathrm{k}_{\mathrm{m}}+\mathrm{F}_{\mathrm{ij}}(\mathrm{U})
$$

is added to the right-hand side.

The wake boundary conditions for rectangular wings also may be carried over into the swept wing coordinate system with little change, since

$$
\varphi_{1 \mathrm{x}}=\varphi_{1 \zeta}
$$

The second equation following equation (35), and equation (38), can be applied with only a change in notation. For $\mathrm{k}=\mathrm{k}_{\mathrm{m}}$, we add to the right-hand side of equations (53) and (57) the additional term 


$$
\mathrm{b}_{\zeta \mathrm{k}_{\mathrm{m}}} \Delta \varphi_{\mathrm{ij}}
$$

and for $\mathrm{k}=\mathrm{k}_{\mathrm{m}}+1$, the additional term

$$
-{ }^{\mathrm{a}} \zeta \mathrm{k}_{\mathrm{m}}+1 \Delta \varphi_{\mathrm{ij}}
$$

\section{Far-Field Boundary Conditions-Three-Dimensional Flow}

In order to solve the difference equations in the flow field, we must prescribe boundary conditions on the exterior boundary of the mesh. This is usually found in terms of the velocity potential. This boundary information is not known a priori but must be computed and periodically corrected in the iteration process used to find the solution. For this purpose we follow an analysis similar to that of Klunker (ref. 8) for the steady-state equation and write the differential equation in the form

$$
\begin{aligned}
\mathrm{L}\left(\varphi_{1}\right) & =\mathrm{K} \varphi_{1 \mathrm{xx}}-(2 \mathrm{i} \omega / \epsilon) \varphi_{1 \mathrm{x}}+\varphi_{1 \mathrm{yy}}+\varphi_{1 \mathrm{zz}}+\left(\omega^{2} / \epsilon\right) \varphi_{1} \\
& =(\gamma+1)\left(\varphi_{0 \mathrm{x}} \varphi_{1 \mathrm{x}}\right)_{\mathrm{x}}+\mathrm{i} \omega(\gamma-1) \varphi_{1} \varphi_{0 \mathrm{xx}}
\end{aligned}
$$

To convert the solution to the swept wing coordinates, we merely substitute $\mathrm{x}=\xi+\lambda \eta$ and $\mathrm{y}=\eta$ into the solution of equation (64). For our purposes, it is convenient to introduce new variables in terms of $x$ and $y$. Let $x_{1}=x, y_{1}=y \sqrt{K}$, and $z_{1}=z \sqrt{K}$. Then

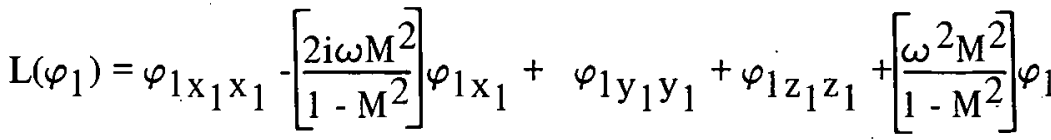

$$
\begin{aligned}
& =\frac{\gamma+1}{\mathrm{~K}}\left(\varphi_{0 \mathrm{x}_{1}} \varphi_{1 \mathrm{x}_{1}}\right)_{\mathrm{x}_{1}}+\frac{\mathrm{i} \omega(\gamma-1)}{\mathrm{K}} \varphi_{1} \varphi_{0 \mathrm{x}_{1} \mathrm{x}_{1}}
\end{aligned}
$$

We derive an integral equation for $\varphi_{1}$ in terms of boundary values by applying Green's theorem in the form

$$
\int_{\mathrm{V}}\left[\psi \mathrm{L}\left(\varphi_{1}\right)-\varphi_{1} \mathrm{~L}(\psi)\right] \mathrm{dv^{ \prime }}=\int_{\mathrm{s}}\left(\varphi_{1} \psi_{\mathrm{n}}-\psi \varphi_{1 \mathrm{n}}+\left[\frac{2 \mathrm{i} \omega \mathrm{M}^{2}}{1-\mathrm{M}^{2}}\right] \varphi_{1} \psi \mathrm{n}_{\mathrm{x}}\right) d \mathrm{~s}^{\prime}
$$

where the volume $v$ is bounded by the surfaces $S=S_{p}+S_{d}+S_{w}+S_{v^{\prime}}$ (see fig. 18). Here $S_{p}$ is the sphere about the specific point $p$. The surface $S_{d}$ is the surface of discontinuity representing shocks. The quantities $S_{w}$ and $S_{v}$ represent the wing and trailing vortex sheet, respectively, as shown in figure 18 . The quantity $\mathrm{n}$ is the normal directed into the fluid from the surfaces.

The fundamental solution $\psi$ is a function of the vector $x_{p}-x^{\prime}$, where $x_{p}$ is the vector reference point and $\mathrm{x}^{\prime}$ is the point vector of integration. 

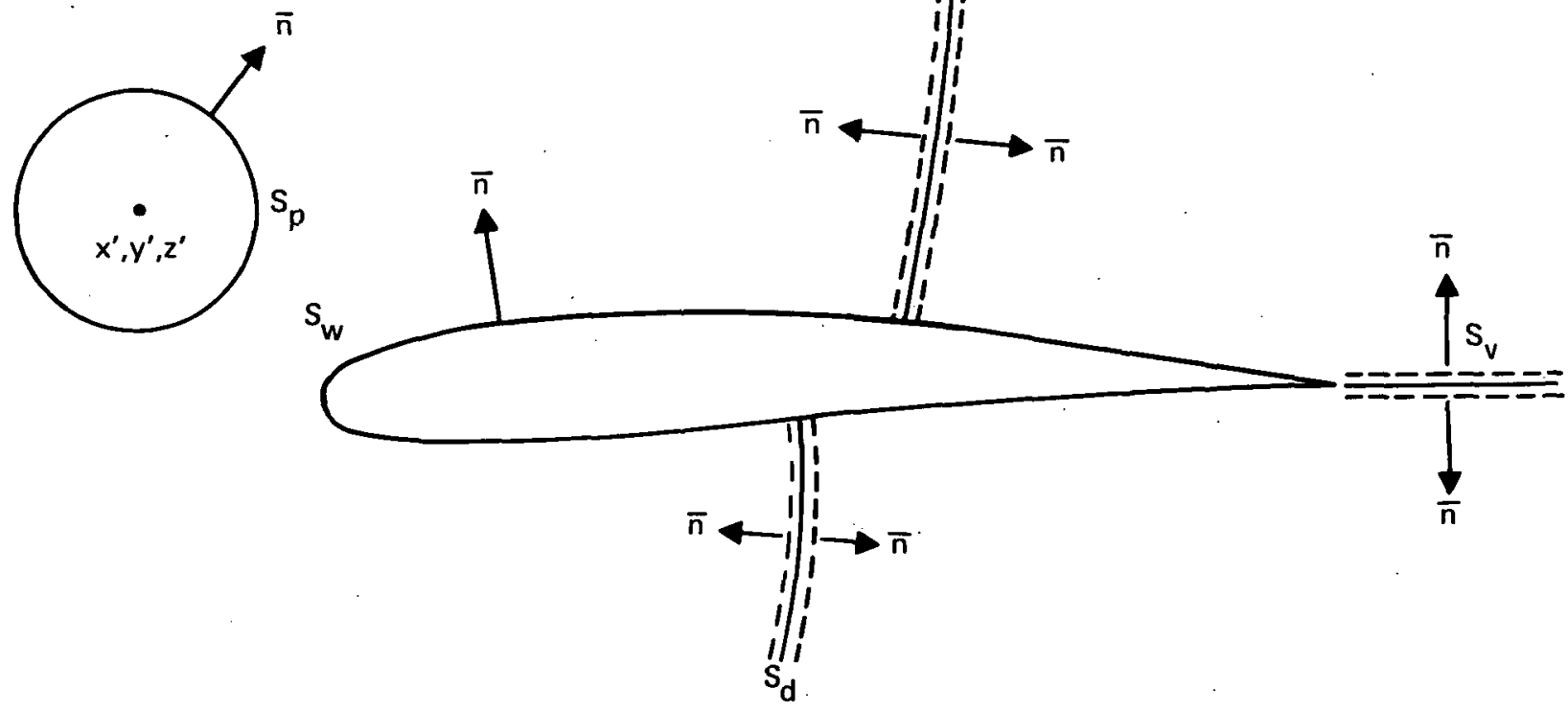

Figure 18.-Sections of the boundary surface $S$

To find the fundamental solution $\psi$, we let

$$
\psi=\mathrm{e}^{\mathrm{i} \omega \mathrm{M}^{2} \mathrm{x}_{1} /\left(1-\mathrm{M}^{2}\right)} \psi_{0}(\mathrm{r})
$$

With $\mathrm{r}=: \sqrt{\mathrm{x}_{1}^{2}+\mathrm{y}_{1}^{2}+\mathrm{z}_{1}^{2}}$, the differential equation, $\mathrm{L}(\psi)=0$, becomes

$$
\psi_{0}^{\prime \prime}+2 \psi_{0}^{\prime} / \mathrm{r}+\lambda_{1}^{2} \psi_{0}=0
$$

where $\lambda_{1}=\omega \mathrm{M} /\left(1-\mathrm{M}^{2}\right)$. The solution of this equation yielding outgoing waves is $\mathrm{e}^{-\mathrm{i} \lambda_{1} \mathrm{r}} / \mathrm{r}$ and leads to

$$
\psi=\mathrm{e}^{\mathrm{i} \lambda_{1}\left(\mathrm{Mx_{1 }}-\mathrm{r}\right)} / \mathrm{r}
$$

for the fundamental solution. We let the radius of the sphere about the reference point $X_{p}=\left(X_{1}\right.$, $\mathrm{Y}_{1}, \mathrm{Z}_{1}$ ) shrink to 0 . Since $\psi_{\mathrm{n}}=\psi_{\mathrm{r}}$, then the contribution of the surface integral on the right-hand side of equation (65) about $S_{p}$ yields

$$
-4 \pi \varphi\left(x_{1}, y_{1}, z_{1}\right)
$$


Since $L(\psi)=0$, the volume integral in Green's theorem becomes

$$
\begin{aligned}
& \int_{\mathrm{V}}\left[\psi \mathrm{L}\left(\varphi_{1}\right)-\varphi_{1} \mathrm{~L}(\psi)\right] \mathrm{dv}^{\prime} \\
= & \frac{1}{\mathrm{~K}} \int_{\mathrm{V}}\left[(\gamma+1) \psi\left(\varphi_{1 \mathrm{x}_{1}}{ }^{\prime} \varphi_{0 \mathrm{x}_{1}}{ }^{\prime}\right)_{\mathrm{x}_{1}}{ }^{\prime}+\mathrm{i} \omega(\gamma-1) \psi \varphi_{0 \mathrm{x}_{1}} \mathrm{x}^{\prime} \varphi_{1}\right] \mathrm{dv}
\end{aligned}
$$

where the primes on the variables denote the running variables of integration. Integrating the first term by parts with respect to $\mathrm{x}_{1}{ }^{\prime}$ and noting that a jump occurs on the shock surface $\mathrm{S}_{\mathrm{d}}$ yields

$$
\begin{aligned}
\frac{(\gamma+1)}{\mathrm{K}} \int_{\mathrm{V}} \psi\left(\varphi_{0 \mathrm{x}_{1}} \varphi_{\left.1 \mathrm{x}_{1}{ }^{\prime}\right)_{\mathrm{x}_{1}} \mathrm{dv}^{\prime}=}\right. & \frac{\gamma+1}{\mathrm{~K}} \int_{\mathrm{S}} \psi\left[\varphi_{0 \mathrm{x}_{1}} \varphi_{\left.1 \mathrm{x}_{1}{ }^{\prime}\right] \cos \theta_{1} \mathrm{ds}^{\prime}}\right. \\
& -\frac{\gamma+1}{\mathrm{~K}} \int_{\mathrm{V}} \psi_{\mathrm{x}_{1}}{ }^{\prime} \varphi_{0 \mathrm{x}_{1}} \varphi_{1 \mathrm{x}_{1}} \mathrm{dv}^{\prime}
\end{aligned}
$$

where $\cos \theta_{1}$ is the inclination of the normal to the shock surface with respect to the $\mathrm{x}_{1}$ axis. The square brackets denote the jump in the quantity across the surface. For the integral over the shock surface, we obtain

$$
\begin{aligned}
& \int s_{d}\left(\varphi_{1} \psi_{n}-\psi \varphi_{1 n}+\left[\frac{2 i \omega M^{2}}{1-M^{2}}\right] \varphi_{1} \psi n_{x}\right) d s^{\prime}=-\int_{s_{d}} \psi\left\{\left[\varphi_{1 n}\right]-\frac{2 i \omega M^{2}}{1-M^{2}}\left[\varphi_{1}\right] n_{x}\right\} d^{\prime}
\end{aligned}
$$

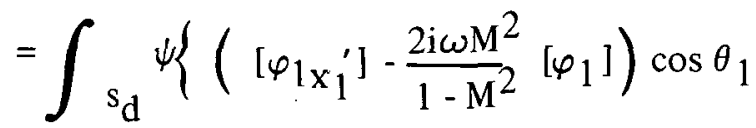

$$
\begin{aligned}
& \left.+\left[\varphi_{1 \mathrm{y}_{1}^{\prime}}\right] \cos \theta_{2}+\left[\varphi_{1 \mathrm{z}_{1}^{\prime}}\right] \cos \theta_{3}\right\} \mathrm{ds}^{\prime}
\end{aligned}
$$

where $\cos \theta_{2}$ and $\cos \theta_{3}$ are the $\mathrm{y}_{1}$ and $z_{1}$ direction cosines of the normal to the shock surface, respectively.

For the thin planar wing, $\varphi_{1 \mathrm{n}} \simeq \pm \varphi_{1 \mathrm{z}_{1}}$; then the surface integral over the wing reduces to

$$
\int_{\mathrm{S}_{\mathrm{W}}}\left(\varphi_{1} \psi_{\mathrm{n}}-\psi \varphi_{1 \mathrm{n}}\right) \mathrm{ds^{ \prime }} \simeq \int_{-\mathrm{y}_{\mathrm{t}}}^{\mathrm{y}_{\mathrm{t}}} \int_{\mathrm{x}_{\ell}\left(\mathrm{y}_{1}^{\prime}\right)}^{\mathrm{x}_{\mathrm{t}}\left(\mathrm{y}_{1}^{\prime}\right)}\left(\Delta \varphi_{1} \psi_{\mathrm{z}_{1}^{\prime}}-\psi \Delta \varphi_{1 \mathrm{z}_{1}^{\prime}}\right) \mathrm{dx} \mathrm{x}_{1}^{\prime} \mathrm{dy} \mathrm{y}_{1}^{\prime}
$$

where $\mathrm{x}_{\ell}$ and $\mathrm{x}_{t}$ designate the $\mathrm{x}_{1}$ coordinates for leading and trailing edges, respectively; $\mathrm{y}_{t}$ is the value of $\mathrm{y}_{1}$, for the tip of the wing, and $\Delta$ denotes the difference between upper and lower values of the quantity on the wing, which is approximated by its projection in the plane $z_{1}=0$.

Similarly, the integral over the trailing vortex sheet, since $\varphi_{1 \mathrm{n}}$ is continuous, yields

$$
\int_{\mathrm{s}_{\mathrm{v}}}\left(\varphi_{1} \psi_{\mathrm{n}}-\psi \varphi_{1 \mathrm{n}}\right) \mathrm{ds^{ \prime }} \simeq \int_{-\mathrm{y}_{\mathrm{t}}}^{\mathrm{y}_{\mathrm{t}}} \int_{\mathrm{x}_{\mathrm{t}}\left(\mathrm{y}_{1}^{\prime}\right)}^{\infty} \Delta \varphi_{1} \psi_{\mathrm{z}_{1}^{\prime}}^{\prime} \mathrm{dx}_{1}^{\prime} \mathrm{dy}_{1}^{\prime}
$$


Now, continuity of pressure across the vortex sheet requires that

$$
\left(\Delta \varphi_{1}\right)_{x_{1}{ }^{\prime}+i \omega \Delta \varphi_{1}=0}
$$

Solving the differential equation yields

$$
\Delta \varphi_{1}\left(\mathrm{x}_{1}^{\prime}, \mathrm{y}_{1}^{\prime}\right)=\Delta \varphi_{\mathrm{t}}\left(\mathrm{y}_{1}{ }^{\prime}\right) \mathrm{e}^{-\mathrm{i} \omega\left(\mathrm{x}_{1}{ }^{\prime}-\mathrm{x}_{\mathrm{t}}\left(\mathrm{y}_{1}^{\prime}\right)\right)}
$$

where $\Delta \varphi_{\mathrm{t}}$ is the jump in $\varphi_{1}$ at the trailing edge of the wing. Substituting equation (72) into equation (70) yields for the wake integral

$$
\int_{-y_{t}}^{y_{t}} e^{1 \omega x_{t}\left(y_{1}^{\prime}\right)} \Delta \varphi_{t}\left(y_{1}^{\prime}\right) d y_{1}^{\prime} \int_{x_{t}\left(y_{1}^{\prime}\right)}^{\infty} e^{-i \omega x_{i}^{\prime}} \psi_{z_{1}} d x_{1}^{\prime}
$$

We have now found the integrals over the volume and over all surfaces of figure 18. Substituting equations (67) through (73) into equation (65) and combining integrals over the discontinuous surface $S_{d}$ yields

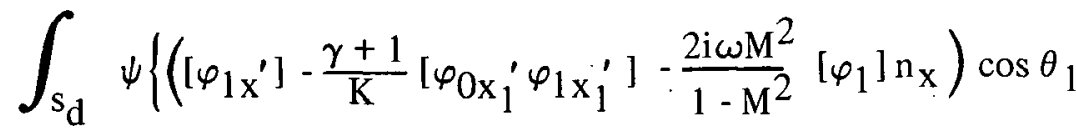

$$
\begin{aligned}
& \left.+\left[\varphi_{1 \mathrm{y}_{1}}\right] \cos \theta_{2}+\left[\varphi_{1 \mathrm{z}_{1}}\right] \cos \theta_{3}\right\} \mathrm{ds^{ \prime }}
\end{aligned}
$$

This can be shown to vanish identically for shocks by using the divergence theorm. The partial differential equation can be written

$$
\mathrm{F}_{1 \mathrm{x}_{1}}+\mathrm{F}_{2 \mathrm{y}_{1}}+\mathrm{F}_{3 \mathrm{z}_{1}}+\mathrm{Q \varphi _{1 }}=0
$$

where

$$
\begin{aligned}
& \mathrm{F}_{1}=\varphi_{1 \mathrm{x}_{1}}-\frac{\gamma+1}{\mathrm{~K}} \varphi_{0 \mathrm{x}_{1}} \varphi_{1 \mathrm{x}_{1}}-\frac{2 \mathrm{i} \omega \mathrm{M}^{2}}{1-\mathrm{M}^{2}} \varphi_{1} \\
& \mathrm{~F}_{2}=\varphi_{1 \mathrm{y}_{1}} \quad \mathrm{~F}_{3}=\varphi_{1 \mathrm{z}_{1}} \\
& \mathrm{Q}=\frac{\mathrm{i} \omega^{2} \mathrm{M}^{2}}{1-\mathrm{M}^{2}}-\mathrm{i} \omega(\gamma-1) \varphi_{0 \mathrm{x}_{1} \mathrm{x}_{1}} .
\end{aligned}
$$


Consider the integral over a small rectangle about the shock as shown in figure 19. Applying the integral of the differential equation (75) over this small volume and letting the thickness $\Delta t \rightarrow 0$ yields from the divergence theorem

$$
1_{\Delta t \rightarrow 0} \int_{v}(\nabla \cdot F+Q) d v^{\prime} \simeq \Delta s[F \cdot n]=0 .
$$

The quantity $[\mathrm{F} \cdot \mathrm{n}]$ is seen to be identical to the quantity enclosed by \{\} in equation (74), since $\mathrm{n}=\left(\cos \theta_{1}, \cos \theta_{2}, \cos \theta_{3}\right)$. This demonstrates that the integral in equation (74) is identically 0 . Thus, the Green's theorem of equation (65) becomes

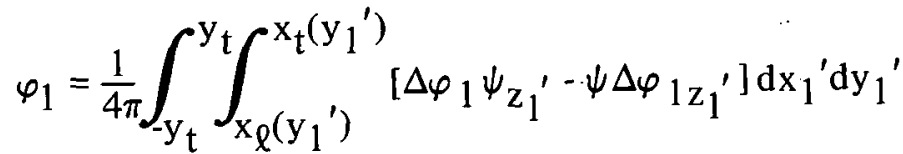

$$
\begin{aligned}
& +\frac{1}{4 \pi} \int_{-y_{t}}^{y_{t}} e^{i \omega x_{t}\left(y_{1}{ }^{\prime}\right)} \Delta \varphi_{t}\left(y_{1}{ }^{\prime}\right) d y_{1} \int_{x_{t}\left(y_{1}{ }^{\prime}\right)}^{\infty} e^{-i \omega x_{1}{ }^{\prime}} \psi_{z_{1}}{ }^{\prime} d x_{1}{ }^{\prime} \\
& +\frac{1}{4 \pi \mathrm{K}} \int_{\mathrm{V}}\left\{(\gamma+1) \varphi_{0 \mathrm{x}_{1}}{ }^{\prime} \varphi_{1 \mathrm{x}_{1}}{ }^{\prime} \psi_{\mathrm{x}_{1}{ }^{\prime}}-\mathrm{i} \omega(\gamma-1) \varphi_{1} \psi \varphi_{0 \mathrm{x}_{1}}{ }^{\prime} \mathrm{x}_{1}{ }^{\prime}\right\} \mathrm{dv}^{\prime}
\end{aligned}
$$

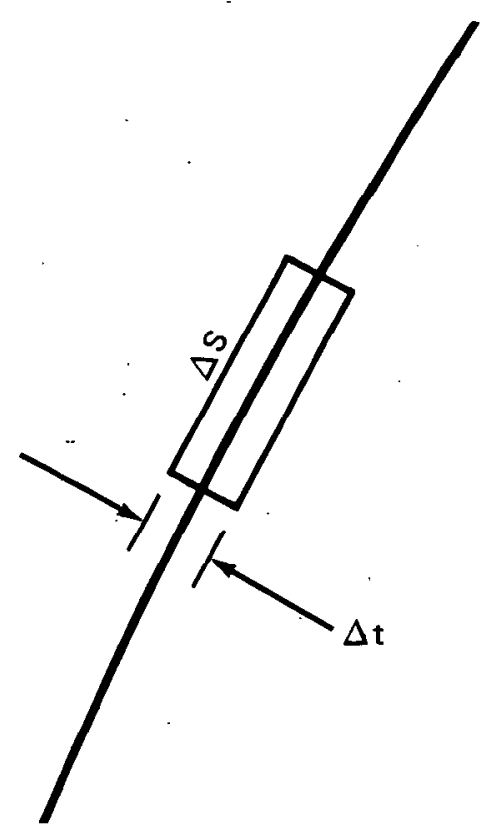

Figure 19.-Shock surface and volume used for divergence theorem integral 
The wake integral can be integrated with respect to $x_{1}^{\prime}$ for the combination $\varphi_{1 \mathrm{x}}+\mathrm{i} \omega \varphi_{1}$, which may be called the pressure potential. We consider

$$
I_{w}=\int_{x_{t}}^{\infty} e^{-i \omega x_{1}^{\prime}}\left[\psi_{z_{1}^{\prime} x_{1}}+i \omega \psi_{z_{1}}{ }^{\prime}\right] d x_{1}^{\prime}
$$

since $\partial / \partial \mathrm{x}_{1}=-\partial / \partial \mathrm{x}_{1}^{\prime}$, we have

$$
I_{w}=-\int_{x_{t}}^{\infty} \frac{\partial}{\partial x_{1}},\left(e^{-i \omega x_{1}^{\prime}} \psi_{z_{1}}{ }^{\prime}\right) d x_{1}^{\prime}=-e^{-i \omega x_{t}} \psi_{z_{1}}\left(x_{t}-x_{1}^{\prime}, y_{1}-y_{1}^{\prime}, z_{1}\right)
$$

Since the wake integral is very slowly convergent, it is more convenient to express the upstream and downstream boundary conditions in terms of $\varphi_{1 \mathrm{x}}+i \omega \varphi_{1}$ rather than $\varphi_{1}$. The pressure function from equation (77) then becomes

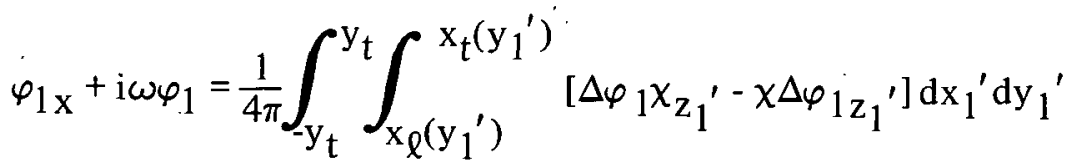

$$
\begin{aligned}
& -\frac{1}{4 \pi} \int_{-y_{t}}^{y_{t}} e^{i \omega x_{t}\left(y_{1}^{\prime}\right)} \Delta \varphi_{t}\left(y_{1}^{\prime}\right) \psi_{z}\left(x_{t}\left(y_{1}^{\prime}\right)-x_{1}, y_{1}-y_{1}^{\prime}, z_{1}\right) d_{1} y_{1}^{\prime} \\
& +\frac{1}{4 \pi \mathrm{K}} \int_{\mathrm{v}}\left\{(\gamma+1) \varphi_{0 \mathrm{x}_{1}}{ }^{\prime} \varphi_{1 \mathrm{x}_{1}} \cdot \chi_{\mathrm{x}_{1}}{ }^{\prime}-\mathrm{i} \omega(\gamma-1) \varphi_{1} \chi \varphi_{0 \mathrm{x}_{1}} \mathrm{x}_{1}^{\prime}\right\} \mathrm{dv}^{\prime}
\end{aligned}
$$

where

$$
\chi=\psi_{x_{1}}+i \omega \psi
$$

\section{Formulation of the Problem of the Harmonically Oscillating Airfoil}

To test the method developed in the preceding sections, we formulate the relations for the harmonically oscillating airfoil, since they are simpler and will require less computing time. The equations for the oscillating wing represent the wing as lying in the plane $z=0$ with the direction of the undisturbed flow in the positive $x$ direction. Relations were derived for the method of relaxation of the difference equation by solving for the values of the potential along lines normal to the $z=0$ plane corresponding to fixed values $i$ and $j$ points in the mesh. To follow the conventional notation for 
airfoil problems, we now consider the airfoil cross section as lying in the $\mathrm{x}, \mathrm{y}$ plane. Since there is no variation with $\mathrm{z}$ then the small perturbation differential equation (17) for the airfoil becomes

$$
\left[\mathrm{u} \varphi_{1 \mathrm{x}}-(2 \mathrm{i} \omega / \epsilon) \varphi_{1}\right]_{\mathrm{x}}+\varphi_{1 \mathrm{yy}}+\mathrm{q} \varphi_{1}=0
$$

where

$$
\begin{aligned}
& \mathrm{u}=\mathrm{K}-(\gamma+1) \varphi_{0 \mathrm{x}} \\
& \mathrm{q}=\omega^{2} / \epsilon-\mathrm{i} \omega(\gamma-1) \varphi_{0 \mathrm{xx}}
\end{aligned}
$$

By representing the airfoil in the $\mathrm{x}, \mathrm{y}$ plane we effectively interchanged $\mathrm{y}$ and $\mathrm{z}$ in the derivation of the fundamental equations. The unsteady boundary conditions on the airfoil corresponding to equation (28) then become

$$
\varphi_{1 \mathrm{y}}=\mathrm{f}_{1}^{\prime}(\mathrm{x})+\mathrm{i} \omega \mathrm{f}_{1}(\mathrm{x})
$$

on $\mathrm{y}=0$, where $\mathrm{y}_{0}=\delta \mathrm{f}_{0}(\mathrm{x})+\delta \mathrm{f}_{1}(\mathrm{x}) \mathrm{e}^{\mathrm{i} \omega \mathrm{t}}$ describes the oscillating airfoil shape. The boundary conditions of equation (34) become $\varphi_{1 \mathrm{y}}$ continuous across $\mathrm{y}=0$ behind the airfoil, and equations (71) and (72) for continuity of pressure lead to

$$
\Delta \varphi_{i}=\Delta \varphi_{t} e^{-i \omega\left(x_{i}-x_{t}\right)} x_{i}>x_{t}
$$

where $\Delta \varphi_{t}$ is the jump in the potential at the first mesh point downstream of the trailing edge. Since we have dropped variation with respect to $\mathrm{z}$ the difference form of the differential equation (80) is found from equation (24) with $\mathrm{a}_{\mathrm{zk}}=\mathrm{b}_{\mathrm{zk}}=0$. For interior points in the flow field we then have

$$
a_{j} \varphi_{i j-1}-\left(a_{j}+b_{j}+E_{1}+E_{2}-q_{i j} / 2\right) \varphi_{i j}+b_{j} \varphi_{i j+1}=-E_{1} \varphi_{i+1 j}-E_{2} \varphi_{i-1 j}
$$

where

$$
E_{1}=c_{i} u_{i+1 / 2 j}-i \omega c_{1 i} / \epsilon, E_{2}=d_{i} u_{i-1 / 2 j}+i \omega d_{1 i} / \epsilon
$$

and we have dropped the subscript $y$ on the coefficients a and $b$.

The boundary conditions on the airfoil are satisfied at $y=0$, the midpoint between $y=y_{j_{\mathrm{m}}}$ and $\mathrm{y}_{\mathrm{j}_{\mathrm{m}}+1}$. From equations (32) and (33) the difference equations̀ corresponding to equation (84) for $\mathrm{j}=\mathrm{j}_{\mathrm{m}}$ and $\mathrm{j}_{\mathrm{m}}+1$ become

$$
a_{j_{m}} \varphi_{i j} j_{m}^{-1}-\left(a_{j_{m}}+E_{1}+E_{2}-q_{i j} / 2\right) \varphi_{i j}=-E_{1} \varphi_{i+1 j_{m}}-E_{2} \varphi_{1}-1 j_{m}-h_{1} b_{j_{m}} F_{i}(L)
$$


and

$$
\begin{aligned}
& -\left(b_{j_{m}}+1+E_{3}+E_{4}-\frac{q_{i j_{m}+1}}{2}\right) \varphi_{i j}+1 b_{j_{m}}+1 \varphi_{i j}+2 \\
& =-E_{3} \varphi_{i}+1 j_{m}+1-E_{4} \varphi_{i-1 j_{m}+1}+h_{1} a_{j_{m}+1} F_{i}(U),
\end{aligned}
$$

where

$$
\begin{aligned}
& E_{1}=c_{i} u_{i+1 / 2 j_{m}}-i \omega c_{1 i} / \epsilon, E_{2}=d_{i} u_{i-1 / 2 j_{m}}+i \omega d_{1 i} / \epsilon \\
& E_{3}=c_{i} u_{i+1 / 2 j_{m}+1}-i \omega c_{1 i} / \epsilon \text {, and } E_{4}=d_{i} u_{i-1 / 2 j_{m}}+1+i \omega d_{1 i} / \epsilon
\end{aligned}
$$

Here

$$
F_{i}=f_{1}^{\prime}\left(x_{i}\right)+i \omega f_{1}\left(x_{j}\right)
$$

Downstream of the wake the boundary condition of continuity of pressure and normal velocity component require that, for $\mathrm{j}=\mathrm{j}_{\mathrm{m}}$, equation (84) holds with the additional term on the right-hand side

$$
\mathrm{b}_{\mathrm{j}_{\mathrm{m}}} \Delta \varphi_{\mathrm{i}}
$$

and for $j=j_{m}+1$, the right-hand side of equation (86) has the additinnal term

$$
-\mathrm{a}_{\mathrm{m}}+1 \Delta \varphi_{\mathrm{i}}
$$

Some of the coefficients of the difference equations for the harmonic motion of an airfoil in transonic flow require the steady-state solution. For this we use a program called TSONIC or TEA330, which was developed by J. A. Krupp (ref. 4) and computes the solution of equation (14) for the transonic flow over lifting airfoils. The output of this program is an array of values of the perturbation potential $\varphi_{0}$ corresponding to the mesh points of the rectangular grid about the airfoil. Since the coefficients in the differential equation depend only on $\varphi_{0 \mathrm{x}}$ and $\varphi_{0 \mathrm{xx}}$, it is convenient at the outset to establish values of $u=K-(\gamma+1) \varphi_{0 x}$ at each mesh point, since $\varphi_{0 \mathrm{x}}$ occurs only in this quantity in the equation. For convenience of coding on the computer we write

$$
u_{i-1 / 2 j} \rightarrow u_{i j}=K-(\gamma+1)\left(\varphi_{0 i j}-\varphi_{0 i-1 j}\right) /\left(x_{i}-x_{i-1}\right)
$$

and

$$
u_{i}+1 / 2 j \rightarrow u_{i+1 j}=K-(\gamma+1)\left(\varphi_{0 i+1 j}-\varphi_{0 i j}\right) /\left(x_{i+1}-x_{i}\right)
$$


Only the quantity $\mathrm{q}$ contains the term $\varphi_{0 \mathrm{xx}}$ :

$$
q=\omega^{2} / \epsilon-i \omega(\gamma-1) \varphi_{0 x x}
$$

From equation (88) we have

$$
\left(\varphi_{0 \mathrm{ij}}-\varphi_{0 \mathrm{i}-1 \mathrm{j}}\right)=\left(\mathrm{x}_{\mathrm{i}}-\mathrm{x}_{\mathrm{i}-1}\right)\left(\mathrm{K}-\mathrm{u}_{\mathrm{ij}}\right) /(\gamma+1)
$$

Using this relation in the difference form for $\varphi_{0 \mathrm{xx}}$ yields

$$
\begin{aligned}
\varphi_{0 \mathrm{xx}} & =c_{\mathrm{i}}\left(\varphi_{0 \mathrm{i}+1 \mathrm{j}}-\varphi_{0 \mathrm{ij}}\right)-\mathrm{d}_{\mathrm{i}}\left(\varphi_{0 \mathrm{ij}}-\varphi_{0 \mathrm{i}-1 \mathrm{j}}\right) \\
& =\left[\left(\mathrm{x}_{\mathrm{i}+1}-\mathrm{x}_{\mathrm{i}}\right) \mathrm{c}_{\mathrm{i}}\left(\mathrm{K}-\mathrm{u}_{\mathrm{i}+1 \mathrm{j}}\right)-\left(\mathrm{x}_{\mathrm{i}}-\mathrm{x}_{\mathrm{i}-1}\right) \mathrm{d}_{\mathrm{i}}\left(\mathrm{K}-\mathrm{u}_{\mathrm{ij}}\right)\right] /(\gamma+1) .
\end{aligned}
$$

where $c_{i}$ and $d_{i}$ are defined following equation (19). Simplifying equation (90) leads to

$$
\varphi_{\mathrm{Oxx}}=\left(u_{\mathrm{ij}}-u_{\mathrm{i}-1 \mathrm{j}}\right) /(\gamma+1)\left(\mathrm{x}_{\mathrm{i}+1}-\mathrm{x}_{\mathrm{i}-1}\right)
$$

Finally, for $\mathrm{q}_{\mathrm{ij}}$ we write

$$
q_{i j}=\omega^{2} / \epsilon+i c_{3 i}\left(u_{i+1 j}-u_{i j}\right)
$$

where

$$
c_{3 i}=\omega(\gamma-1) /(\gamma+1)\left(x_{i+1}-x_{i-1}\right)
$$

For the volume integrals in the far-field integral relation, we require $\varphi_{0 \mathrm{x}}$ at the points $\mathrm{i}, \mathrm{j}$. For this we write

$$
\varphi_{0 \mathrm{x}}=\mathrm{c}_{1 \mathrm{i}}\left(\varphi_{0 \mathrm{i}+1 \mathrm{j}}-\varphi_{0 \mathrm{ij}}\right)+\mathrm{d}_{1 \mathrm{i}}\left(\varphi_{0 \mathrm{ij}}-\varphi_{0 \mathrm{i}-1 \mathrm{j}}\right)
$$

which, with the aid of equation (89), simplifies to

$$
(\gamma+1) \varphi_{0 x}=K-c_{4 i} u_{i+1 j}-d_{4 i} u_{i j}
$$

where 


$$
\begin{aligned}
& c_{4 i}=\left(x_{i}-x_{i-1}\right) /\left(x_{i+1}-x_{i-1}\right) \\
& d_{4 i}=\left(x_{i+1}-x_{i}\right) /\left(x_{i+1}-x_{i-1}\right) .
\end{aligned}
$$

Equations (91) through (94) provide all the relations for the steady-state solution needed in the difference formulation of the harmonically oscillating airfoil. We have replaced the $\varphi_{0 \mathrm{ij}}$ array by the $u_{i j}$ array defined by equation (88).

\section{Evaluation of the Jump in $\varphi_{1}$ on the Airfoil}

Since the values of $\varphi_{1}$ are computed only at mesh points, we must interpolate these values to the limit $y=0$ in order to compute the values of $\Delta \varphi_{i}$ required in the wake boundary conditions. The limiting value of $\varphi_{1}(\mathrm{U})$ from above the airfoil and $\varphi_{1}(\mathrm{~L})$ from below are found by Taylor's expansion about the points $y=y_{j_{m}}$ and $y=y_{j_{m}+1}$. We obtain

$$
\begin{aligned}
& \varphi_{1}^{(\mathrm{L})}=\varphi_{\mathrm{ij}}+\left.(\mathrm{h} / 2) \varphi_{1 \mathrm{y}}\right|_{\mathrm{j}_{\mathrm{m}}}+\left(\mathrm{h}^{2} / 8\right) \varphi_{1 \mathrm{yy}} \mathrm{j}_{\mathrm{m}}+\cdots \\
& \varphi_{1}(\mathrm{U})=\varphi_{\mathrm{ij}_{\mathrm{m}}+1}-\left.(\mathrm{h} / 2) \varphi_{1 \mathrm{y}}\right|_{\mathrm{j}_{\mathrm{m}}+1}+\left.\left(\mathrm{h}^{2} / 8\right) \varphi_{\mathrm{lyy}}\right|_{\mathrm{j}_{\mathrm{m}}+1}+\cdots
\end{aligned}
$$

where $\mathrm{h}=\mathrm{y}_{\mathrm{j}_{\mathrm{m}}+1}-\mathrm{y}_{\mathrm{j}}$. We use a second-order difference form for $\varphi_{1 \mathrm{y}}$. Following the formula developed for $\varphi_{1 \mathrm{x}}$, we write for $\varphi_{1 \mathrm{y}}$

$$
\begin{gathered}
\varphi_{1 \mathrm{y}} \mathrm{j}_{\mathrm{m}}+1 \\
=\mathrm{c}_{3}\left(\varphi_{\mathrm{ij}_{\mathrm{m}}}+2-\varphi_{\mathrm{ij}}+1\right)+\mathrm{d}_{3}\left(\varphi_{\mathrm{ij}}+1-\varphi_{1}(\mathrm{U})\right) \\
\varphi_{\left.1 \mathrm{y}\right|_{\mathrm{j}_{\mathrm{m}}}}=\mathrm{c}_{4}\left(\varphi_{1}(\mathrm{~L})-\varphi_{\mathrm{ij}}\right)+\mathrm{d}_{4}\left(\varphi_{\mathrm{ij}_{\mathrm{m}}}-\varphi_{\mathrm{ij}} \mathrm{m}^{-1}\right)
\end{gathered}
$$

By comparison with $c_{1 j}$ and $d_{1 j}$ following equation (20), we obtain

$$
\begin{aligned}
& \mathrm{c}_{3}=1 / \mathrm{hs}_{1}\left(2 \mathrm{~s}_{1}+1\right) \quad \mathrm{d}_{3}=4 \mathrm{~s}_{1} / \mathrm{h}\left(2 \mathrm{~s}_{1}+1\right) \\
& c_{4}=4 s_{2} / h\left(2 s_{2}+1\right) \quad d_{4}=1 / h s_{2}\left(2 s_{2}+1\right)
\end{aligned}
$$

where

$$
s_{1}=\left(y_{j_{m}}+2-y_{j_{m}+1}\right) / h \quad \text { and } \quad s_{2}=\left(y_{j_{m}}-y_{j_{m}-1}\right) / h
$$


The second derivatives at $y=y_{j_{m}}$ and $y=y_{j_{m}}+1$ become

$$
\begin{aligned}
& \begin{aligned}
\varphi_{\left.1 y y\right|_{j_{m}}} & =\frac{2}{y_{j_{m}+1-y_{j}-1}}\left[F_{\mathrm{i}}(\mathrm{L})-\frac{\varphi_{\mathrm{ij}}{ }_{\mathrm{m}}^{-\varphi_{\mathrm{ij}}-1}}{\left.\mathrm{y}_{\mathrm{j}_{\mathrm{m}}}-\mathrm{y}_{\mathrm{j}_{\mathrm{m}}-1}\right]}\right. \\
= & 2 \mathrm{~F}_{\mathrm{i}}(\mathrm{L}) / \mathrm{h}\left(\mathrm{s}_{2}+1\right)-2\left(\varphi_{\mathrm{ij}}-\varphi_{\mathrm{ij}-1}\right) / \mathrm{h}_{\mathrm{m}} \mathrm{s}_{2}\left(\mathrm{~s}_{2}+1\right)
\end{aligned} \\
& \varphi_{\left.1 \mathrm{yy}\right|_{\mathrm{m}}+1}=\frac{2}{\mathrm{~h}^{2} \mathrm{~s}_{1}\left(\mathrm{~s}_{1}+1\right)}\left(\varphi_{\mathrm{ij}}+2-\varphi_{\mathrm{ij}}+1\right)-2 \mathrm{~F}_{\mathrm{i}}(\mathrm{U}) / \mathrm{h}\left(\mathrm{s}_{1}+1\right)
\end{aligned}
$$

Substituting equations (97) through (101) into equations (95) and (96) and solving for $\varphi_{1}^{(\mathrm{U})}$ and $\varphi_{1}^{(L)}$ leads to the following relations after some simplification:

$$
\varphi_{1}^{(L)}=\varphi_{i j_{m}}+\left(\varphi_{i j_{m}}-\varphi_{i j}-1\right) / 4 s_{2}\left(s_{2}+1\right)+h\left(2 s_{2}+1\right) F_{i}^{(L)} / 4\left(s_{2}+1\right)
$$

and

$$
\varphi_{1}^{(\mathrm{U})}=\varphi_{\mathrm{ij}}+1-\left(\varphi_{\mathrm{ij}}+2-\varphi_{\mathrm{ij}}+1\right) / 4 \mathrm{~s}_{1}\left(\mathrm{~s}_{1}+1\right)-\mathrm{h}\left(2 \mathrm{~s}_{1}+1\right) \mathrm{F}_{\mathrm{i}}^{(\mathrm{U}) / 4\left(\mathrm{~s}_{1}+1\right)}
$$

Finally, the jump in $\varphi_{1}$ is given by

$$
\begin{aligned}
\Delta \varphi= & \varphi_{1}{ }^{(\mathrm{U})}-\varphi_{1}(\mathrm{~L})=\varphi_{\mathrm{ij}}+1-\varphi_{\mathrm{ij}}-\mathrm{c}_{\mathrm{s} 1}\left(\varphi_{\mathrm{ij}}{ }_{\mathrm{m}}+2-\varphi_{\mathrm{ij}}+1\right) \\
& -\mathrm{c}_{\mathrm{s} 2}\left(\varphi_{\mathrm{ij}} \mathrm{m}-\varphi_{\mathrm{ij}}-1\right)-\left(\mathrm{d}_{\mathrm{s} 1} \mathrm{~F}_{\mathrm{i}}(\mathrm{U})+\mathrm{d}_{\mathrm{s} 2} \mathrm{~F}_{\mathrm{i}}^{(\mathrm{L})}\right)
\end{aligned}
$$

where

$$
\begin{array}{ll}
\mathrm{c}_{\mathrm{s} 1}=1 / 4 \mathrm{~s}_{1}\left(\mathrm{~s}_{1}+1\right) & \mathrm{c}_{\mathrm{s} 2}=1 / 4 \mathrm{~s}_{2}\left(\mathrm{~s}_{2}+1\right) \\
\mathrm{d}_{\mathrm{s} 1}=\mathrm{h}\left(2 \mathrm{~s}_{1}+1\right) / 4\left(\mathrm{~s}_{1}+1\right) & \mathrm{d}_{\mathrm{s} 2}=\mathrm{h}\left(2 \mathrm{~s}_{2}+1\right) / 4\left(\mathrm{~s}_{2}+1\right)
\end{array}
$$

These formulas hold only for values of $i$ corresponding to $x$ values on the airfoil and are accurate to the second order in mesh size. The jump in $\varphi_{1}$ is required for updating the far-field boundary conditions as well as satisfying the Kutta condition on the airfoil trailing edge. 


\section{Far-Field Boundary Conditions-Airfoil}

A procedure similar to that used for three-dimensional wings is employed to obtain an integral relation for the far-field boundary condition for the two-dimensional airfoil. We write for $L\left(\varphi_{1}\right)$ in place of equation (64)

$$
\begin{aligned}
& \mathrm{L}\left(\varphi_{1}\right)=\varphi_{1 \mathrm{x}_{1} \mathrm{x}_{1}}-\frac{2 \mathrm{i} \omega \mathrm{M}^{2}}{1-\mathrm{M}^{2}} \varphi_{1 \mathrm{x}_{1}}+\varphi_{1 \mathrm{y}_{1} \mathrm{y}_{1}}+\frac{\omega^{2} \mathrm{M}^{2}}{1-\mathrm{M}^{2}} \varphi_{1} \\
& =\frac{\gamma+1}{\mathrm{~K}}\left(\varphi_{0 \mathrm{x}_{1}} \varphi_{1 \mathrm{x}_{1}}\right)_{\mathrm{x}_{1}}+\frac{\mathrm{i} \omega(\gamma-1)}{\mathrm{K}} \varphi_{1} \varphi_{0 \mathrm{x}_{1} \mathrm{x}_{1}}
\end{aligned}
$$

For the fundamental solution $\psi$ of the differential equation $L(\psi)=0$, the function $\psi_{0}(\mathrm{r})$ takes the form

$$
\psi_{0}^{\prime \prime}+\psi_{0}^{\prime} / \mathrm{r}+\lambda_{1}^{2} \psi_{0}=0
$$

where $r=\sqrt{x_{1}^{2}+y_{1}^{2}}$ and $\lambda_{1}=\omega M /\left(1-M^{2}\right)$. The solution to this equation yielding outgoing waves with the source at the origin is $\mathrm{H}_{0}{ }^{(2)}\left(\lambda_{1} \mathrm{r}\right)$. The fundamental solution then is

$$
\psi=\mathrm{e}^{\mathrm{i} \lambda_{1} \mathrm{Mx}} \mathrm{H}_{0}^{(2)}\left(\lambda_{1} \mathrm{r}\right)
$$

where $\mathrm{H}_{0}{ }^{(2)}(\mathrm{z})$ is the Hankel function of the second type. For small $\mathrm{r}$

$$
\psi \simeq-(2 \mathrm{i} / \pi) \mathrm{e}^{\mathrm{i} \lambda_{1} \mathrm{Mr} \cos \theta} \log \left(\lambda_{1} \mathrm{r} / 2\right)
$$

Since $\psi_{\mathrm{n}}=\psi_{\mathrm{r}}$, the integration of the surface integral of equation (65) over the circle about the reference point $\mathrm{x}_{1}, \mathrm{y}_{1}$ becomes, on letting the radius of the circle go to zero,

$$
-4 \mathrm{i} \varphi_{1}\left(\mathrm{x}_{1}, \mathrm{y}_{1}\right)
$$

The evaluation of the remaining integrals for the two-dimensional flow follows with little change from the three-dimensional analysis. Noting that the factor multiplying $\varphi_{1}$ is $-4 \mathrm{i}$ insteady of $-4 \pi$, we obtain easily the following equations for the airfoil equivalent to equations (77):

$$
\begin{aligned}
\varphi_{1} & =(1 / 4 \mathrm{i}) \int_{-1}^{1}\left(\Delta \varphi_{1} \psi_{\mathrm{y}_{1}}-\psi \Delta \varphi_{1 \mathrm{y}_{1}}\right) \mathrm{dx}_{1}^{\prime}+\left(\Delta \varphi_{\mathrm{t}} / 4 \mathrm{i}\right) \\
& +(1 / 4 \mathrm{iK}) \int_{\mathrm{v}}^{\infty} \mathrm{e}^{-\mathrm{i} \omega\left(\mathrm{x}_{1}{ }^{\prime}-1\right)} \psi_{\mathrm{y}_{1}} \mathrm{dx}_{1}{ }^{\prime}
\end{aligned}
$$


The quantities in the first two integrals are evaluated at $\mathrm{y}_{1}=0$. Since $\partial / \partial \mathrm{x}_{1}{ }^{\prime}=-\partial / \partial \mathrm{x}_{1}, \partial / \partial \mathrm{y}_{1}{ }^{\prime}=$ $-\partial / \partial \mathrm{y}_{1}{ }^{\prime}$, equation (109) takes the more convenient form

$$
\begin{aligned}
& \varphi_{1}\left(\mathrm{x}_{1}, \mathrm{y}_{1}\right)=(\mathrm{i} / 4) \int_{-1}^{1}\left(\Delta \varphi_{1} \psi \mathrm{y}_{1}+\psi \Delta \varphi_{1 \mathrm{y}_{1}}{ }^{\prime}\right) \mathrm{dx}_{1}{ }^{\prime \prime}+\left(\mathrm{i} \Delta \varphi_{\mathrm{t}} / 4\right) \int_{1}^{\infty} \mathrm{e}^{-\mathrm{i} \omega\left(\mathrm{x}_{1}{ }^{\prime}-1\right)} \psi_{\mathrm{y}_{1}} \mathrm{dx}_{1}{ }^{\prime} \\
& +(\mathrm{i} / 4 \mathrm{~K}) \int_{\mathrm{v}}\left[(\gamma+1) \psi_{\mathrm{x}_{1}} \varphi_{0 \mathrm{x}_{1}}{ }^{\prime} \varphi_{1 \mathrm{x}_{1}}{ }^{\prime}+\mathrm{i} \omega(\gamma-1) \varphi_{0 \mathrm{x}_{1}}{ }^{\prime} \mathrm{x}_{1}{ }^{\prime} \varphi_{1} \psi\right] \mathrm{dx}_{1}{ }^{\prime} \mathrm{dy}_{1}{ }^{\prime}
\end{aligned}
$$

As shown for the planar wing, the integration of the second integral can be performed for the combination $\varphi_{1 \mathrm{x}_{1}}+\mathrm{i} \omega \varphi_{1}$. Thus

$$
\begin{aligned}
& \varphi_{1 \mathrm{x}_{1}}+\mathrm{i} \omega \varphi_{1}=(\mathrm{i} / 4) \int_{-1}^{1}\left(\Delta \varphi_{1} \mathrm{x}_{\mathrm{y}_{1}}+\chi \Delta \varphi_{1 \mathrm{y}_{1}}{ }^{\prime}\right) \mathrm{dx}_{1}{ }^{\prime}+\left(\mathrm{i} \Delta \varphi_{\mathrm{t}} / 4\right) \psi_{\mathrm{y}_{1}}
\end{aligned}
$$

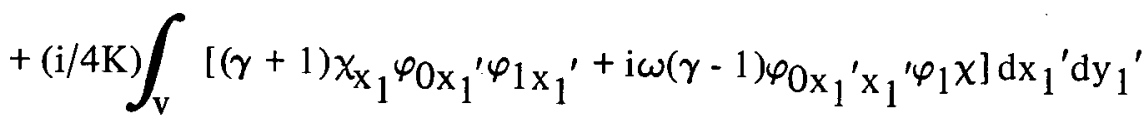

The quantity $\chi=\psi_{x_{1}}+i \omega \psi$ is a function of the arguments $x_{1}-x_{1}^{\prime}$, and $y_{1}$ in the first integral and of $\mathrm{x}_{1}-\mathrm{x}_{1}{ }^{\prime}$ and $\mathrm{y}_{1}-\mathrm{y}_{1}{ }^{\prime}$ in the volume integral. In terms of $\mathrm{x}$ and $\mathrm{y}$, we obtain

$$
\begin{aligned}
& \varphi_{1 \mathrm{x}}+\mathrm{i} \omega \varphi=(\mathrm{i} / 4 \sqrt{\mathrm{K}}) \int_{-1}^{1}\left(\Delta \varphi_{1} \mathrm{x}_{\mathrm{y}}+\chi \Delta \varphi_{1 \mathrm{y}^{\prime}}\right) \mathrm{dx} \mathrm{x}^{\prime}+\left(\mathrm{i} \Delta \varphi_{\mathrm{t}} / 4 \sqrt{\mathrm{K}}\right) \psi_{\mathrm{y}} \\
& +(\mathrm{i} / 4 \sqrt{\mathrm{K}}) \int_{\mathrm{v}}\left[(\gamma+1) \mathrm{x}_{\mathrm{x}} \varphi_{0 \mathrm{x}^{\prime}} \varphi_{1 \mathrm{x}^{\prime}}+\mathrm{i} \omega(\gamma-1) \varphi_{\left.0 \mathrm{x}^{\prime} \mathrm{x}^{\prime} \varphi_{1} \chi\right] \mathrm{dx}^{\prime} \mathrm{dy}^{\prime}}\right.
\end{aligned}
$$

where

$$
\begin{aligned}
& \psi=e^{i M \lambda_{1} x} H_{0}(2)\left(\lambda_{1} \sqrt{x^{2}+K y^{2}}\right) \\
& \psi_{y}=-\lambda_{1} K y e^{i M \lambda_{1} x_{H_{1}}}(2)\left(\lambda_{1} \sqrt{x^{2}+K y^{2}}\right) / \sqrt{x^{2}+K y^{2}}
\end{aligned}
$$




$$
\begin{aligned}
& \chi=i \omega \psi /\left(1-M^{2}\right)-\lambda_{1} x e^{i \lambda_{1} M x} H_{1}{ }^{(2)}\left(\lambda_{1} \sqrt{x^{2}+K y^{2}}\right) / \sqrt{x^{2}+K y^{2}} \\
& x_{y}=i \omega \psi_{y} /\left(1-M^{2}\right)+\dot{\lambda}_{1} K x y e^{i \lambda_{1} M x}\left[2 H_{1}^{(2)}\left(\lambda_{1} \sqrt{x^{2}+K y^{2}}\right) / \sqrt{x^{2}+K y^{2}}\right. \\
& -\lambda_{1} \mathrm{H}_{0}{ }^{(2)}\left(\lambda_{1} \sqrt{\left.\left.\mathrm{x}_{1}^{2}+\mathrm{Ky}^{2}\right)\right] /\left(\mathrm{x}^{2}+\mathrm{Ky}\right.}{ }^{2}\right) .
\end{aligned}
$$

Equation (112) holds everywhere in the flow field. Since we are only interested in the far-field boundary values, we approximate $\mathrm{x}-\mathrm{x}^{\prime}$ in $\chi$ and $\chi_{\mathrm{y}}$ of the integral over the wing by $\mathrm{x}$. The terms $\chi$ and $x_{y}$ can be taken outside the integral, and the first term in equation (112) then takes the form

$$
(\mathrm{i} / 4 \sqrt{\mathrm{K}})\left[\chi_{\mathrm{y}} \int_{-1}^{1} \Delta \varphi_{1} \mathrm{dx^{ \prime }}+\chi \int_{-1}^{1} \Delta \varphi_{1 \mathrm{y}^{\prime}} \mathrm{dx^{ \prime }}\right] .
$$

The second integral of the preceding expression can be evaluated once and for all at the beginning of calculations since it depends upon the airfoil boundary conditions. For the oscillating flap, the unsteady boundary conditions are the same above and below the airfoil, and hence the second integral vanishes. Equation (112) then takes the form

$$
\begin{aligned}
\varphi_{1 \mathrm{x}}+\mathrm{i} \omega \varphi_{1} & =(\mathrm{i} / 4 \sqrt{\mathrm{K}})\left\{\chi_{\mathrm{y}} \int_{-1}^{1} \Delta \varphi_{1} \mathrm{dx}^{\prime}+\Delta \varphi_{\mathrm{t}} \psi_{\mathrm{y}}\right. \\
& +\int_{\mathrm{v}}\left[(\gamma+1) \chi_{\mathrm{x}} \varphi_{0 \mathrm{x}^{\prime}} \varphi_{1 \mathrm{x}^{\prime}}+\mathrm{i} \omega(\gamma-1) \varphi_{\left.\left.0 \mathrm{x}^{\prime} \mathrm{x}^{\prime} \varphi_{1} \chi\right] \mathrm{dx}^{\prime} \mathrm{dy}^{\prime}\right\}}\right.
\end{aligned}
$$

Because the wake integral in equation (110) is slowly convergent, it is best to formulate the mesh boundary conditions in terms of the function $\varphi_{1 \mathrm{x}}+i \omega \varphi_{1}$. Let $\mathrm{i}=1$ be the column of $\mathrm{x}$ for the upstream boundary. Since derivative boundary conditions are best formulated between mesh points we have at $\mathrm{x}=\left(\mathrm{x}_{1}+\mathrm{x}_{2}\right) / 2$ and all $\mathrm{y}_{\mathrm{j}}$ along the upstream boundary the following difference formula for the pressure function:

$$
\varphi_{1 \mathrm{x}}+\mathrm{i} \omega \varphi_{1}=\left(\varphi_{2 \mathrm{j}}-\varphi_{1 \mathrm{j}}\right) /\left(\mathrm{x}_{2}-\mathrm{x}_{1}\right)+\mathrm{i} \omega\left(\varphi_{2 \mathrm{j}}+\varphi_{1 \mathrm{j}}\right) / 2=\mathrm{P}\left(\frac{\mathrm{x}_{1}+\mathrm{x}_{2}}{2}, \mathrm{y}_{\mathrm{j}}\right)=\mathrm{P}_{1 \mathrm{j}}
$$

where $P(x, y)$ represents the right-hand side of equation (114). 
Solving for $\varphi_{1 \mathrm{j}}$ yields

$$
\varphi_{1 \mathrm{j}}=\mathrm{c}_{\mathrm{k} 1} \varphi_{2 \mathrm{j}}-\mathrm{c}_{\mathrm{k} 2} \mathrm{P}_{1 \mathrm{j}}
$$

where

$$
\begin{aligned}
& c_{\mathrm{k} 1}=\left(1+\mathrm{i} \omega \delta_{1} / 2\right) /\left(1-\mathrm{i} \omega \delta_{1} / 2\right) \\
& \mathrm{c}_{\mathrm{k} 2}=\delta_{1} /\left(1-\mathrm{i} \omega \delta_{1} / 2\right)
\end{aligned}
$$

and

$$
\delta_{1}=\mathrm{x}_{2}-\mathrm{x}_{1}
$$

Substituting $\varphi_{-1 \mathrm{j}}$ into equation (84) for $\mathrm{i}=2$ yields

$$
\begin{aligned}
& a_{j} \varphi_{2 j-1}-\left(a_{j}+b_{j}+E_{1}+E_{2}-E_{2} c_{k 1}-q_{i j} / 2\right) \varphi_{2 j}+b_{j} \varphi_{2 j+1} \\
& =-E_{1} \varphi_{3 j}+E_{2} c_{k 2} P_{i j}
\end{aligned}
$$

Similarly for $\mathrm{i}=\mathrm{i}_{\max }$, the downstream mesh boundary, we have

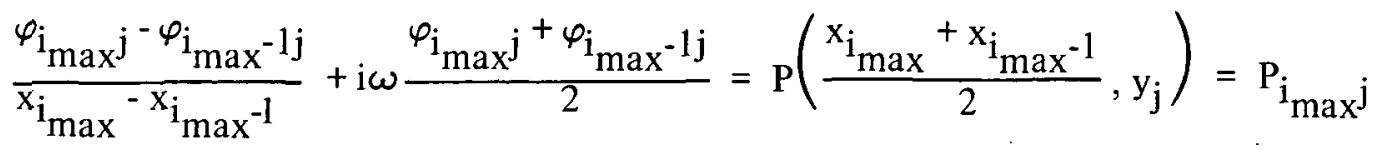

Solving for $\varphi_{i_{\max }} \mathrm{j}$ yields

$$
\varphi_{\mathrm{i}_{\max }}{ }=c_{\mathrm{k} 3} \varphi_{\mathrm{i}_{\text {max }}}{ }^{-1 \mathrm{j}}+\mathrm{c}_{\mathrm{k} 4} \mathrm{P}_{\mathrm{i}_{\max }} \mathrm{j}
$$

where

$$
\begin{aligned}
c_{\mathrm{k} 3} & =\left(1-i \omega \delta_{2} / 2\right) /\left(1+i \omega \delta_{2} / 2\right) \\
c_{\mathrm{k} 4} & =\delta_{2} /\left(1+i \omega \delta_{2} / 2\right) \\
\delta_{2} & =x_{i_{\max }}-x_{i_{\max }-1} .
\end{aligned}
$$


Equation (84) for $\mathrm{i}=\mathrm{i}_{\max }-1$ with $\varphi_{\mathrm{i}_{\max }} \mathrm{j}$ replaced by equation (120) leads to

$$
\begin{aligned}
& { }_{j} \varphi_{i_{\max }}{ }^{-1 j-1}-\left(a_{j}+b_{j}+E_{1}+E_{2}-E_{1} c_{k 3}-q_{i_{\max }-1 j} / 2\right) \varphi_{i} \max ^{-1 j} \\
& +b_{j} \varphi_{i_{\max }-1 j+1}=-E_{1} c_{k 4} P_{i_{\max }}-E_{2} \varphi_{i_{\max }}-2 j
\end{aligned}
$$

Equations (118) and (121) follow the same pattern as equation (84) for interior columns if we define in equation (84) for the right-hand sides

$$
\begin{aligned}
& \varphi_{1 j}=-c_{k 2} P_{1 j} \\
& \varphi_{i_{\text {max }}}=c_{k 4} P_{i_{\text {max }}} j
\end{aligned}
$$

and add the terms $\mathrm{E}_{2} \mathrm{C}_{\mathrm{k} 1}$ and $\mathrm{E}_{3} \mathrm{C}_{\mathrm{k} 3}$, respectively, to the coefficients of the diagonal terms.

The boundary conditions on the upper and lower mesh boundaries must be given in terms of $\varphi_{1}$. If the value of $\varphi_{1}$ at one point is given on the lower boundary, then the values of $\varphi_{1}$ at other points on the lower boundary may be found by integrating

$$
\varphi_{1 \mathrm{x}}+\mathrm{i} \omega \varphi_{1}=\mathrm{P}(\mathrm{x}, \mathrm{y})
$$

where $\mathrm{P}(\mathrm{x}, \mathrm{y})$ is defined by the right-hand side of equation (114). Between $\mathrm{x}_{\mathrm{i}-1}$ and $\mathrm{x}_{\mathrm{i}}$, integration yields

$$
\varphi_{i 1} e^{i \omega x_{i}-\varphi_{i-11}} e^{i \omega x_{i-1}}=\int_{x_{i-1}}^{x_{i}} e^{i \omega x^{\prime}} P\left(x^{\prime}, y_{1}\right) d x^{\prime}
$$

When the integral is evaluated by the trapezoidal rule at the $x_{i}$ mesh points, then a simple recursion formula results from $\varphi_{\mathrm{i} 1}$ in terms of $\varphi_{\mathrm{i}-11}$ and $\mathrm{P}(\mathrm{x}, \mathrm{y})$. Thus

$$
\varphi_{i 1}=\varphi_{i-11} e^{-i \omega\left(x_{i}-x_{i-1}\right)}+\left[P\left(x_{i}, y_{1}\right)+P\left(x_{i-1}, y_{1}\right) e^{-i \omega\left(x_{i}-x_{i-1}\right)}\right]\left(x_{i}-x_{i-1}\right) / 2
$$

For backward integration, we can solve for $\varphi_{\mathrm{i}-11}$ once $\varphi_{\mathrm{i} 1}$ is known by

$$
\varphi_{i-11}=\varphi_{11} e^{i \omega\left(x_{i}-x_{i-1}\right)}-\left[P\left(x_{i}, y_{1}\right) e^{i \omega\left(x_{i}-x_{i-1}\right)}+P\left(x_{i-1}, y_{1}\right)\right]\left(x_{i}-x_{i-1}\right) / 2
$$

Similar equations may be written for the upper boundary at $y=y_{j_{\max }}$. 
Since the value of $\varphi_{1}$ must be given at one point on each of the upper and lower boundaries, it is wise to choose the points at which the wake integration can most easily be performed. The wake integral is

$$
\left(i \Delta \varphi_{t} / 4 \sqrt{K}\right)(\partial / \partial y) \int_{1}^{\infty} e^{-i \omega\left(x^{\prime}-1\right)+i M \lambda_{1}\left(x-x^{\prime}\right)} H_{0}{ }^{(2)}\left(\lambda_{1} \sqrt{\left(x-x^{\prime}\right)^{2}+K y^{2}}\right) d x^{\prime}
$$

We note that for $x=1$, the integral can be simplified to

$$
(\partial / \partial y) \int_{0}^{\infty} e^{-i \omega z /\left(1-M^{2}\right)} H_{0}^{(2)}\left(\lambda_{1} \sqrt{z^{2}+K y^{2}}\right) d z
$$

This integral converges like $1 / \mathrm{z}^{3}$, but it can be expressed as an integral with exponential convergence by using contour integration. Consider the contour in the complex plane of figure 20 for $\mathrm{R}$ going to infinity. Since no poles lie inside the contour of $C=C_{R}+C_{1}+C_{2}$, then

$$
\int_{C} \mathrm{e}^{-\mathrm{i} \omega z /\left(1-\mathrm{M}^{2}\right)} \mathrm{H}_{0}{ }^{(2)}\left(\lambda_{1} \sqrt{\mathrm{z}^{2}+\mathrm{Ky}^{2}}\right) \mathrm{dz}=0
$$

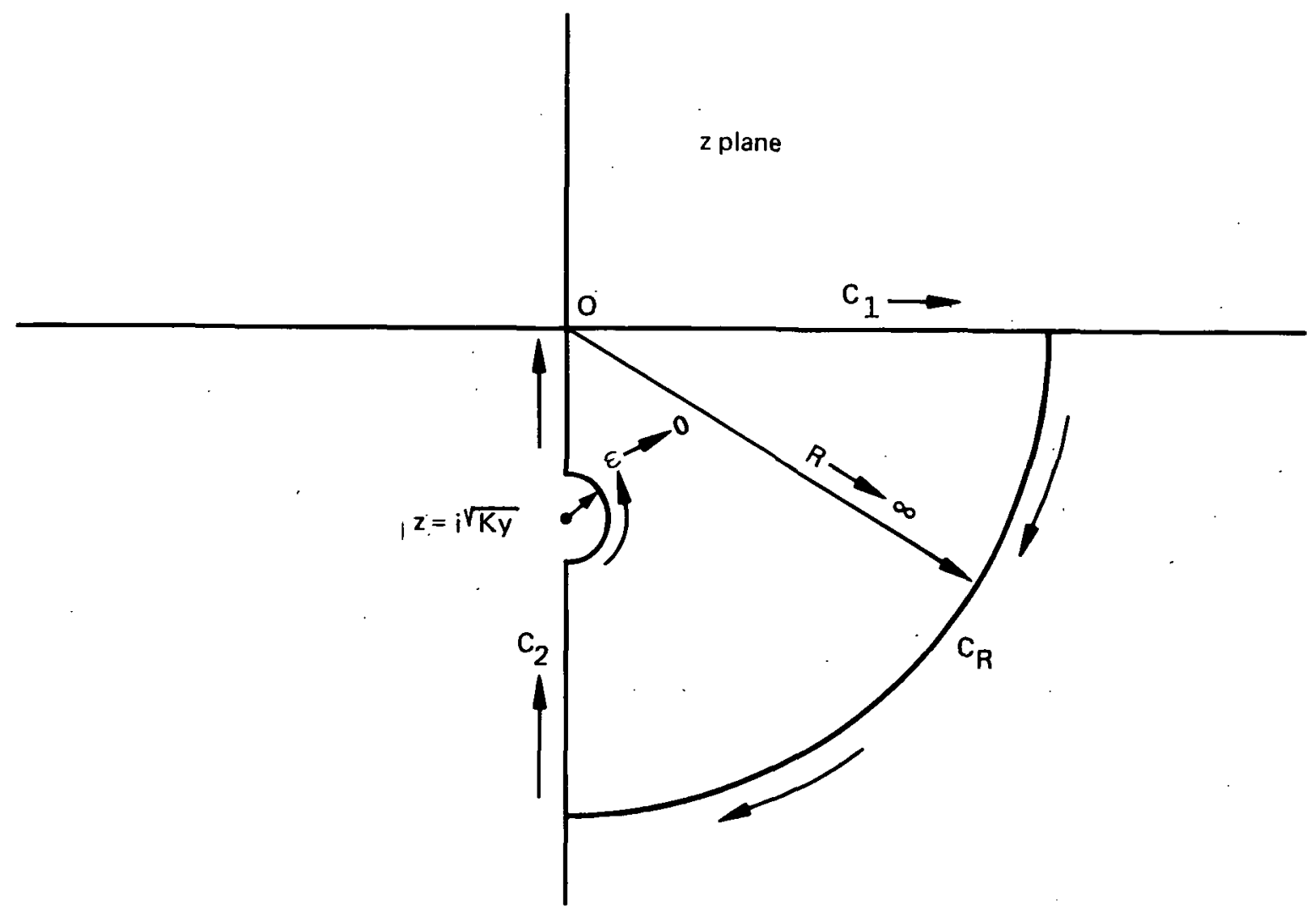

Figure 20.-Contours of integration in the complex $z$ plane 
Since the integral over $C_{R}$ vanishes as $R$ goes to infinity, then we have

$$
\begin{aligned}
& \int_{0}^{\infty} \mathrm{e}^{-i \omega z /\left(1-M^{2}\right)} H_{0}^{(2)}\left(\lambda_{1} \sqrt{\left.z^{2}+K y^{2}\right)} d z=-i \iint_{0}^{\sqrt{K y}} e^{-\omega t /\left(1-M^{2}\right)} H_{0}{ }^{(2)}\left(\lambda_{1} \sqrt{\left.K y^{2}-t^{2}\right)} d t\right.\right. \\
& +(2 / \pi) \int_{\sqrt{K y}}^{\infty} e^{-\omega t /\left(1-M^{2}\right)} K_{0}\left(\lambda_{1} \sqrt{\left.t^{2}-K y^{2}\right)} d t\right.
\end{aligned}
$$

Differentiation with respect to $\mathrm{y}$ yields

$$
\begin{aligned}
& (\partial / \partial y) \int_{0}^{\infty} \mathrm{e}^{-i \omega z /\left(1-M^{2}\right)} \mathrm{H}_{0}{ }^{(2)}\left(\lambda_{1} \sqrt{\mathrm{z}^{2}+\mathrm{Ky} \mathrm{y}^{2}}\right) \mathrm{dz} \\
& =\lim _{\epsilon \rightarrow 0}\left\{-(\partial / \partial y) \int_{0}^{\sqrt{K} y-\epsilon} i \mathrm{e}^{-\omega t /\left(1-M^{2}\right)} \mathrm{H}_{0}(2)\left(\lambda_{1} \sqrt{\left.K y^{2}-t^{2}\right) d t}\right.\right. \\
& \left.+(2 / \pi)(\partial / \partial y) \int_{\sqrt[K]{ } y+\epsilon}^{\infty} e^{-\omega t /\left(1-M^{2}\right)} K_{0}\left(\lambda_{1} \sqrt{t^{2}-K y^{2}}\right) d t\right\}
\end{aligned}
$$

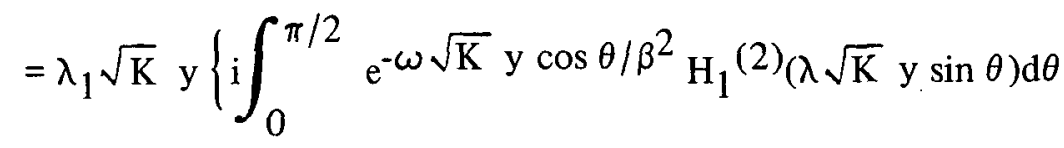

$$
\begin{aligned}
& \left.\left.+(2 / \pi) \int_{0}^{\infty} \mathrm{e}^{-\omega \sqrt{\mathrm{K}} \mathrm{y} \cosh \theta / \beta^{2}} \mathrm{~K}_{1} \lambda \sqrt{\mathrm{K}} \mathrm{y} \sinh \theta\right) \mathrm{d} \theta\right\}
\end{aligned}
$$

where

$$
\beta^{2}=1-M^{2} .
$$

It is convenient to combine the real and imaginary parts in the form

$$
\begin{aligned}
& (\partial / \partial y) \int_{0}^{\infty} \mathrm{e}^{-\mathrm{i} \omega z / \beta^{2}} \mathrm{H}_{0}^{(2)}\left(\lambda_{1} \sqrt{\mathrm{z}^{2}+\mathrm{Ky}}\right) \mathrm{dz}
\end{aligned}
$$

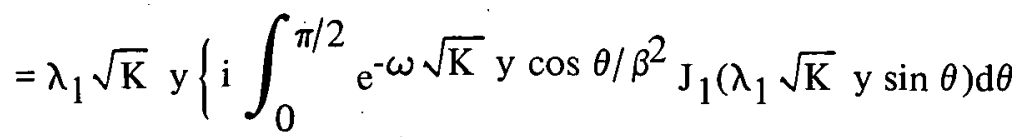




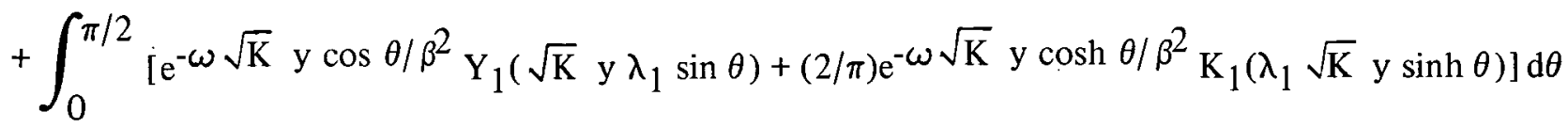

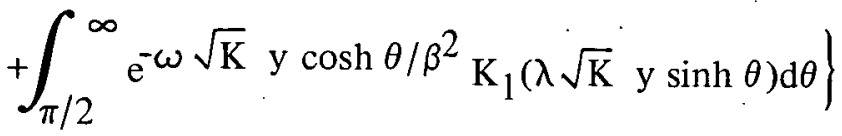

All the integrals are defined on the range of integration, except the second integral at $\theta=0$. The quantity in square brackets, however, goes to zero like $\theta \log \theta$ as $\theta$ goes to zero. Assigning the value of 0 for the integrand at $\theta=0$, then defines the integrands for all $\theta$ in the range of integration.

\section{Analysis of Truncation Terms in the Difference Equations}

Whenever a differential equation is replaced by a difference equation and some iteration scheme is employed, a question arises concerning the stability of the calculations and correctness of the final solution. When the quantities in the difference equations are expanded in Taylor's series about the central point and all terms proportional to powers of the mesh spacing are neglected, the original differential equation is obtained. A higher order differential equation results, however, when the lowest order terms in the mesh spacing are retained, and the nature of this equation will yield some information on the stability of the numerical method. To investigate the method set forth in this document, we consider the differential equation for the harmonically oscillating airfoil and will confine our study to an equally spaced $\mathrm{x}$ grid and an equally spaced $\mathrm{y}$ grid, but $\Delta \mathrm{x}$ not necessarily equal to $\Delta y$. For the elliptic points, we obtain for the point $i, j$

$$
\begin{aligned}
& u_{i+1 / 2 j}\left(\varphi_{i+1 j}-\varphi_{i j}\right) / 2 \Delta x^{2}-u_{i-1 / 2 j}\left(\varphi_{i j}-\varphi_{i-1 j}\right) / 2 \Delta x^{2} \\
& -(i \omega / \epsilon)\left[\varphi_{i+1 j}-\varphi_{i-1 j}\right] / 2 \Delta x \\
& +\left[\varphi_{i j-1}-2 \varphi_{i j}+\varphi_{i j+1}\right] / 2 \Delta y^{2}+\left(q_{i j} / 2\right) \varphi_{i j}=0 .
\end{aligned}
$$

We now expand in Taylor series about the point $\mathrm{i}, \mathrm{j}$, letting $\mathrm{u}_{\mathrm{ij}}=\mathrm{u}$ and $\varphi_{\mathrm{ij}}=\varphi_{1}$. Substituting

$$
\begin{aligned}
& \varphi_{\mathrm{i}+1 \mathrm{j}}=\varphi_{1}+\Delta \mathrm{x} \varphi_{1 \mathrm{x}}+\left(\Delta \mathrm{x}^{2} / 2\right) \varphi_{1 \mathrm{xx}}+\cdots \\
& \varphi_{\mathrm{i}-1 \mathrm{j}}=\varphi_{1}-\Delta \mathrm{x} \varphi_{1 \mathrm{x}}+\left(\Delta \mathrm{x}^{2} / 2\right) \varphi_{1 \mathrm{xx}}+\cdots \\
& u_{\mathrm{i}+1 / 2 \mathrm{j}}=\mathrm{u}+(\Delta \mathrm{x} / 2) \mathrm{u}_{\mathrm{x}}+\left(\Delta \mathrm{x}^{2} / 8\right) \mathrm{u}_{\mathrm{xx}}+\cdots
\end{aligned}
$$




$$
\begin{aligned}
& u_{\mathrm{i}-1 / 2 \mathrm{j}}=\mathrm{u}-(\Delta \mathrm{x} / 2) \mathrm{u}_{\mathrm{x}}+\left(\Delta \mathrm{x}^{2} / 8\right) \mathrm{u}_{\mathrm{xx}}+\cdots \\
& \varphi_{\mathrm{ij}-1}=\varphi_{1}-\Delta \mathrm{y} \varphi_{1 \mathrm{y}}+\left(\Delta \mathrm{y}^{2} / 2\right) \varphi_{1 \mathrm{yy}}+\cdots \\
& \varphi_{\mathrm{ij}+1}=\varphi_{1}+\Delta \mathrm{y} \varphi_{1 \mathrm{y}}+\left(\Delta \mathrm{y}^{2} / 2\right) \varphi_{1 \mathrm{yy}}+\cdots
\end{aligned}
$$

into equation (124) and retaining lower order terms in $\Delta \mathrm{x}$ and $\Delta \mathrm{y}$ yields

$$
\begin{aligned}
& (\partial / \partial x)\left(u \varphi_{1 x}\right)-2 i \omega \varphi_{1 x} / \epsilon+\varphi_{1 y y}+q \varphi_{1} \\
& +\left(\Delta x^{2} / 12\right)\left[u \varphi_{1 x x x x}-2 u_{x} \varphi_{1 x x x}-4 i \omega \varphi_{1 x x x} / \epsilon+3 u_{x x} \varphi_{1 x x} / 2+u_{x x x} \varphi_{1 x} / 2\right] \\
& +\left(\Delta y^{2} / 12\right) \varphi_{1 \text { yyyy }}=0
\end{aligned}
$$

To determine whether the differential equation is elliptic or hyperbolic depends only upon the highest order differential operator; this is seen to be

$$
\Delta x^{2} u \varphi_{1 x x x x}+\Delta y^{2} \varphi_{1 \text { yyyy }}
$$

Since $u$ is greater than 0 , the differential equation is elliptic and hence there are no characteristic directions to place restrictions on $\Delta \mathrm{x}$ and $\Delta \mathrm{y}$ for stability.

For hyperbolic points the difference equations become

$$
\begin{aligned}
& u_{i-1 / 2 j}\left(\varphi_{i j}-\varphi_{i-1 j}\right) / 2 \Delta x^{2}-u_{i-3 / 2 j}\left(\varphi_{i+1 j}-\varphi_{i-2 j}\right) / 2 \Delta x^{2} \\
& -(i \omega / \epsilon)\left[3\left(\varphi_{i j}-\varphi_{i-1 j}\right) / 2 \Delta x-\left(\varphi_{i-1 j}-\varphi_{i-2 j}\right) / 2 \Delta x\right] \\
& +\left[\varphi_{i j-1}-2 \varphi_{i j}+\varphi_{i j+1}\right] / 2 \Delta y^{2}+q_{i j} \varphi_{i j} / 2=0 .
\end{aligned}
$$

Expanding about the point $i, j$ yields the differential equation

$$
\begin{aligned}
& \left(\mathrm{u} \varphi_{1 \mathrm{x}}\right)_{\mathrm{x}}-2 \mathrm{i} \omega \varphi_{1 \mathrm{x}} / \epsilon+\varphi_{1 \mathrm{yy}}+\mathrm{q} \varphi_{1} \\
& -\Delta \mathrm{x}\left\{\mathrm{u} \varphi_{1 \mathrm{xx}}+\text { lower order derivatives in } \mathrm{x}\right\}=0
\end{aligned}
$$


The lower order terms omitted have coefficients which are negligible in comparison with the corresponding coefficients of the same derivative terms in the differential equation. Sichel (ref. 17) studied the viscous transonic equation

$$
\psi_{\mathrm{x}} \psi_{\mathrm{xx}}-\psi_{\mathrm{yy}}=\nu \psi_{\mathrm{xxx}}
$$

and investigated the nature of shock waves. Since $u$ is less than 0 , the dominant terms of the differential equation become

$$
(-\mathrm{u}) \varphi_{1 \mathrm{xx}}-\varphi_{1 \mathrm{yy}}=(-\mathrm{u}) \Delta \mathrm{x} \varphi_{1 \mathrm{xxx}}+\text { lower order derivatives }
$$

Thus, the term (-u) $\Delta \mathrm{x} \varphi_{1 \mathrm{xxx}}$ introduces a numerical viscosity which Murman (ref. 2) found caused shock waves to develop smoothly in the iteration. From the foregoing analysis, the chosen method of differencing appears to be a stable formulation.

\section{Solution of the Complete Set of Difference Equations}

It was pointed out earlier in the text that the complete set of difference equations are linear in the $\varphi_{\mathrm{ij}}$ and that consideration of solving this complete set instead of column relaxation might be feasible. The resulting matrix is exceedingly large since there is an equation corresponding to every interior point of the rectangular mesh. For the computed cases, this is $73 \times 56=4088$ variables and equations. However, special methods for solving this set may be sought which take advantage of the particular sparsity of the matrix. To study the form of the equations we see that, for the interior points of the mesh, the difference equations for elliptic points may be written

$$
a_{j} \varphi_{i j-1}+c_{i j} \varphi_{i j}+b_{j} \varphi_{i j+1}+D_{i j} \varphi_{i+1 j}+E_{i j} \varphi_{i-1 j}=R_{i j}
$$

and for hyperbolic points

$$
a_{j} \varphi_{i j-1}+c_{i j} \varphi_{i j}+b_{j} \varphi_{i j+1}+E_{i j} \varphi_{i-1 j}+F_{i j} \varphi_{i-2 j}=R_{i j}
$$

The indices $i, j$ here run from 1 to $i_{\max }$ and $j_{\max }$ for interior points of the mesh.

For 0 values of the subscript, the terms vanish on the left side and become incorporated into the $R_{i j}$ since they are mesh far-field boundary conditions. Since there are $i_{\max }$ columns and $j_{\max }$ rows in the interior of the mesh, then there are $N=i_{\max } \times j_{\max }$ variables with $\mathrm{N}$ equations to be solved for them. 
We order the variables as follows: Let

$$
\mathrm{X}_{\mathrm{n}}=\varphi_{\mathrm{ij}}
$$

where $n=i+(j-1) i_{\max }$ with $1 \leqslant i \leqslant i_{\max }, 1 \leqslant j \leqslant j_{\max }$.

Then equation (125) takes the form

$$
a_{j} X_{n-i_{\max }}+E_{i j} X_{n-1}+c_{i j} X_{n}+D_{i j} X_{n+1}+b_{j} X_{n+i_{\max }}=R_{i j}
$$

for the $n^{\text {th }}$ equation at elliptic points, and equation (126) takes the form

$$
a_{j} X_{n-i_{\max }}+F_{i j} X_{n-2}+E_{i j} X_{n-1}+C_{i j} X_{n}+b_{j} X_{n+i_{\max }}=R_{i j}
$$

for the $\mathrm{n}^{\text {th }}$ equation at hyperbolic points. Since only the interior points about the airfoil are apt to be hyperbolic, we will study the form of the equations assuming all elliptic points. Equation (127) will contain all five terms on the left side when

$$
\mathrm{i}_{\max }<\mathrm{n}<\mathrm{N}-\mathrm{i}_{\max }
$$

For the other equations, we will have one negative subscript for $\mathrm{X}$ which represents the mesh far-field boundary conditions and will be incorporated into the right-hand side term, $R_{i j}$. All main diagonal terms are nonzero, and we see that the coefficients of the terms adjacent to the diagonal terms are also nonzero. Also, the term $i_{\max }$ points to the left of the diagonal and the term $i_{\max }$ points to the right have nonzero coefficients when

$$
\mathrm{i}_{\max }<\mathrm{n}<\mathrm{N}-\mathrm{i}_{\max }
$$

Thus, the matrix has only five diagonals.

As seen from equation (128), the addition of a supersonic point in the flow field places a zero in the diagonal to the right of the main diagonal and adds a nonzero value in the second diagonal to the left of the main diagonal. Thus, a local supersonic region introduces a six th nonzero diagonal to the matrix. 


\section{REFERENCES}

1. Garabedian, P. R.; and Korn, D. G.: Analysis of Transonic Airfoils. Comm. Pure Appl. Math., vol. 24,1971 , pp. $841-851$.

2. Murman, E. M.; and Cole, J. D.: Calculation of Plane Steady Transonic Flows. AIAA J., vol. 9, no. 1, Jan. 1971; pp. 121-141.

3. Krupp, J. A.; and Murman, E. M.: Computation of Transonic Flows Past Lifting Airfoils and Slender Bodies. AIAA J., vol. 10, July 1972, pp. 880-887.

4. Krupp, J. A.: The Numerical Calculation of Plane Steady Transonic Flows Past Thin Lifting Airfoils. Doctor of Philosophy Thesis, University of Washington, 1971, also Boeing Scientific Research Laboratories, document D180-12958-1, June 1971.

5. Steger, J. L.; and Lomax, H.: Generalized Relaxation Methods Applied to Problems in Tran* sonic Flow. Presented at the 2nd Inter. Conf. on Numerical Methods in Fluid Dynamics, Sept. 1970.

6. Newman, P. A.; and Klunker, E. B.: Computation of Transonic Flow about Finite Lifting Wings. AIAA J., vol. 10, 1972, p. 971.

7. Ballhaus, W. F.; and Bailey, F. R.: Numerical Calculation of Transonic Flow about Swept Wings. AIAA paper no. 72-677, presented at AIAA 5th Fluid and Plasma Dynamics Conference, Boston, Mass., June 26-28, 1972.

8. Klunker, E. B.: Contribution to Methods for Calculating the Flow about Thin Lifting Wings at Transonic Speeds-Analytic Expressions for the Far Field. NASA TN D-6530, Nov. 1971.

9. Tijdeman, H.; and Schippers, P.: Results of Pressure Measurement on an Airfoil With Oscillating Flap in Two-Dimensional Flow (Zero Incidence and Zero Mean Flap Position). National Lucht-en Ruimtevaart Laboratorium, NLR TR 73078 U, 1973.

10. Rowe, W. S.: Collocation Method for Calculating the Aerodynamic Pressure Distribution on a Lifting Surface Oscillating in Subsonic Compressible Flow. AIAA Symposium on Structural Dynamics and Aeroelasticity, Aug. 1965, pp. 31-45.

11. Ashley, H.; and Rowe, W. S.: On the Unsteady Aerodynamic Loading of Wings with Control Surfaces. Z. Flugwiss 18 (1970) Heft 9/10, pp. 321-330 (in English). 
12. Destuynder, R.; and Tijdeman, H.: An Investigation of Different Techniques for Unsteady Pressure Measurements in Compressible Flow and Comparison With Lifting Surface Theory. AGARD Rep. No. 617, Jan. 1974.

13. Semarne, H. M.: New Direct Method of Solution of a System of Simultaneous Linear Equations. SIAM Review, vol. 1, 1959, p. 53.

14. Elliott, D. L.: A Note on Systems of Linear Equations. SIAM Review, vol. 3, 1961, p. 66.

15. Landahl, M. T.: Unsteady Transonic Flow. Pergamon Press, New York, Oxford, London, Paris, 1961.

16. Hormander, L.: Linear Partial Differential Operators. Academic Press, Inc., New York, 1963. See also: Ehlers, F. E.: Application of the Theory of Hormander to Finding the Fundamental Solution of Hyperbolic Linear Partial Differential Equations. Boeing Scientific Research Laboratories, D1-82-0497, 1965.

17. Sichel, M.: Structure of Weak Non-Hugoniot Shocks. Phys. of Fluids, 6(5), May 1963. 
"The aeronautical and space activities of the United States shall be conducted so as to contribute . . to the expansion of human knowledge of phenomena in the atmosphere and space. The Administration shall provide for the widest practicable and appropriate dissemination of information concerning its activities and the results thereof."

-National Aeronautics and Space ACt of 1958

\section{NASA SCIENTIFIC AND TECHNICAL PUBLICATIONS}

TECHNICAL REPORTS: Scientific and technical information considered important, complete, and a lasting contribution to existing knowledge.

TECHNICAL NOTES: Information less broad in scope but nevertheless of importance as a contribution to existing knowledge.

TECHNICAL MEMORANDUMS:

Information receiving limited distribution because of preliminary data, security classification, or other reasons. Also includes conference proceedings with either limited or unlimited distribution.

CONTRACTOR REPORTS: Scientific and technical information generated under a NASA contract or grant and considered an important contribution to existing knowledge.
TECHNICAL TRANSLATIONS: Information published in a foreign language considered to merit NASA distribution in English.

SPECIAL PUBLICATIONS: Information derived from or of value to NASA activities. Publications include final reports of major projects, monographs, data compilations, handbooks, sourcebooks, and special bibliographies.

\section{TECHNOLOGY UTILIZATION}

PUBLICATIONS: Information on technology used by NASA that may be of particular interest in commercial and other non-aerospace applications. Publications include Tech Briefs, Technology Utilization Reports and Technology Surveys.

Details on the availability of these publications may be obtained from:

SCIENTIFIC AND TECHNICAL INFORMATION OFFICE 